\title{
ZUSES
}

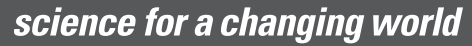

\section{Multi-Resource Analysis}

Methodology and Syuthesis

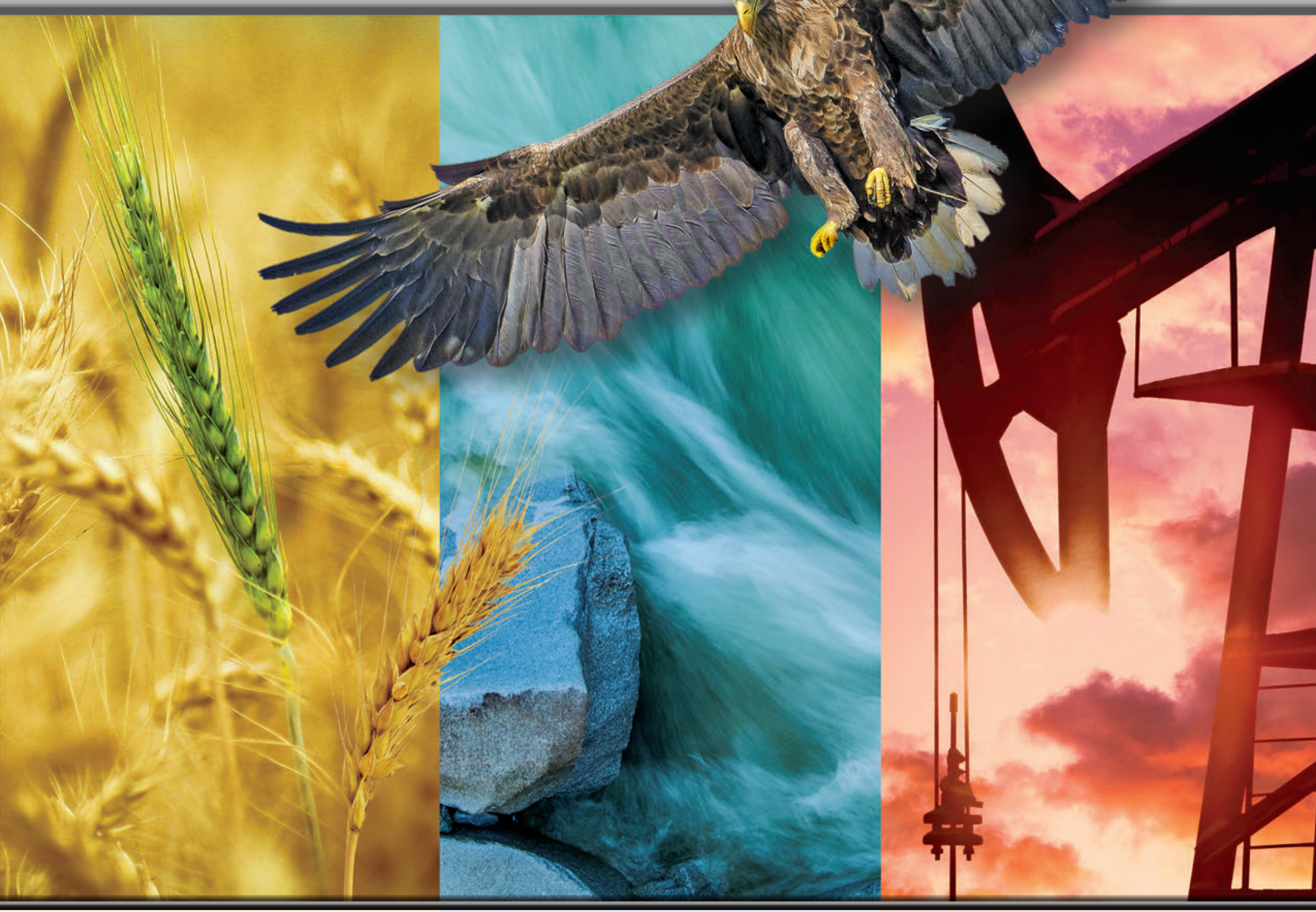

Circular 1442

U.S. Department of the Interior

U.S. Geological Survey 
M 


\section{Multi-Resource Analysis- Methodology and Syuthesis}

By Karen E. Jenni, Emily Pindilli, Richard Bernknopf, Timothy L. Nieman, and Carl Shapiro

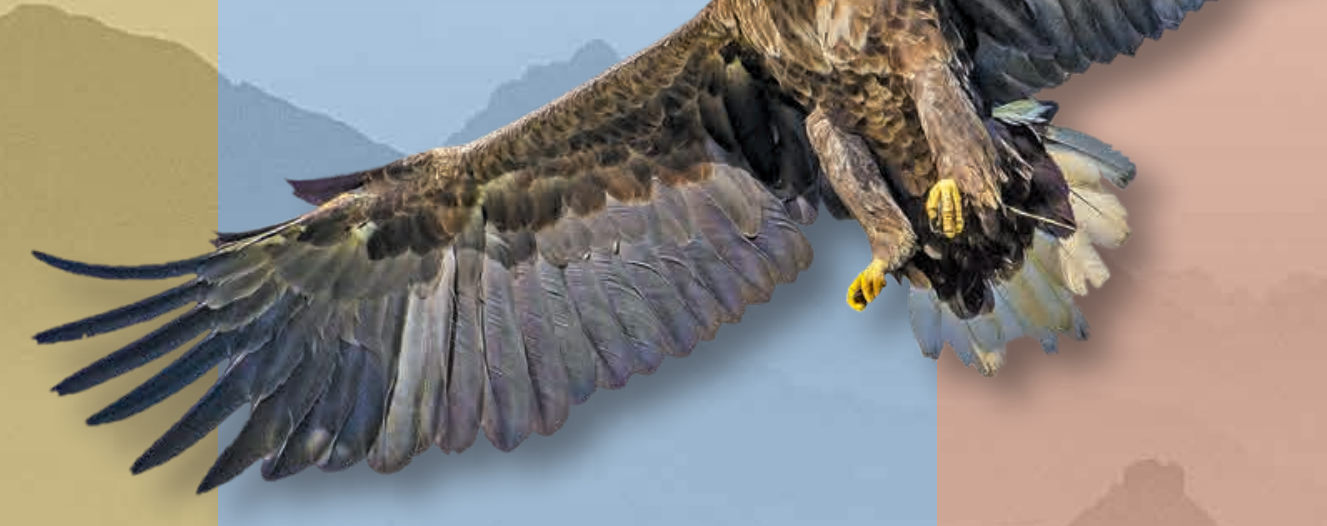

Circular 1442

U.S. Department of the Interior

U.S. Geological Survey 


\section{U.S. Department of the Interior RYAN K. ZINKE, Secretary}

\section{U.S. Geological Survey James F. Reilly II, Director}

\section{U.S. Geological Survey, Reston, Virginia: 2018}

For more information on the USGS - the Federal source for science about the Earth, its natural and living resources, natural hazards, and the environment-visit https://www.usgs.gov/ or call 1-888-ASK-USGS (1-888-275-8747).

For an overview of USGS information products, including maps, imagery, and publications, visit https://store.usgs.gov. Any use of trade, firm, or product names is for descriptive purposes only and does not imply endorsement by the U.S. Government.

Although this information product, for the most part, is in the public domain, it also may contain copyrighted materials as noted in the text. Permission to reproduce copyrighted items must be secured from the copyright owner.

\section{Suggested citation:}

Jenni, K.E., Pindilli, E., Bernknopf, R., Nieman, T.L., and Shapiro, C., 2018, Multi-Resource Analysis-

Methodology and synthesis: U.S. Geological Survey Circular 1442, 81 p., https://doi.org/10.3133/cir1442.

\section{Library of Congress Cataloging-in-Publication Data}

Names: Jenni, Karen E., author. | Geological Survey (U.S.), issuing body.

Title: Multi-Resource Analysis--methodology and synthesis / by Karen E. Jenni [and four others].

Other titles: U.S. Geological Survey circular ; 1442. 1067-084X

Description: Reston, Virginia : U.S. Department of the Interior, U.S.

Geological Survey, 2018. | Series: USGS circular, ISSN 1067-084X; 1442 |

Includes bibliographical references.

Identifiers: LCCN 2018029664 | ISBN 9781411342361 (paperback)

Subjects: LCSH: Land use--United States--Data processing. | Natural

resources--United States--Management--Data processing. |

Landscapes--United States--Data processing.

Classification: LCC HD205 .J46 2018 | DDC 333.730973--dc23 | SUDOC |

19.4/2:1442

LC record available at https://lccn.loc.gov/2018029664 


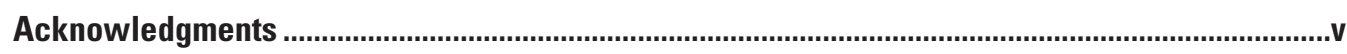

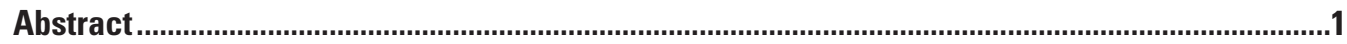

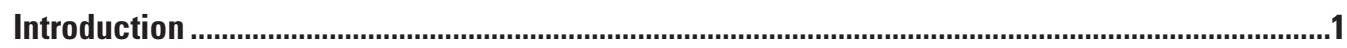

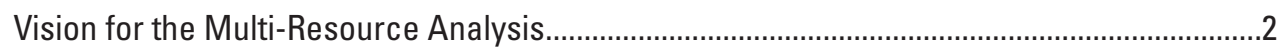

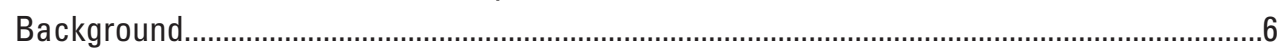

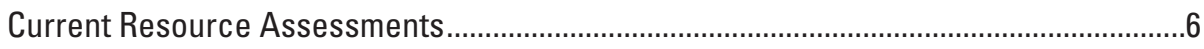

Enhancing and Integrating Resource Assessments.....................................................

Supporting Studies and Activities................................................................................10

Proof-of-Concept Studies.......................................................................................10

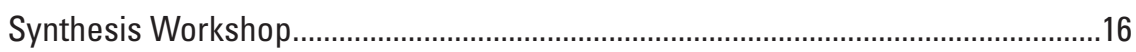

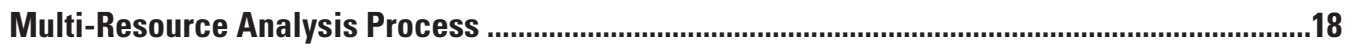

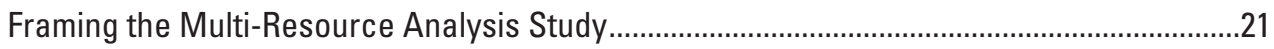

Multidisciplinary Multi-Resource Analysis Team..........................................................

Defining the Scope of the Multi-Resource Analysis.....................................................24

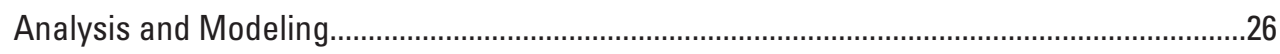

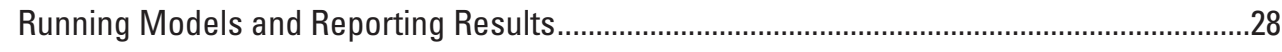

Development of Multi-Resource Analysis Components ..........................................................30

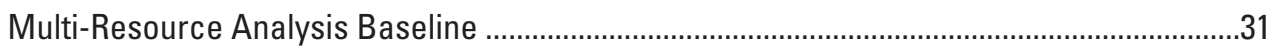

Baselines — Synthesis of Previous Efforts................................................................31

Challenges for Future Multi-Resource Analysis Baselines..............................................34

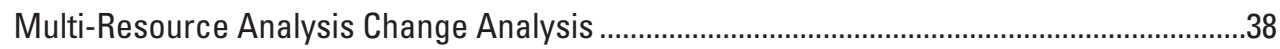

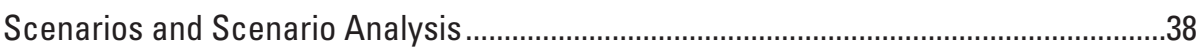

Scenario Development-Synthesis of Previous Efforts ...........................................44

Challenges for Future Multi-Resource Analysis Scenario Development................46

Integrated, Dynamic Models of Physical and Biological Interrelationships ...................48

Integrated Dynamic Models — Synthesis of Previous Efforts .................................50

Challenges for Future Multi-Resource Analysis Modeling.....................................56

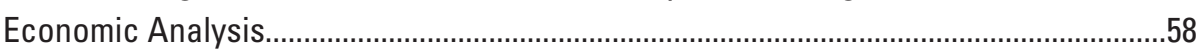

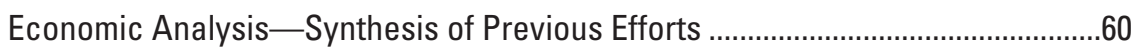

Challenges for Future Economic Analysis ............................................................62

Multi-Resource Analysis Outlook and Information Delivery ...............................................64

Outlook and Information Delivery —Synthesis of Previous Efforts .................................64

Challenges for Future Multi-Resource Analysis Information Delivery ...........................68

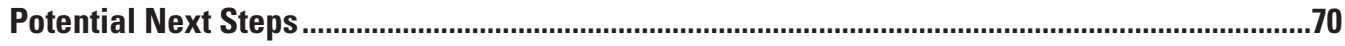

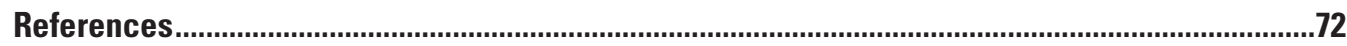

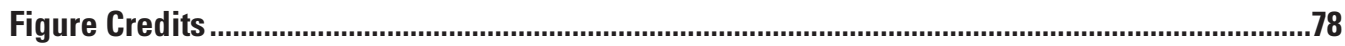




\section{Highlights}

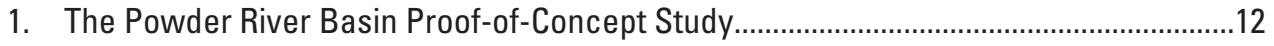

2. The Piceance Basin Proof-of-Concept Study ...............................................................14

3. A Multi-Resource Analysis Team Structure .................................................................22

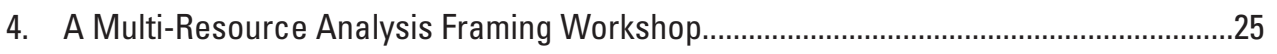

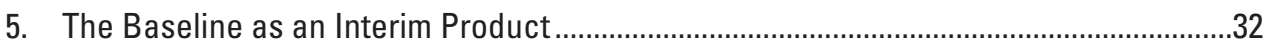

6. Example: User-Specified Energy Development Scenario...............................................40

7. Example: Potential Development Restrictions .............................................................42

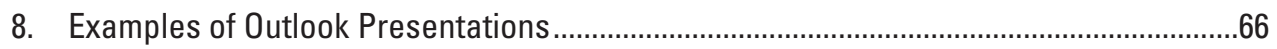

\section{Figures}

1. Multi-Resource Analysis process and components........................................................

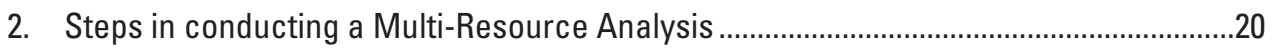

3. Overview of the Powder River Basin Multi-Resource Analysis models of interrelationships among resources

4. Overview of the Piceance Basin Multi-Resource Analysis models of interrelationships among resources and other factors

\section{Abbreviations}
CBNG coal-bed natural gas
DA decision analysis
MRA Multi-Resource Analysis
PRB Powder River Basin
USGS U.S. Geological Survey 


\section{Acknowledgments}

The

he authors thank David Brookshire of the University of New Mexico, Lynne Koontz of the National Park Service, lone Taylor of Queens University, and Jim Coleman and Vito Nuccio of the U.S. Geological Survey for support, encouragement, and many discussions about Multi-Resource Analysis problems and solutions over the years. We thank Lynne Koontz and Jay Diffendorfer (U.S. Geological Survey) for the helpful reviews of this document. We would also like to thank the many participants in the proof-of-concept studies and synthesis workshop that advanced Multi-Resource Analysis concepts and provided the foundation for this document, including Dadhi Adhikari (University of New Mexico); Christopher Babis (University of New Mexico); Craig Broadbent (Brigham Young University_ldaho); Steve Garman (Bureau of Land Management); Rebecca Moore (Bureau of Land Management); Vince Tidwell (Sandia National Laboratories); and Steve Aulenbach, Zachary Bowen, Sky Bristol, Natasha Carr, Sarah Carter, Monica Dorning, Susan Hall, Sarah Hawkins, Seth Haines, Cerecia Martinez, Mark Mihalasky, Darius Semmens, Paul Pierce, and Katherine Walton-Day of the U.S. Geological Survey. Final thanks go to Sally Almeria for her careful and helpful editing and to Carol Quesenberry for translating "we want it to look nice" into a layout nicer than we imagined possible. 


\section{Multi-Resource Analysis-}

Methodology and Syuthesis

By Karen E. Jenni, ${ }^{1}$ Emily Pindilli, ${ }^{1}$ Richard Bernknopf, ${ }^{2}$ Timothy L. Nieman, ${ }^{3}$ and Carl Shapiro'

$\frac{25}{2-2-2 x}$

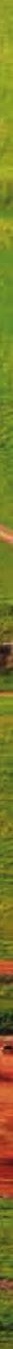




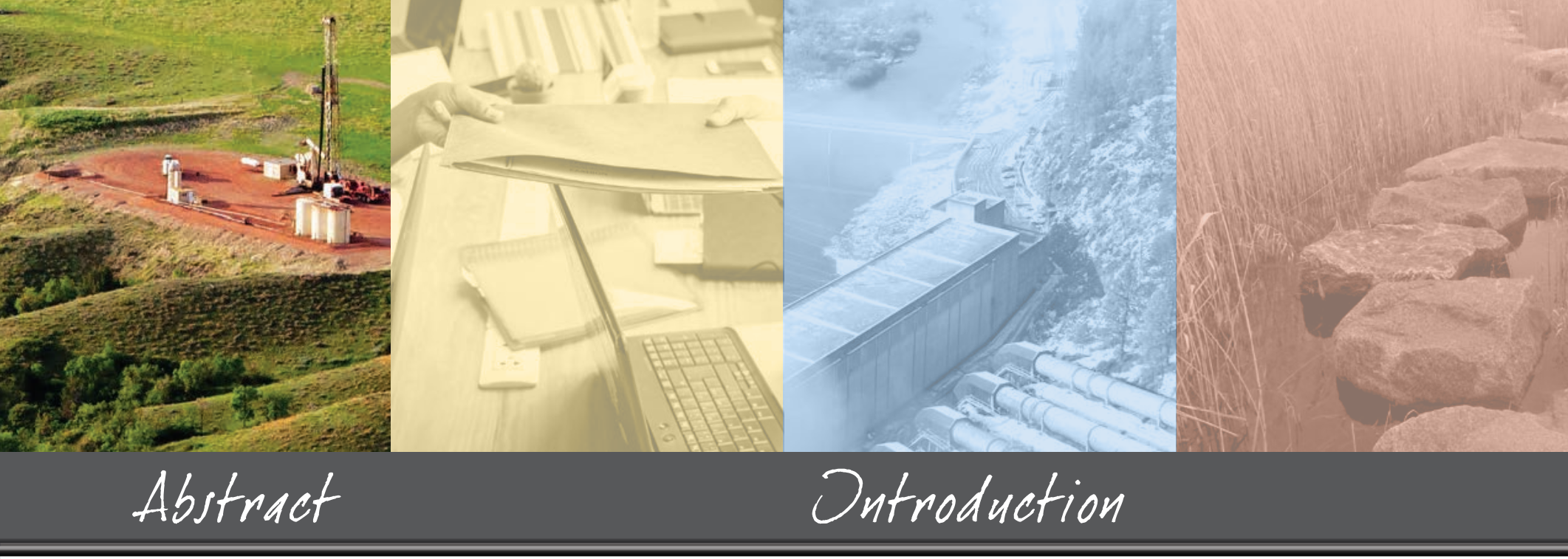

This document introduces the Multi-Resource Analysis (MRA), a set of products that are being designed to integrate information on multiple natural resources in a region, combine that information with models of resource interrelationships and scenarios of change, and provide meaningful insights on the implications of those changes to people and the resources they value. The MRA builds from and enhances a wide range of existing U.S. Geological Survey assessment products. These enhancements will help natural resource managers better understand the connections among the resources they manage and the changes that might occur due to natural events and human decisions. This knowledge will help them identify solutions to landscape-scale management issues that best meet their objectives. MRA products are developed through a structured process that brings together scientists, decision makers, and other stakeholders to address relevant issues and decisions for a specified geographic region, ensuring that the analysis is directly relevant. This circular introduces the MRA, describes the envisioned process for developing a region-specific MRA, and discusses the various MRA components and products. The MRA process and products are shown through descriptions and examples drawn from two proof-of-concept studies and related work.
${ }^{1}$ U.S. Geological Survey. ${ }^{2}$ University of New Mexico. ${ }^{3}$ Decision Applications, Inc.
The Multi-Resource Analysis (MRA) is conceived as a next-generation suite of analytical products that can be used to inform land use and resource management decisions. The MRA integrates scientific information about natural resources and explicitly recognizes changes to those resources caused by natural events and human decisions. The MRA considers the effects of these changes on multiple natural resources, the natural resources' interrelationships, and the economic and societal consequences of these changes to humans. It builds on the wealth of geologic, hydrologic, biologic, and social/ cultural resource assessments produced by the U.S. Geological Survey (USGS) and others to provide public-sector resource managers and other decision makers with landscape-scale science products and perspectives.

With the enhanced resource assessment information that results from the MRA, resource managers can identify more and better management options and have greater understanding of how those options will affect the landscape and its resources, and the people who depend on those resources. Decision makers almost always need to act without knowing exactly what the future will bring, and thus they benefit from tools that help them anticipate potential future conditions and the effects of various management options. The MRA provides an enhanced description of how the many resources in a specific region connect, as well as projections of future conditions under different scenarios. These products allow decision makers to consider both decision-driven and external or stressor-driven changes in resources and resource-related benefits.

This circular summarizes the vision, status, and results of efforts undertaken by the USGS Science and Decisions Center to develop the MRA. The "Vision for the Multi-Resource Analysis" section of this document describes the vision and motivation for developing the MRA approach, and briefly describes a set of studies that were conducted as part of the development process. The "Multi-Resource Analysis Process" section describes the envisioned process for conducting an MRA, and the "Development of Multi-Resource Analysis Components" section outlines each of the MRA components and how they are to be developed and provides examples from experiences to date. The " Potential Next Steps" section concludes with a set of next steps for moving the MRA from the conceptual and demonstration stage to a real decision-support process and set of tools. 


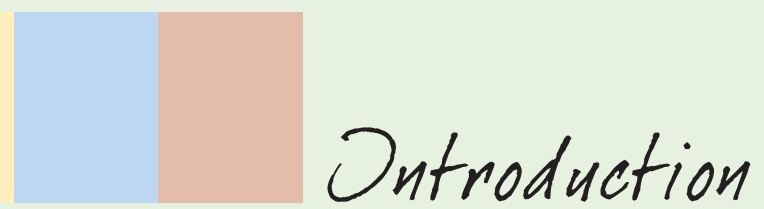

\section{Vision for the Multi-Resource Analysis}

The MRA combines information on multiple resources into a single analytical framework that includes (1) a baseline assessment of the quantity and quality of colocated natural resources in a defined geographic region, (2) models of those resources' interrelationships and the effects on humans of changes in those resources, and (3) projections of the future conditions of those resources as they experience various disruptions and stressors. By providing this critical information through a timely, relevant, and scientifically sound set of data and tools, the MRA supports resource managers as they make decisions that affect our Nation's natural resources and economic and societal well-being.

An individual, regionally specific MRA is developed through a structured and iterative process that brings together scientists, decision makers, and other stakeholders to identify and address issues and decisions of most relevance for a specified geographic region. The process and major MRA components are shown in figure 1 and described on the following pages.

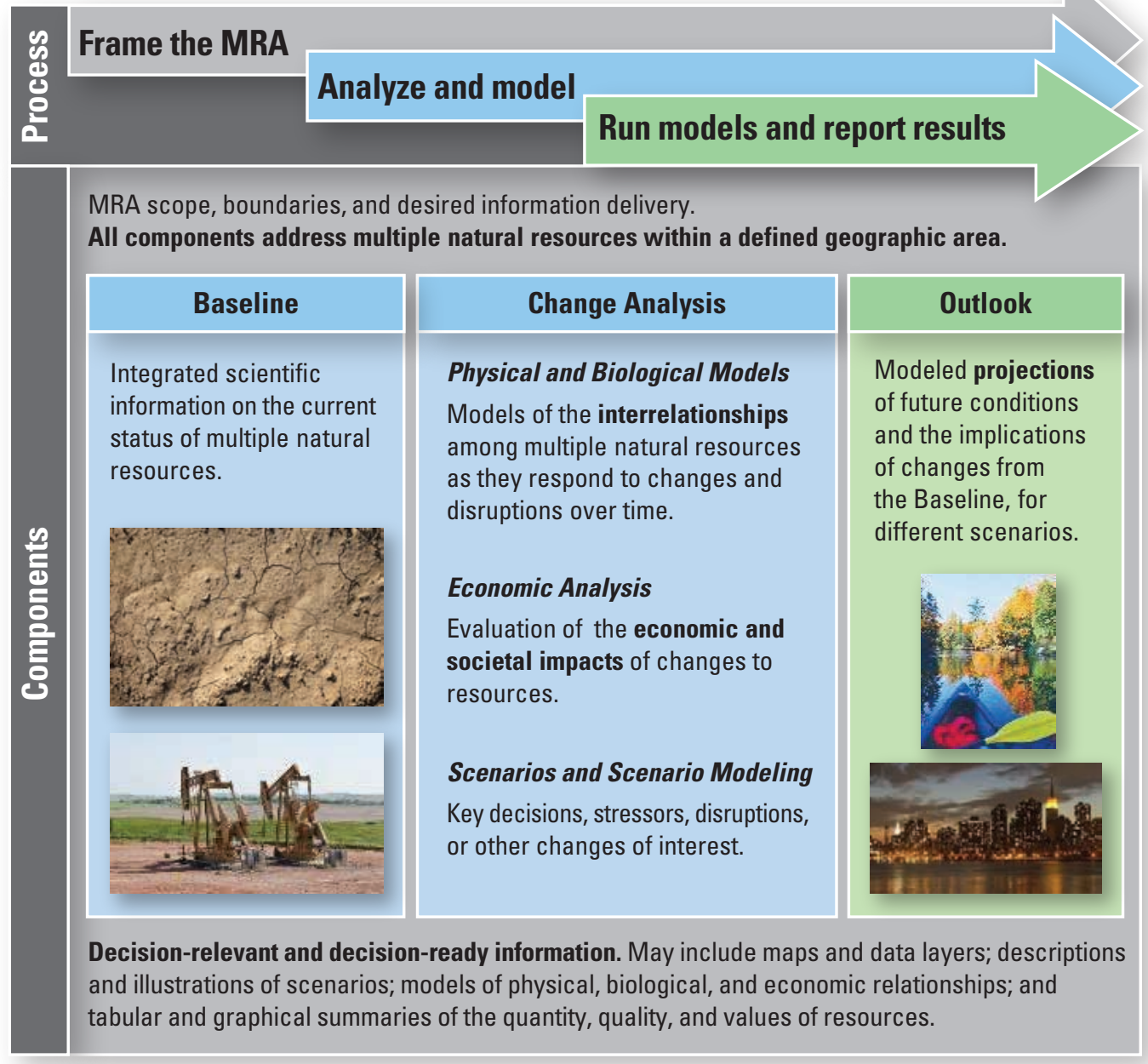

Figure 1. Multi-Resource Analysis (MRA) process and components. 


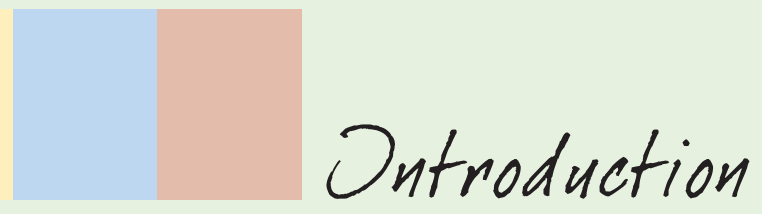

Baseline.-The MRA Baseline combines scientific information on multiple natural resources into an integrated framework so that the information can be reviewed, analyzed, and disseminated. The Baseline includes information on the quality and quantity of resources in a region at a point in time, as well as relevant history, trends, and the current economic context for the region and its natural resources. Developing an MRA Baseline requires integrating data from different disciplines and at different scales and summarizing and presenting that information in ways that are relevant to decision-makers' interests. The "Background" section discusses some of the variety of resource assessments that may be available for a particular region. Even when several assessments exist in a region, they are typically conducted for different purposes or over different geographic and temporal boundaries, may not be easy to access, and are not integrated. The MRA Baseline provides that integration and easy access.

Change Analysis.-The Change Analysis component of MRA consists of models and analyses that connect the Baseline (current conditions) to the Outlook (potential future conditions). Change Analysis includes three types of analyses.

- Scenarios of change.-Natural processes and events and human decisions can change landscapes, their natural resources, and the services and benefits those resources provide. Resource managers must make decisions in the face of uncertainty without knowing what the future will bring. So, tools and approaches that help them anticipate future conditions, and how their management options might affect resources, landscapes, and people are needed. Scenarios of change are a key part of the MRA and the use of scenarios is a standard tool decision makers can use to better understand the risks and benefits of different actions given uncertainties about the future. Developed by scientists, decision makers, and other stakeholders with deep knowledge of the region being analyzed, the scenarios of change in an MRA are developed from an understanding of the most important stressors, disruptions, and decisions that may affect the future landscape. Scenarios help identify the issues that should be modeled further in the Change Analysis, and define and constrain what the MRA Outlook will produce.
- Physical and biological models of natural resource interrelationships.-The MRA includes explicit descriptions and models of the interrelationships among natural resources. Quantifying information on the biophysical relationships between those resources allows analysts to model and project how a change in one resource (for example, extraction of an energy resource) affects other resources (for example, water availability and water quality). For the MRA, models of resource interrelationships address (1) spatial issues, to capture regionally and locally important connections; and (2) temporal issues, to capture changes in resources and impacts over time. An important part of the vision for the MRA is that uncertainty is considered directly in each component; that is, where there is lack of information about and (or) regional variability in resource relationships, MRA models address and communicate that uncertainty.

- Economic analysis.-The connections between natural resources and humans are a principal consideration in the MRA. As the landscape and resources in a region change over time, there can be direct economic consequences (for example, effects of energy extraction, water availability for agriculture, and effects of recreational spending) and indirect societal benefits (for example, ecosystem services, benefits associated with preserving the heritage and ways of life for Native American and rural communities, and benefits associated with fishable and swimmable waters). Through analysis and valuation of the effects of changes in resources, the economic analysis in the MRA brings together the Baseline, models of the physical and biological interrelationships among resources, and scenarios of change into a common reference system that crosscuts multiple natural resources and enables consideration of the economic and societal effects of changes in those resources. 
Outlook.-The results of the Change Analysis constitute the MRA Outlook. The Outlook provides decision makers with information on potential outcomes of decisions, actions, and other factors that affect resources over time. Similar to the Baseline, the Outlook describes the quality and quantity of each resource, but under changed conditions rather than current conditions. Comparing the Outlook to the Baseline provides a picture of potential changes over time: spatially and temporally referenced effects on the landscape, including changes in colocated resources and changes in the benefits that are being derived from that landscape. Comparing the Outlook under different scenarios of change provides resource managers and stakeholders with insights about the tradeoffs that might be incurred under different management options and different scenarios.
To maximize the usability of the MRA and ensure results are decision-relevant and decision-ready, all of the components are packaged in one or more accessible, easy-to-use and easyto-understand information-delivery platforms. These platforms can take the form of maps of colocated resources; descriptions and illustrations of scenarios considered; models of resource interrelationships; and (or) tabular and graphical summaries of the quantity, quality, and values of resources both in the Baseline and under different scenarios. Decision-support systems provide a decision maker or stakeholder with desktop access and a variety of ways to explore the multidimensional outputs of the MRA.

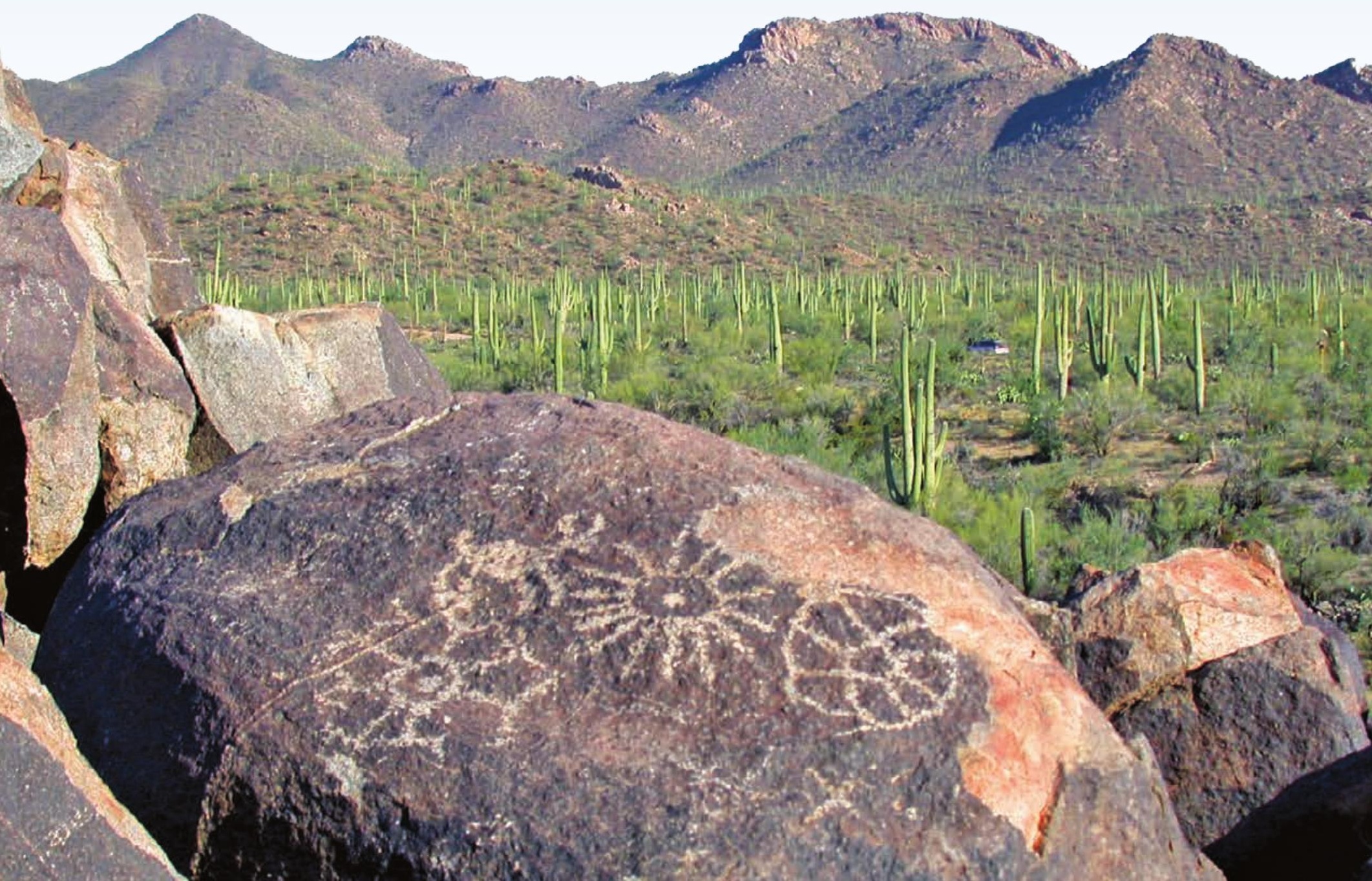




\section{Ontroduction}

\section{Background}

The USGS has been conducting resource assessments for a variety of natural resources for several decades as part of the agency's mandated responsibilities stated in the Organic Act of 1879 and later amendments (20 Stat. 394; 43 U.S.C. 31, et seq.). Energy and mineral resource assessments were one of the earliest focuses of the USGS, which has been conducting such assessments almost since its founding (Ferrero and others, 2013).

Quantities of undiscovered, technically recoverable energy resources are estimated based on historic data, current technologies, and well-established and vetted probabilistic modeling approaches. The USGS also assesses water and biologic resources by using resource-specific methodologies. The differences in the resources assessed, the methodologies used, and the focuses of the assessments make it challenging to compare and (or) integrate existing assessments of multiple natural resources in a common framework.

The information provided by various types of resource assessments supports decisions in land management, water allocation, energy and mineral policy, and environmental protection in both Government and the private sector, but current resource assessments are typically conducted under single-discipline assumptions and are not conducive to evaluating interrelationships among resources and the consequences of change. However, the demand for more sophisticated analyses of those connections is increasing. To help meet this need, the MRA requires that multiple natural resources are assessed in a way that allows data and information on those resources to be compared, combined, and synthesized, resulting in an integrated understanding of the region being assessed. With the enhanced assessment capabilities of the MRA, colocated natural resources and the tradeoffs between different resource uses can be considered, and the multifaceted effects of changes in resources can be analyzed.

\section{Current Resource Assessments}

Energy and mineral resource assessments are typically geologically based, probabilistic estimates of volumes of commodities that include conventional oil and gas, unconventional oil and gas, coal, uranium, and nonfuel minerals. In energy resource assessments, quantities of undiscovered, technically recoverable oil and gas resources are estimated based on historic data, current technologies, and well-established and vetted probabilistic modeling approaches (Charpentier and Cook, 2012). The goal of a quantitative mineral resource assessment is to identify and clarify factors that are relevant to mineral-related decisions (Singer and Menzie, 2010). USGS energy and mineral resource assessments provide information about the quantity and quality of energy resources and the uncertainty surrounding them (after Pierce and others, 2007) within a geologically defined boundary. Cost of extraction and resource prices are assessed for some, but not all, of these resources and are only rarely included within resource assessments focused on quantity and quality.

Water and biologic resource assessments are conducted for their own unique purposes and use approaches that are unique to those resources. They are not designed to be directly comparable to energy and mineral resource assessments or with each other.

Water resource assessments include real-time and historical stream-stage and streamflow information from the National Water Information System (https://waterdata.usgs.gov/nwis/sw); national and regional water quality assessments from the National Water-Quality Assessment Project (https://water.usgs. gov/nawqa/); and groundwater levels and trends based on a combination of observations from streamgages, groundwater wells, and models (https://water.usgs.gov/ogw/). Additionally, USGS assesses water use across the United States every 5 years through the National Water-Use Information Program (Barber, 2014). 
Biologic resource assessments use scientific and statistically reliable methods and protocols to assess the status and trends of the Nation's biological resources, with focus on the abundance, distribution, productivity, and health of those resources. The USGS provides assessments of seasonal life-cycle events through the National Phenology Network (https://www.usanpn.org/) and remote sensing approaches (https://remotesensing.usgs. gov/), and assessments of the status and trends of a variety of species- or species-group-specific studies (Mac and others, 1998). The National Gap Analysis Project is working to map predicted species distributions and associated land ownership and land cover across the United States (https://gapanalysis. usgs.gov/about-gap/). In a few regions, biologic resource assessments address multiple species and their connections to habitats (for example, the Upper Mississippi River Restoration Program [https://www.umesc.usgs.gov/ltrmp. html]). Anthropogenic trends and the effects of these trends on biological resources may also be assessed.

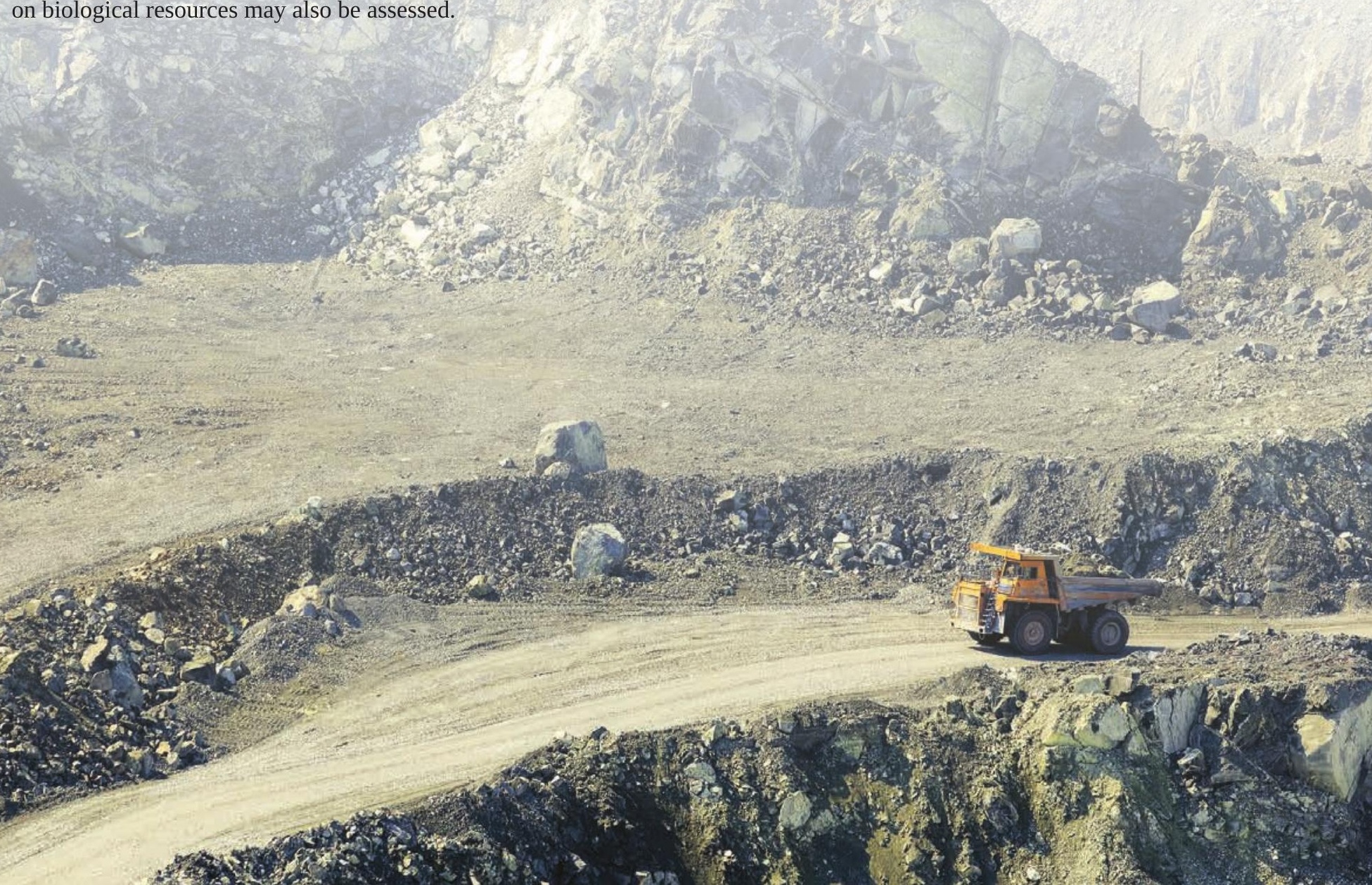

In addition to assessments of energy and mineral resources, water resources, and biological resource systems, the USGS has made significant investments in systematically understanding changes to land itself, particularly under land remote sensing programs (https://remotesensing.usgs.gov/). These data enable understanding of both long-term and short-term changes in land resources, including shifts between types of land use, such as changes from forest to agricultural use, and shifts in the quality of resources, such as changes in forest density. 


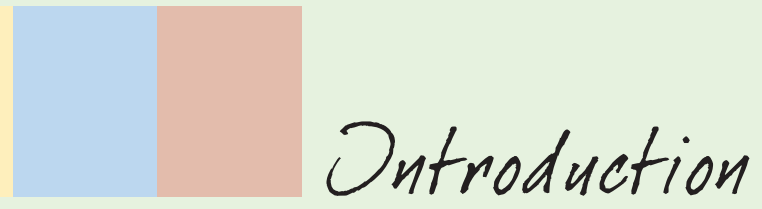

Most existing USGS resource assessment methods do not include assessment of the economic and societal consequences of changes in resources and do not consider ecosystem service benefits that may be derived from natural resources. When ecosystem service assessments are conducted, they are largely conducted on an ad-hoc, demand-driven basis. For example, recent USGS ecosystem service assessments have focused on fire mitigation as one ecosystem service provided by the Great Dismal Swamp National Wildlife Refuge in Virginia (Parthum and others, 2017); on the employment, recreation, and nourishment services from inland fisheries (Deines and others 2017); and on habitat, soil carbon, and water supply for a subset of watersheds included in a larger scale study (Byrd and others, 2015). Existing resource assessments and methods also do not typically attempt to quantify impacts (cumulative or otherwise) of changes in those resources. Environmental impacts are regularly quantified under section 102 of the National Environmental Policy Act of 1969 (42 U.S.C. 4321 et seq.) which "requires federal agencies to incorporate environmental considerations in their planning and decisionmaking through a systematic interdisciplinary approach" (U.S. Environmental Protection Agency, 2017). However, these analyses are conducted reactively in response to a specific proposed action, whereas the resource assessments described throughout this section are typically more general.

\section{Enhancing and Integrating Resource Assessments}

Although traditional resource assessment methods have matured and continue to provide important information, societal choices and decisions now demand enhanced information. The emergence of integrated approaches and examples of larger scale studies aimed at supporting decision making indicate an appetite for these more ambitious approaches. For example, strategic environmental assessment explicitly focuses on decision support, but most analyses are project specific (Lobos and Partidário, 2014). The U.S. Fish and Wildlife Service is using strategic habitat conservation as a framework for managing resources at larger geographic scales (U.S. Fish and Wildlife Service, 2016), but it tends to focus only on ecological resources. Integrated environmental modeling (Laniak and others, 2013) focuses on modeling the connections across resources and processes at a variety of scales, but it is less connected to decision making.

With enhanced resource assessment information, resource managers can identify more and better management options and have greater understanding of how those options will affect the landscape, its resources, and the people who depend on them-the MRA provides exactly this kind of enhanced resource assessment. The MRA brings together information on multiple natural resources, the economic and societal values associated with those resources, and the services and benefits those resources provide into a single decision-oriented framework. An MRA provides an enhanced description of how the many resources in a specific region connect, thus allowing decision makers to consider both decision-driven changes and changes that might be driven by external stressors in those resources and in resource benefits over time. 



\section{Supporting Studies and Activities}

The Science and Decisions Center has been developing the MRA concept by reviewing related work and information from a series of workshops and studies held in the past several years. These efforts culminated in two separate proof-of-concept studies that were designed to determine the challenges, feasibility, and value of the MRA as a new type of USGS product. Based on the results of these studies, other related research, and an MRA synthesis workshop held in 2016, the Science and Decisions Center concludes that the MRA could be developed and implemented by the USGS. The proof-of-concept studies and synthesis workshop helped define the vision for the MRA and provide an important part of the basis for the MRA process and approach described in this document.

\section{Proof-of-Concept Studies}

The two MRA proof-of-concept studies were designed to be multipurpose; they were intended to demonstrate the feasibility of the MRA, identify approaches that are most promising, and evaluate the challenges to conducting an MRA. The independently conducted studies explored several perspectives on how to develop an MRA. One study, conducted by a team of USGS scientists and private consultants under contract, focused on the Powder River Basin (PRB) of northeastern Wyoming, where the main energy resource is coal and the impacts of coal mining and coal-bed natural gas (CBNG) development on water, ecology, and the local economy are important issues in the region. The second study, led by researchers from the University of New Mexico under a cooperative agreement with the USGS, focused on the Piceance Basin in northwestern Colorado, where the main energy resource is shale gas and the impacts of gas extraction and hydraulic fracturing on water quality and wildlife are important issues in the region.
The proof-of-concept studies were designed as exploratory efforts; the focus was on research that supported development of the MRA using existing USGS data and models rather than on producing analyses ready to support specific decision making. The primary objectives of the two studies were

- to develop and test an approach for integrating existing data and assessments of multiple natural resources, their interrelationships, and the impacts of changes on economic values and

- to identify and explore ways to make that integrated information useful to land and natural resource managers and stakeholders.

Beyond these objectives, there were few constraints on exactly how the proof-of-concept studies were approached, and it was understood that each study would evolve during the process as the concepts of the MRA were being developed. In each case, the study team had to identify a geographic area, a set of natural resources, at least one potential source or type of change, and a future time horizon on which to focus the study. Because both studies were conducted by small teams with very few dedicated resources, in practice those studies were highly constrained in terms of the amount and type of work that could be done to accomplish the study goals. For example, both studies had to rely exclusively on existing and accessible data. The two studies took different approaches when no such data were available, choosing either to not evaluate that resource or impact or to use data and models from a different region for illustration purposes. Both studies were also of limited scope - only a few of the relevant natural resources were included and a few scenarios considered in each study; only one study included stakeholder interactions, and only one illustrated an economic valuation of an ecosystem service.

These limitations mean that the "results" of these proofof-concept studies are illustrative only. Although decisionrelevant conclusions should not be drawn from them, these studies met their goals of advancing the MRA concepts, identifying promising approaches and challenges associated with MRA implementation. The two proof-of-concept studies are summarized in the highlights on pages 12-13 and 14-15. 


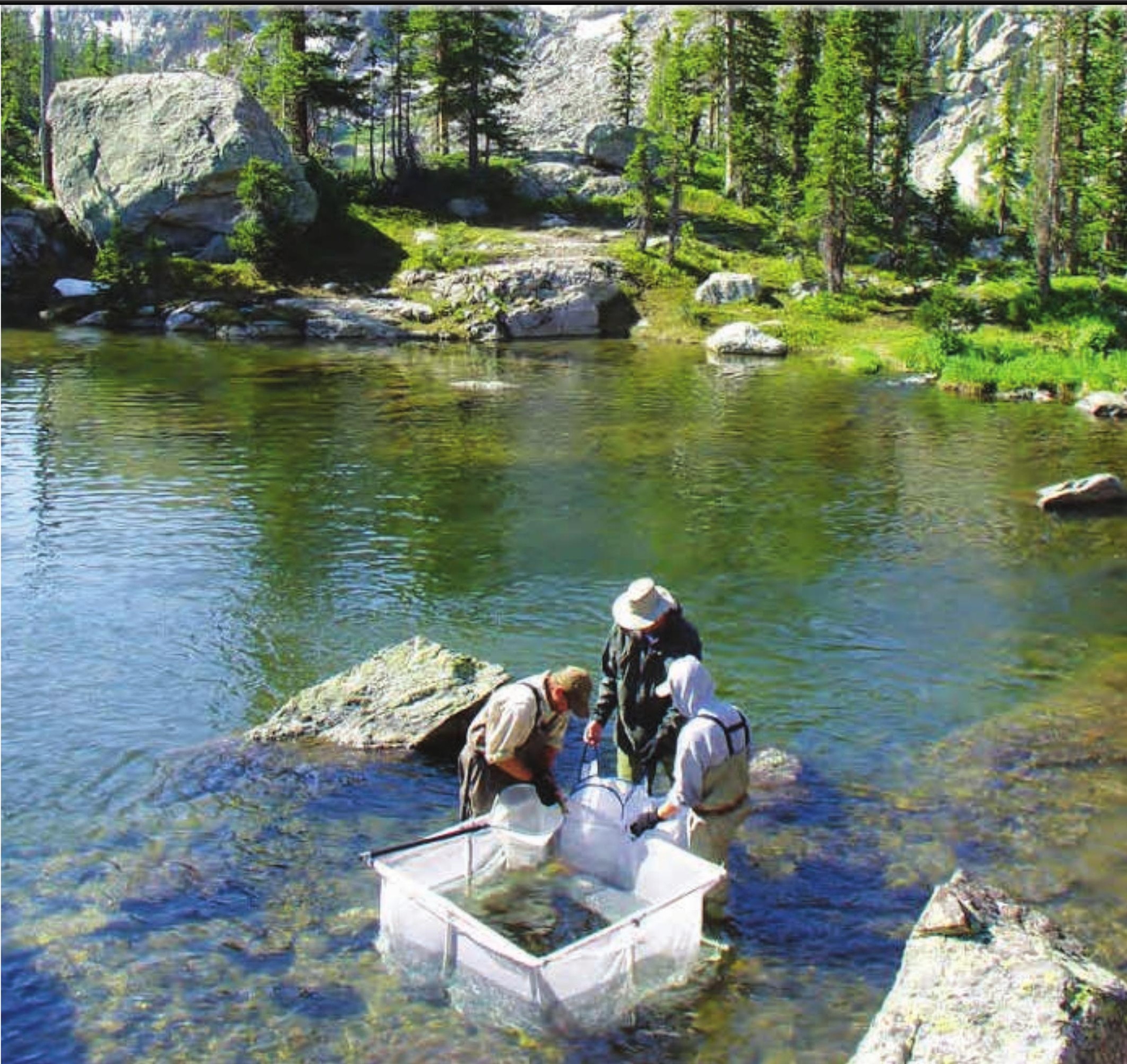



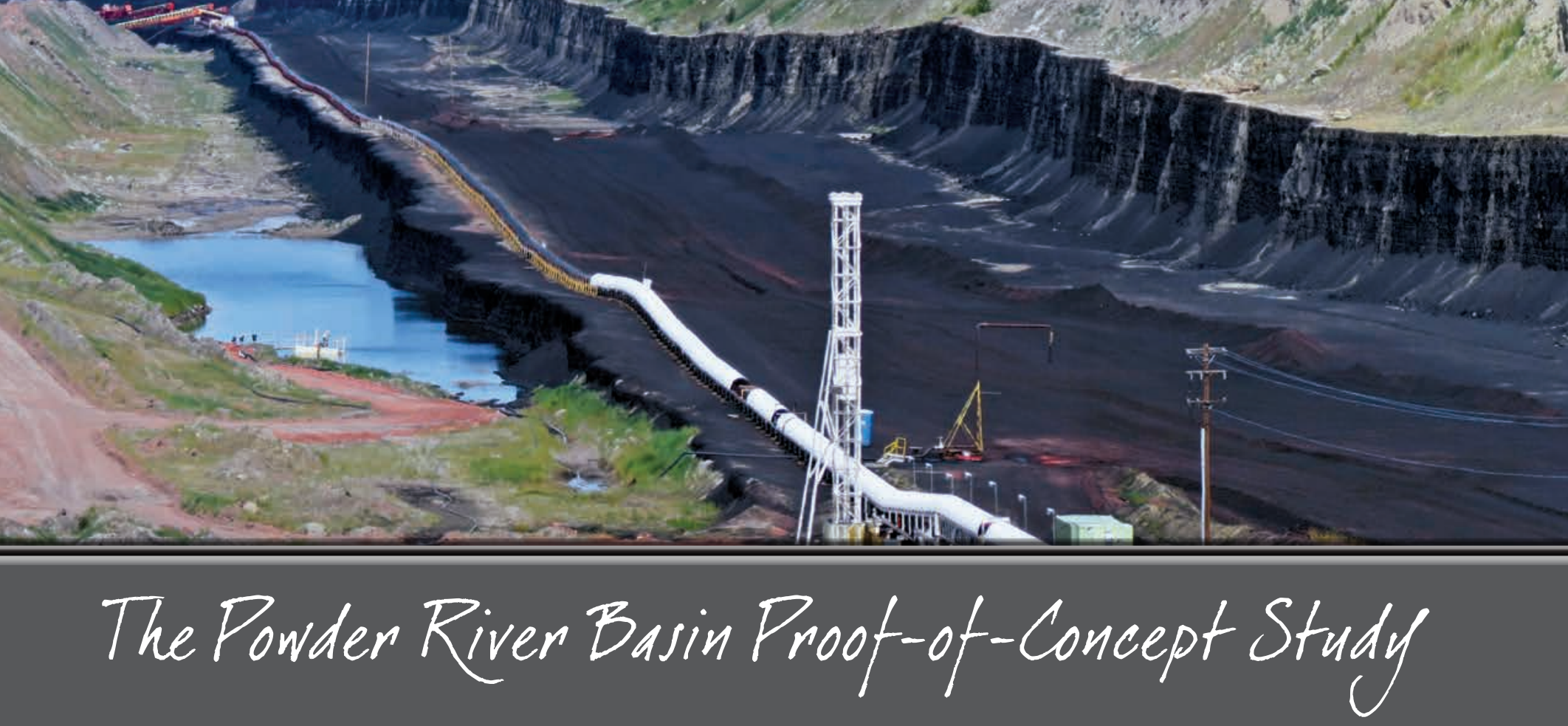

The Powder River Basin is a rural, coal-rich region in Montana and Wyoming consisting primarily of grassland and containing some important habitat for greater sage-grouse (Centrocercus urophasianus). In developing a proof-of-concept study for the Multi-Resource Analysis (MRA) in this region, the study team sought broad input across U.S. Geological Survey disciplines and from partners and stakeholders, including local and regional scientists, headquarterslevel Federal agencies (for example, U.S. Department of the Interior, U.S. Fish and Wildlife Service, Bureau of Land Management, and Forest Service), and State and local constituents. These discussions were essential for understanding the scope of resources and stressors that are relevant in the region and provided highly valuable information about the kinds of information, modeling tools, and analysis results that would be most useful to on-the-ground decision makers. Each of the major components of the MRA was developed, at varying levels of detail, in this proof-of-concept study. Some specific details about the study are provided here.
- Baseline information collected and summarized included data on the quantity, quality, and location of coal, coal-bed natural gas (CBNG), surface water, groundwater, some wildlife species and associated habitats, grazing, land disturbance, and land ownership.

- Energy development, specifically of coal and CBNG, was identified as the key driver of change for this modeling effort, and several development scenarios were hypothesized and modeled.

- The Change Analysis evaluated the potential effects of coal and CBNG extraction on surface disturbance, groundwater and surface water, and specially designated habitats, as well as several basic economic factors such as development revenue.

- Several methods for presenting the results of the Change Analysis (that is, the Outlook) were explored, including maps comparing the Outlook under different scenarios and graphs illustrating resource changes over time under different scenarios. 

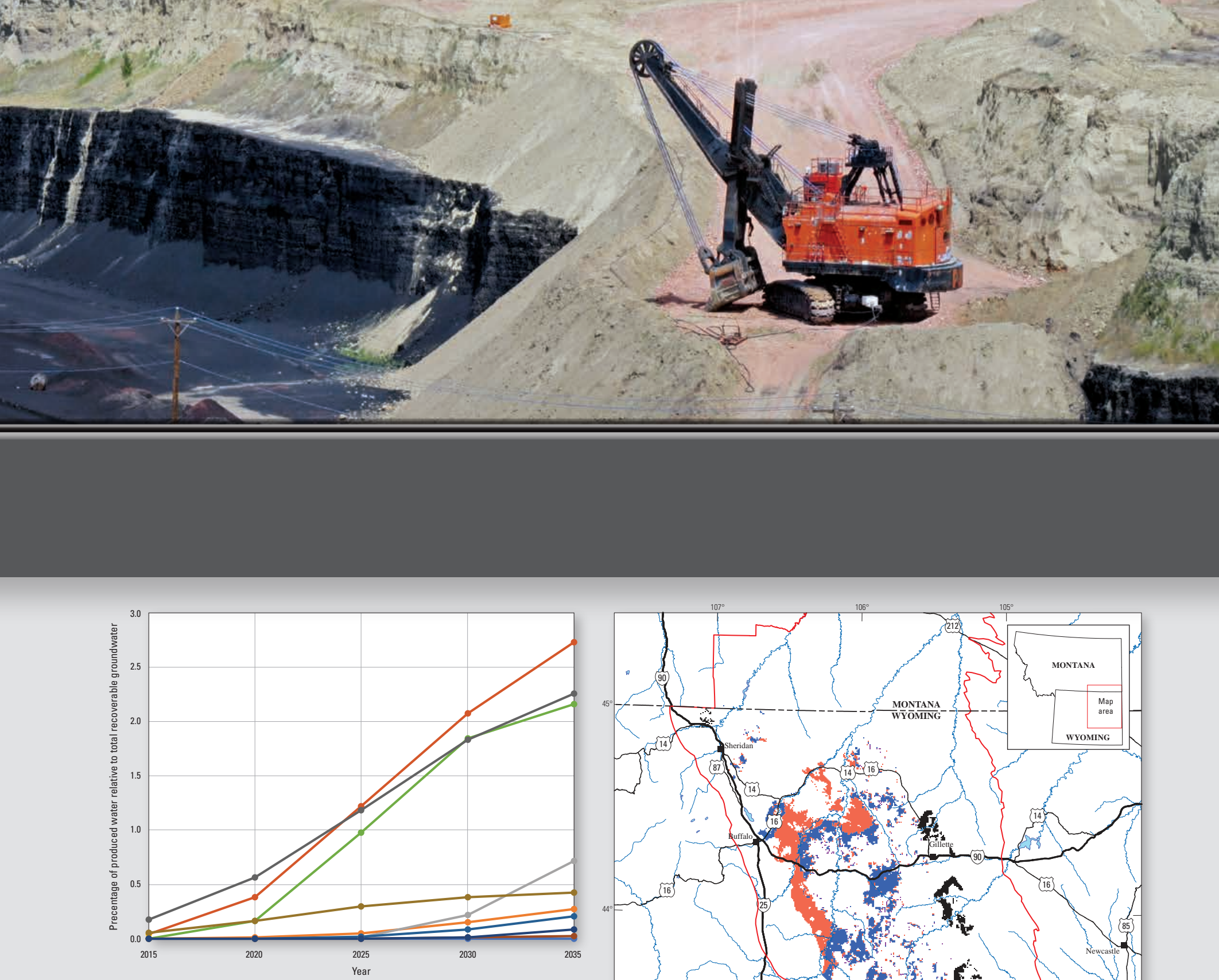

Note: The Powder River Basin MRA was not intended to address a specific issue or question in the Powder River Basin region or to be a substitute for focused studies; rather, it was a feasibility test and exploration of the challenges and benefits of developing an MRA.

Produced water relative to total recoverable groundwater over time for a single development scenario. Each line represents an individual watershed.

Map of study area illustrating areas with energy development under different scenarios.

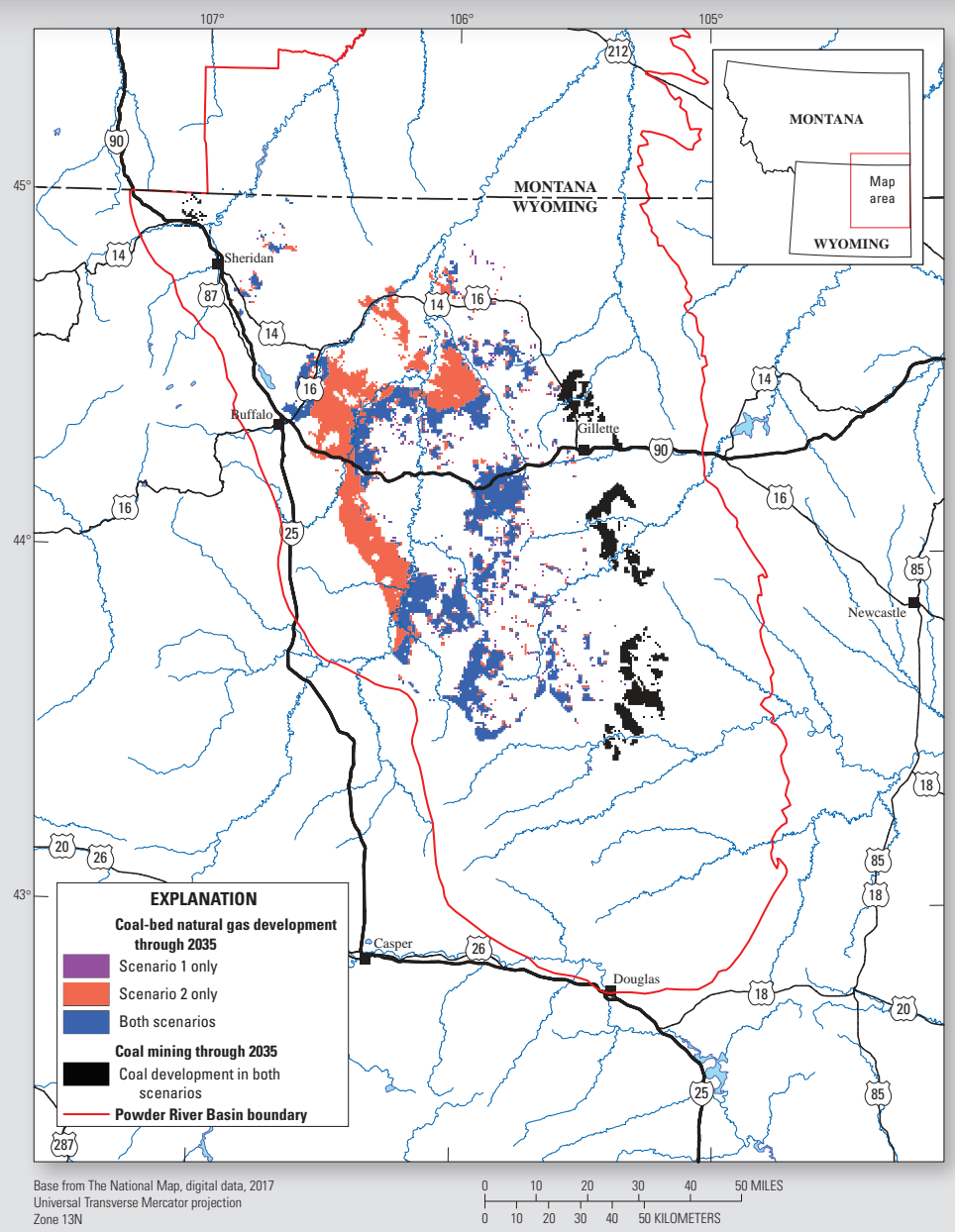

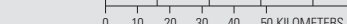




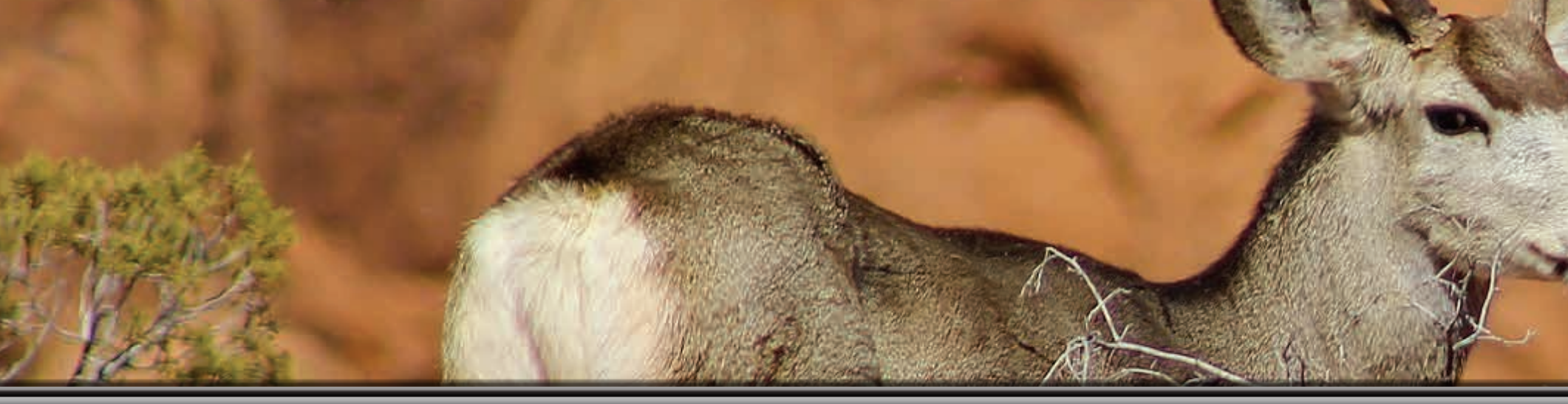

\section{The Piceance Basin Proof-of-Concept Study}

The Piceance Basin is a rural, energy-rich region in northwest Colorado that contains coal, natural gas, and oil shale resources. It is also home to one of Colorado's most important populations of mule deer (Odocoileus hemionus) (Colorado Parks and Wildlife, 2014). In developing a proof-of-concept study for the Multi-Resource Analysis (MRA) in this region, the study team focused on the development of an analytical decision-support tool (DST) that combines natural resource and economic information to model the potential effects of energy resource development on ecosystem services. The DST produces a "net resource value" that is the sum of the economic benefits from energy and mineral production and the economic value of the effects this development has on several other natural resources in the area. The Piceance Basin MRA explored all major elements of the MRA concept described in this circular but at different levels of depth and sophistication. Some specific details of this MRA are provided here.
- Baseline information collected and used included the location(s) of natural gas and surface water resources, mule deer habitat, and key surface conditions related to habitat suitability.

- The Piceance Basin study considered energy development, specifically natural gas extraction using hydraulic fracturing, to be a key driver of change in the region. The proof-of-concept study focused on the development of the DST, which allows users to define their own scenarios. The study team illustrated this capability by considering how development might proceed under different hypothesized scenarios that varied the pace of development over time, and the number of wells installed per well pad.

- The Change Analysis focused on the potential effects of gas extraction on water use, surface disturbances, and mule deer, which were all connected through a systems dynamics model that considers the interaction of geology, hydrology, ecology, and economics in the region over time. The study also included an economic analysis of reduced water availability and reduced fish and mule deer populations potentially resulting from development. 


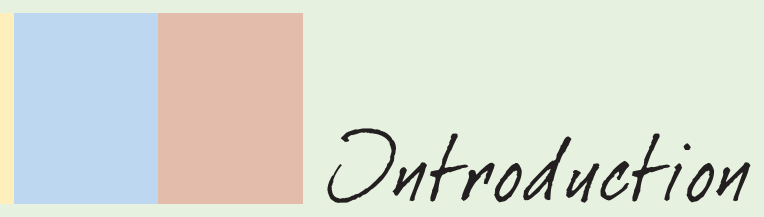

Synthesis Workshop

The Science and Decisions Center convened a 2-day MRA synthesis workshop to identify and discuss best practices and promising methods that can be used to implement the MRA. Participants from both proof-of-concept studies were joined by USGS and other U.S. Department of the Interior scientists who had interests in and experiences with other multidisciplinary studies that focus on understanding the interrelationships among natural resources (for example, Haines and others, 2013; USGS Assessment Team, 2015; Wyoming Landscape Conservation Initiative, 2015; USGS, 2016). The workshop discussions informed and helped clarify the MRA vision; emphasized the importance of a clear, structured process for implementing an MRA and for decisionmaker involvement throughout that process; and identified promising methods (and challenges) for each component of the MRA. All of these insights are reflected in the MRA vision and process described in this circular. A few of the key takeaways from the MRA synthesis workshop are summarized here.

Overall use and structure.-The MRA is a multiuse product and the process should be undertaken for a given region with the goal of developing products that can be useful to multiple decision makers as they grapple with a variety of complicated land and resource management decisions. The MRA resembles traditional USGS resource assessments in that it is intended to be developed proactively rather than in response to a specific or single decision-support need. However, by building resource manager and stakeholder perspectives into the analyses from the beginning, the scope of the MRA can be better managed and the resulting analytical products will be useful to those intended end users. The MRA can then be useful as a starting point for more detailed decisionspecific studies, making them faster and easier to complete. Baseline data, models of resources interrelationships, and future scenarios of interest can then be tailored to specific decisions.
Partnerships, engagement, and leveraging related work.For an MRA study to achieve its primary goal of providing information to support resource management decision making, it is essential that it be developed in close collaboration with entities and individuals who manage the natural resources in a region. In many cases, regional and local partners may have data, models, and projects underway that address at least a subset of the issues to be considered in an MRA, and working with those groups will increase both the quality and the relevance of MRA products.

Resources and data considered.-Individual MRAs for different regions should have some commonalities while also addressing regionally specific issues. Use of national datasets, where available, will increase the comparability of MRAs for different regions and may enable some cross-regional comparisons. Use of the best available local and regional data is also necessary to ensure decision relevance and credibility with local and regional decision makers and stakeholders. In addition to the basic information on quantity and quality of the natural resources, the MRA Baseline should include resource history and trend information, as well as information on the regulatory, economic, and societal context of the region. This contextual information is important for communicating a clear and accurate understanding of regional issues, is helpful for identifying potential scenarios of change that are of interest, and can inform the multiresource modeling efforts. 
Uncertainty.-There are many sources of uncertainty in an MRA, including uncertainty arising from a lack of data, a lack of scientific understanding, and natural variability. Lack of data may mean that no data at all are available, that available data are only partially relevant to the region and resources being considered, or that the predictive power of existing data is poor. Lack of scientific understanding arises because many of the resource interrelationships have not been studied carefully; even the general nature of those relationships may not yet have been examined. In addition, when broad spatial and temporal scales are considered, there is natural variability across time and space in the underlying resource characteristics. The MRA will only represent reality adequately if it reflects these uncertainties. It should include uncertainties explicitly and propagate them through the models so that the full uncertainty in the final analysis results can be communicated clearly. Tracking the sources of uncertainty is also useful when determining where additional data and science can reduce the uncertainty that matters to decision makers and when establishing research priorities.

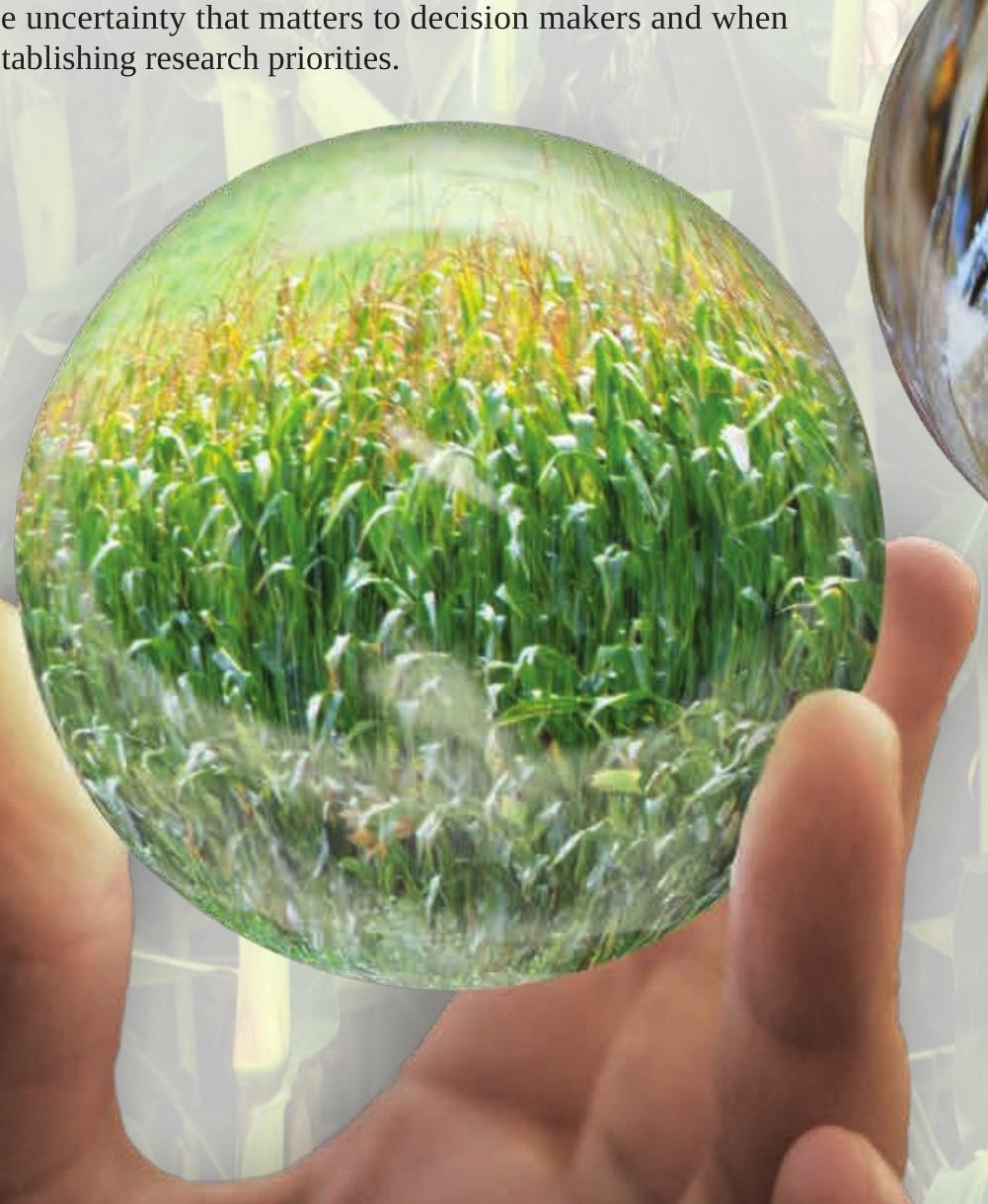

Information delivery.-Important issues that require additional exploration are how, and what, information from the MRA can and should be delivered to end users. The goal is to provide products and analytical results to decision makers, either as tools they can use directly or as data and models developed for the MRA that they can use as initial information for more detailed analyses of specific decision problems. Multiple media and deliverables are necessary to deliver information to different stakeholders. A key message from the MRA synthesis workshop was to focus first on what needs to be communicated to users, and then to let the goals of the MRA determine what information delivery technologies can be used.

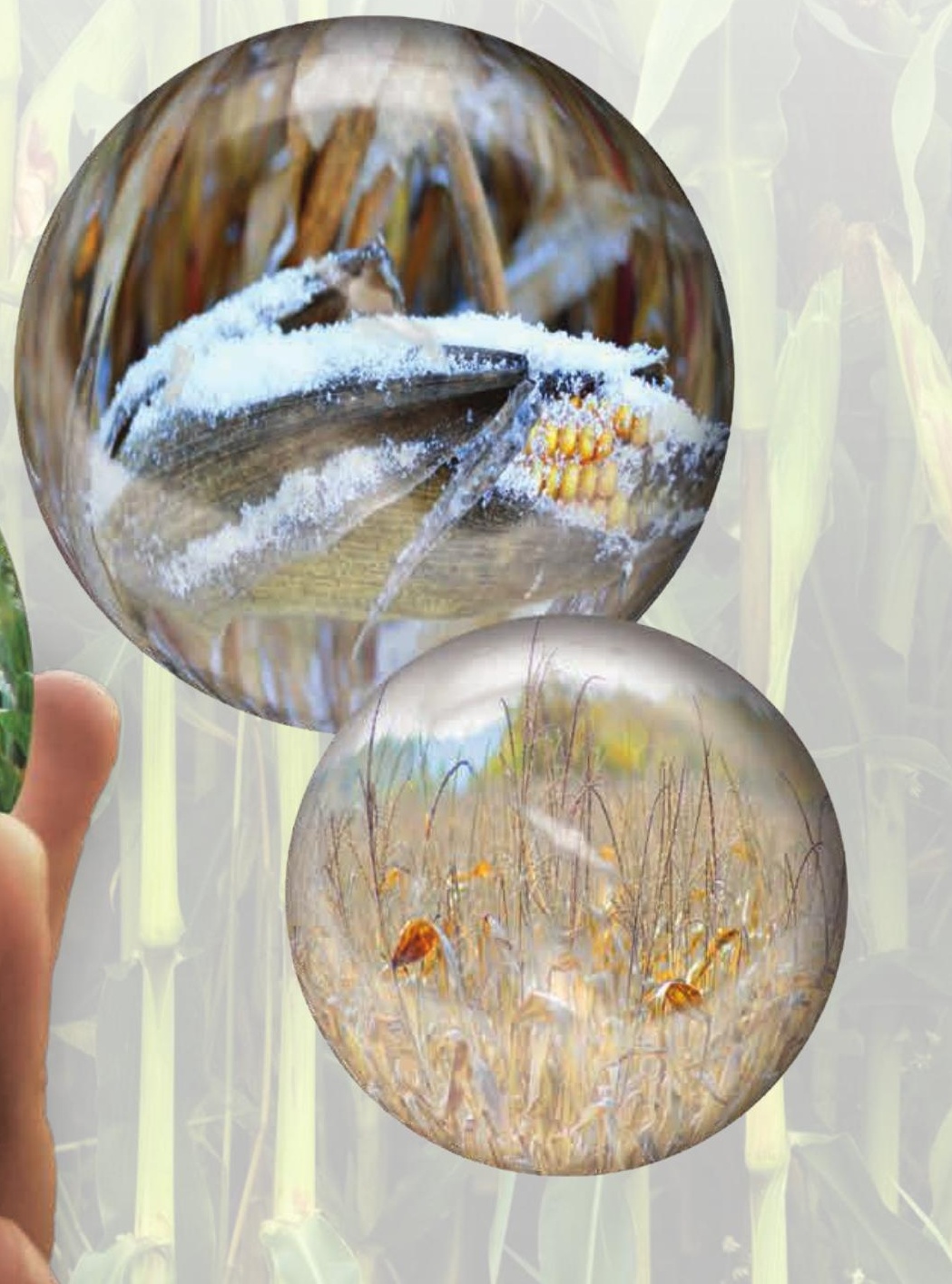


Multi-Resounce Analysis Process

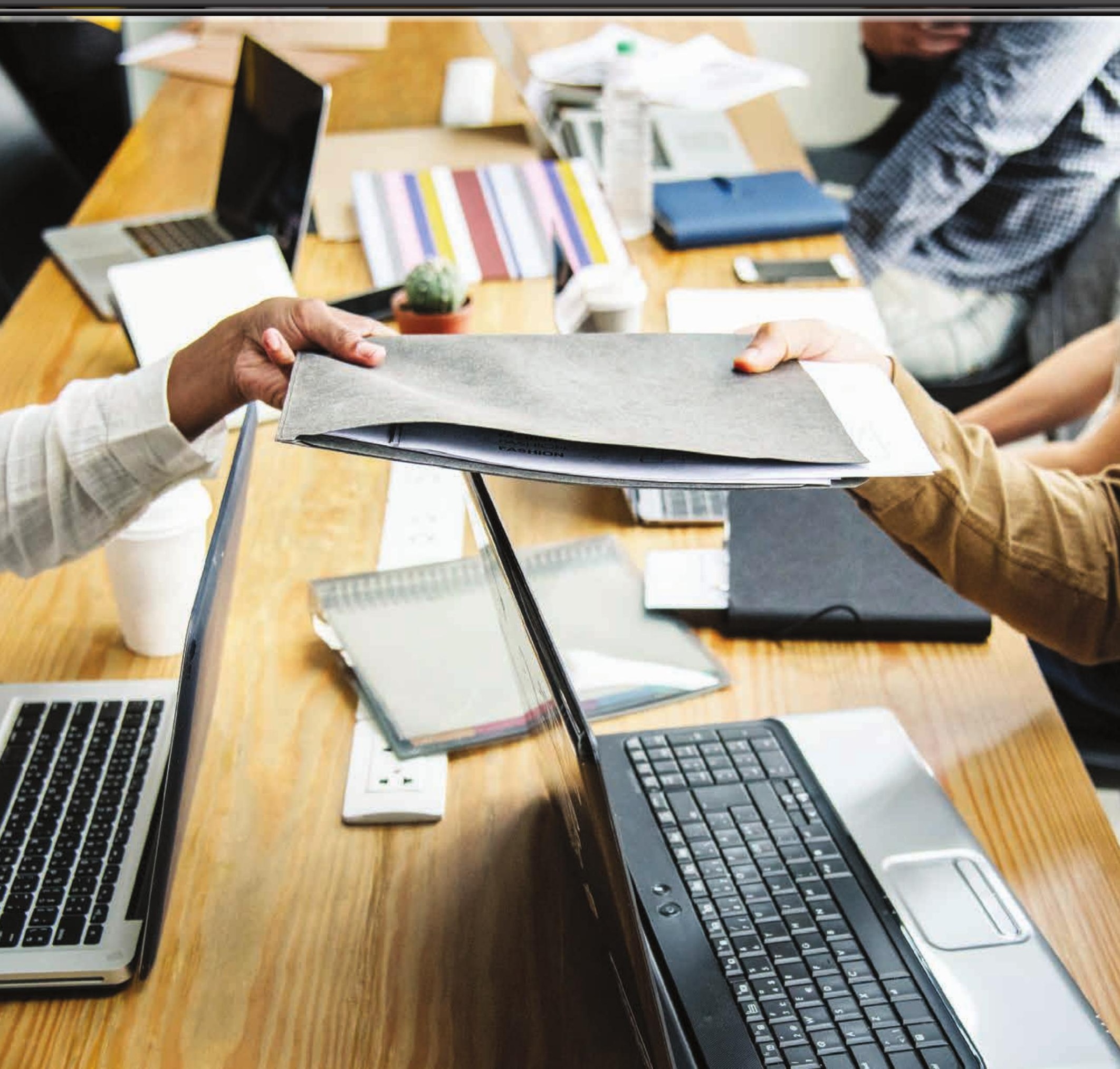




\section{Multi-Resource Analysis Process}

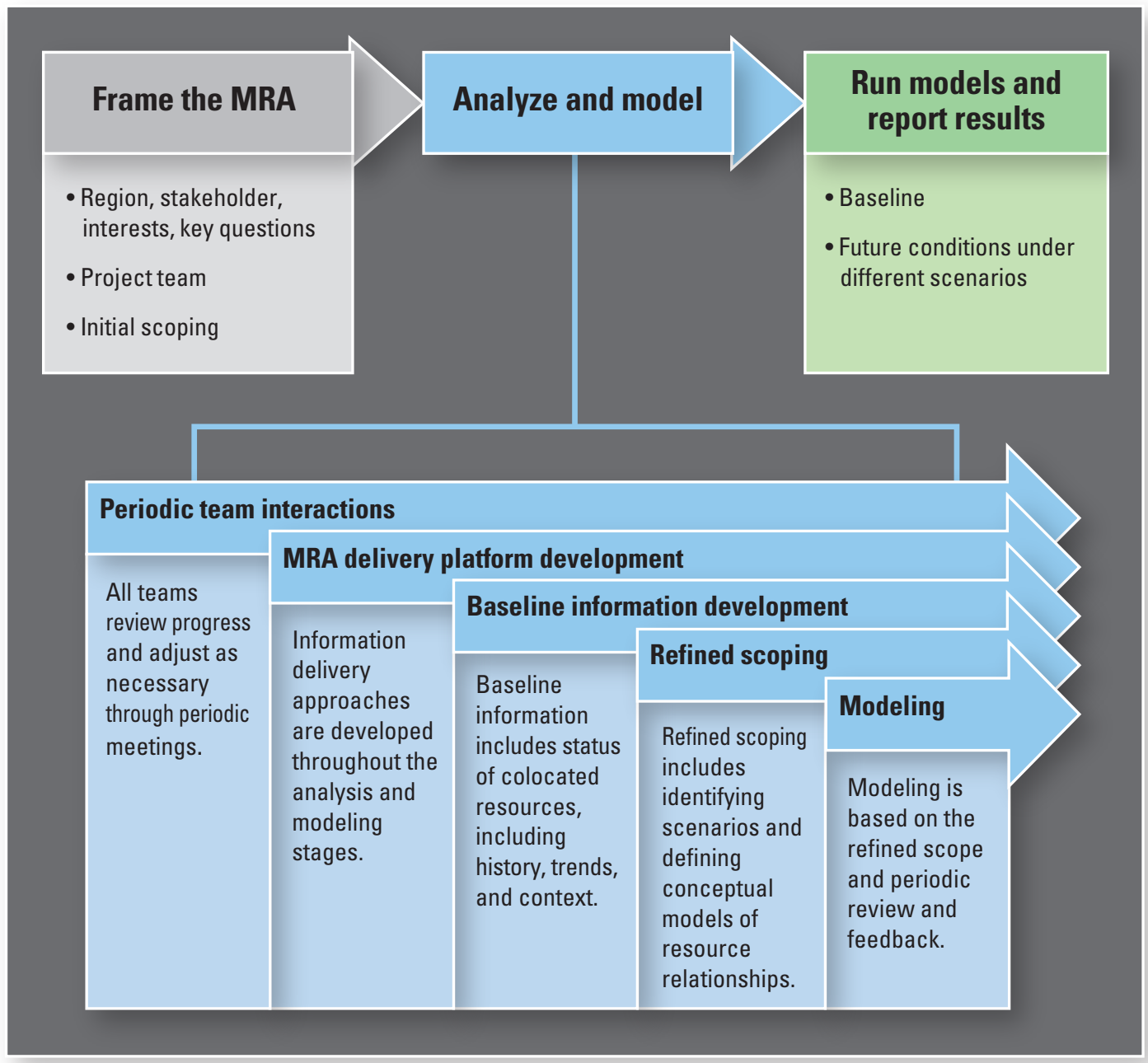

Figure 2. Steps in conducting a Multi-Resource Analysis (MRA). Although shown here as if they are sequential steps, in practice, framing, analysis and modeling, and running models and reporting results are connected and overlap. For example, analysis and modeling may produce new questions that suggest re-scoping of some questions and reporting results may raise new issues that should be modeled. 


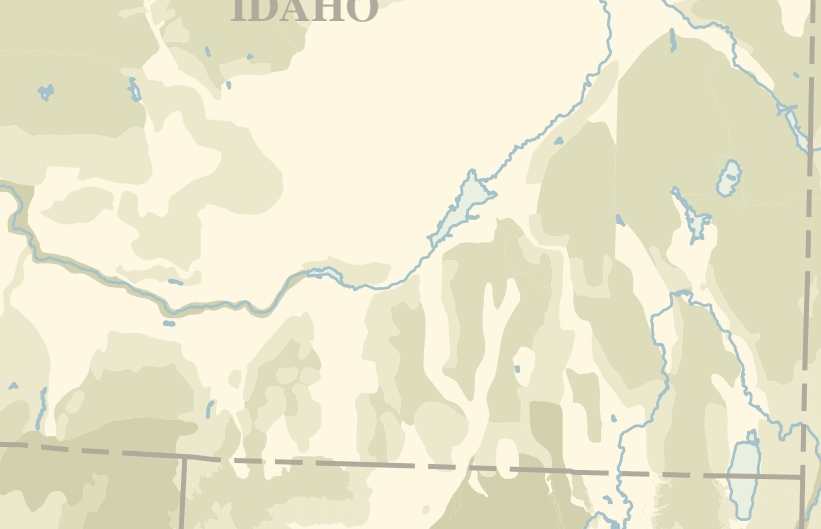

\section{WYOMING}

\section{Framing the Multi-Resource Analysis Study}

As with the construction of a good house or a good organization, good analysis and good decisions rest on a strong foundation. The framing step provides the foundation for how the MRA will be used and is the first step in developing products that will be useful to resource managers. Framing allows us to articulate the goals and purposes of an MRA before proceeding to product development. Essentially, we want to be sure we have the right people involved, we are treating the right problems, and we are doing it from the right perspectives.

Because an MRA is used to support managers of natural resources, it will most likely be initiated in a region where one or more decision-making entities have or anticipate a need for the kinds of information and tools that an MRA will provide. An MRA is a multiuse set of products, so it will be especially appropriate in regions where there are multiple decision-making entities interested in the results and where there are several upcoming decisions that would benefit from having multiresource information available. In some cases, interest in conducting an MRA in a particular region may be triggered by the availability of new single-resource assessments, new scientific information, or even new national or regional policies.

\section{Multidisciplinary Multi-Resource Analysis Team}

Proper framing requires broad input from a variety of participants, including decision makers, scientists, and other stakeholders with interests in the study region. Each of these participants brings important knowledge and different perspectives to the analysis. Decision makers and other potential end users provide input on their intended use of an MRA, decisions they may need to make in the near future, their management objectives, and potential stressors and disruptions that are of concern for the region. Technical personnel provide scientific information on resource interrelationships and uncertainties and bring expertise required for building models. Developing a set of products that address resource interrelationships and resource values requires a multidisciplinary team of scientists; providing results in a form that is useful to decision makers requires a team with expertise in information processing and information delivery.

A successful MRA team structure ensures solid and ongoing connections among the entire team and throughout the process. Decision makers and scientists will have joint responsibility for creating a successful MRA for a given study region, so they will need to interact closely throughout the development of the MRA. The specific team structure and process for interacting can be tailored to the needs and existing stakeholder relationships in any particular area. The highlight on pages 22-23 illustrates one possible team structure.

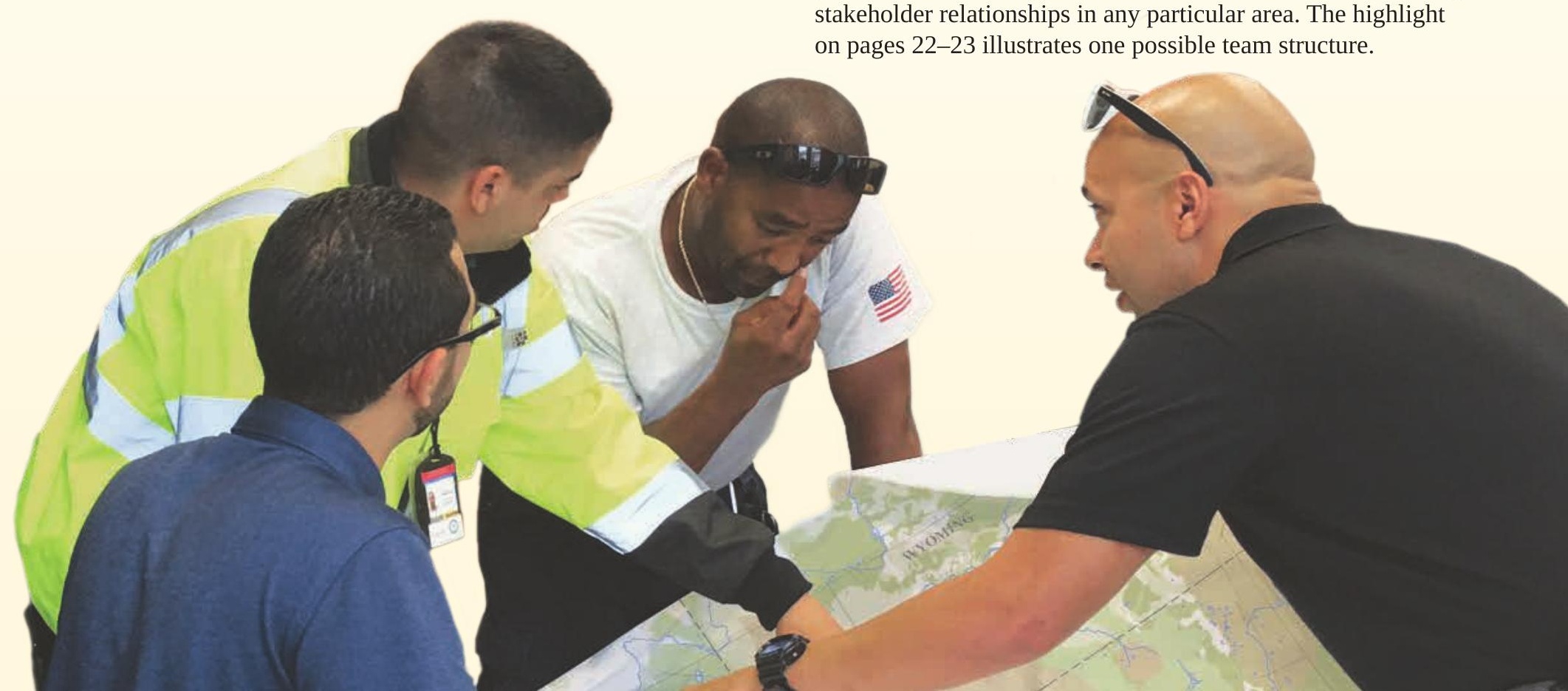





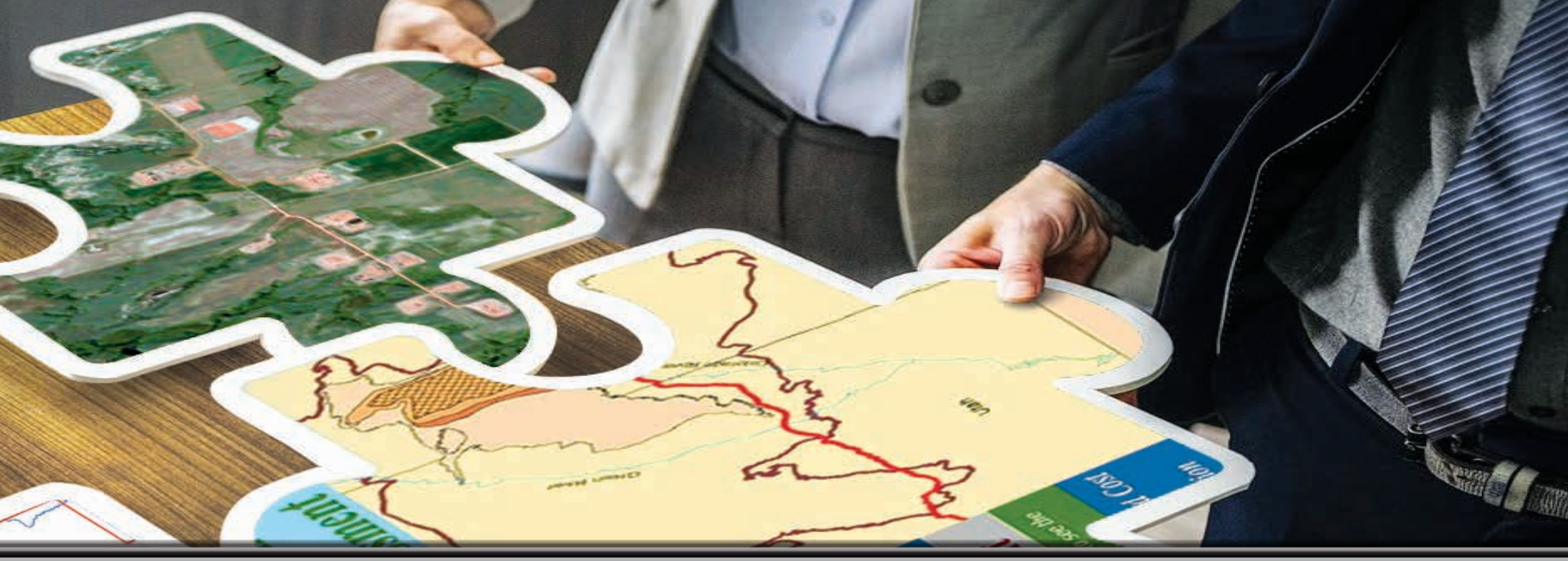

The MRA Core Team bears primary responsibility for developing the MRA and its products and for keeping the technical work and the needs and interests of the Guidance Team aligned. Much of the technical work will be done by various subteams. The subteam structure is intended to be flexible, with individual researchers often serving in multiple capacities and on several teams. At a minimum, the Core Team will be supported by an Integrated Modeling Team that will focus on identifying and modeling the links between resources, resource changes, and resource values and by an Information Delivery Team that will take the lead on developing the platform(s) for delivering the MRA to the end user. Subject Matter Expert Teams may be used by any of the other teams when there is a need to explore an issue in greater depth.

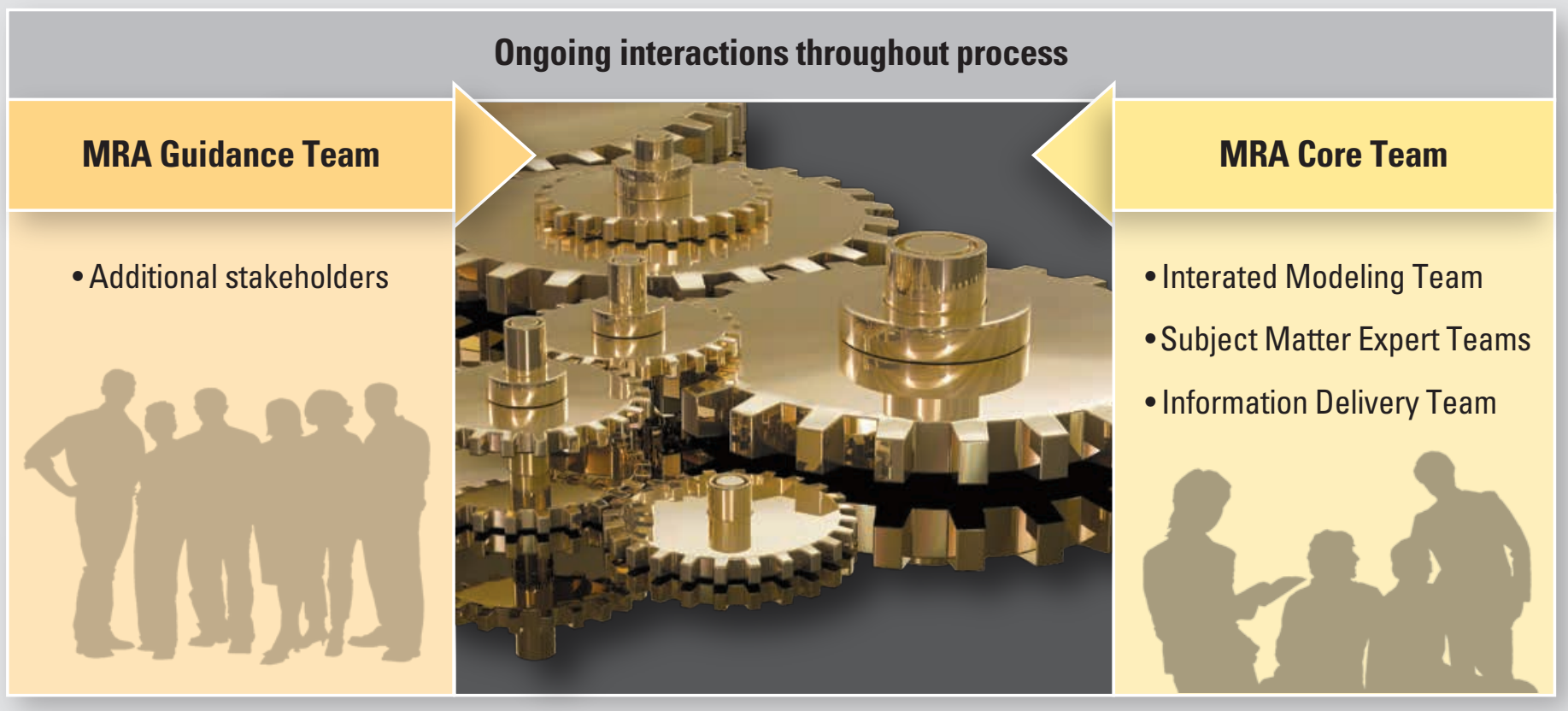

One possible team structure. 


\section{Multi-Resource Analysis Process}

\section{Defining the Scope of the Multi-Resource Analysis}

The final element of the framing stage is defining in more detail the initial scope and scale of the MRA. The MRA teams will need to clarify what upcoming decisions would benefit from the MRA, what decision makers would like to achieve (their management objectives), the factors that may make it difficult to achieve those objectives (such as stressors and disruptions outside of the decision makers' control), and the challenges with predicting whether those objectives can be met (for example, knowledge gaps and uncertainties about resource interrelationships and resource values).

In addition, during the framing part of the process, the MRA teams will need to identify past, current, and anticipated future drivers of change in the region. Those drivers of change may be natural or human forces, and there may be considerable uncertainty about them. Examples include the frequency or severity of natural hazards (such as floods or fires), changes in weather and precipitation patterns (such as droughts or changes in growing seasons), changes in energy and mineral leasing policies and practices, changes in agricultural practices, and so on. This scenario identification is intended to generate a robust list of potential drivers of change, which can then be narrowed to a smaller set for inclusion in the MRA analysis and modeling steps. Scoping also includes identifying an appropriate set of geographic and temporal boundaries for the MRA. Traditional resource assessments are defined around boundaries that make the most sense for single resources: geologic boundaries for energy resources, watershed boundaries for water resources, and viable economic zones for economic assessments. Rarely, if ever, do those boundaries coincide, so decision makers, scientists, and other stakeholders will have to make carefully considered decisions about how best to bound the analyses that will become part of the MRA.
The outcome of the initial framing steps consists of documentation of the mosaic of decisions, objectives, values, uncertainties, constraints, scenarios, and other factors that need to be considered; the geographic and temporal scope for the analysis; and identification of potential project participants. This information will provide a rich and clear context for the upcoming steps, a shared understanding of the context among all participants, and a draft schedule or project plan for completing the MRA. As the project evolves, this frame may be adjusted, potentially more than once. Establishing a good working relationship among participants during the initial framing efforts will facilitate later discussions and adjustments. (See the highlight on page 25 for information on an MRA framing workshop.) 


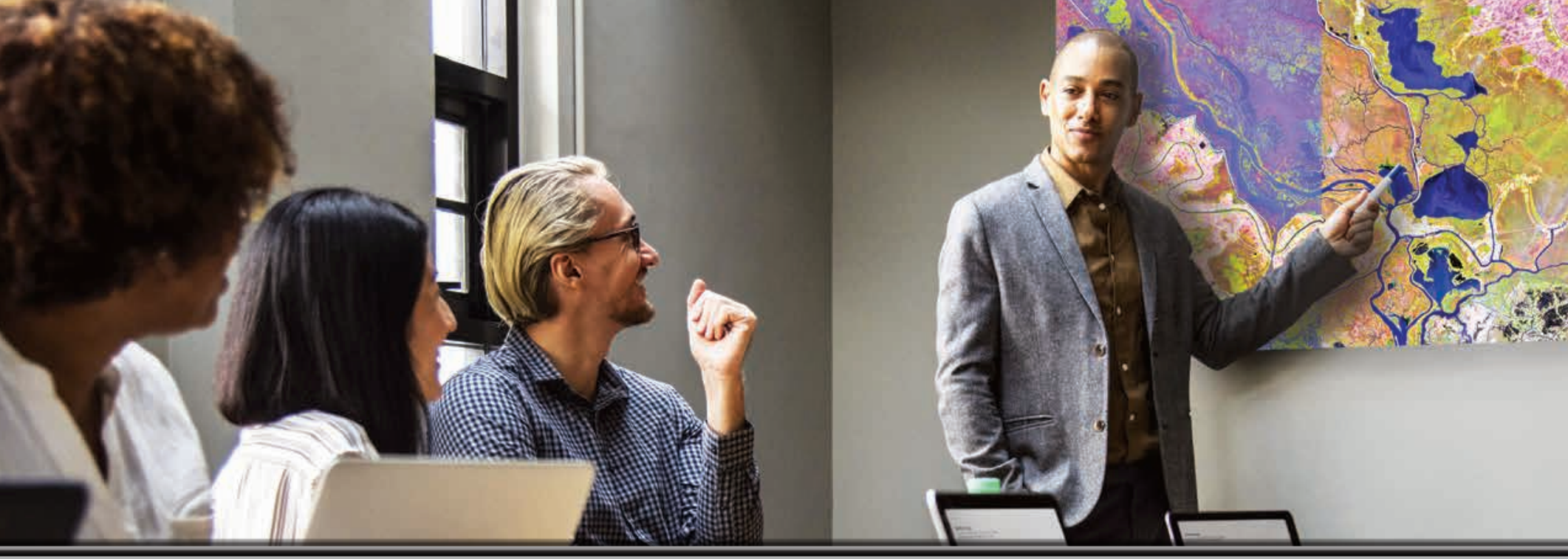

\section{A Multi-Resounce Analysis Framing Workshop}

O to help define the scope and overall framing for many projects is to hold dedicated in-person workshops where all participants provide input and structure. The Powder River Basin MultiResource Analysis (MRA) study (see the highlight on pages 12-13) began with such a workshop. The workshop approach offers several key benefits. In particular, it helps build a common sense of purpose among the project participants, and it allows for a considerable amount of work to be accomplished in a short amount of time. Through a workshop setting and a structured framing process, team members quickly develop an appreciation for the skills and perspectives of other participants and can make fairly quick progress on developing a shared vision for what an MRA for the region they all care about should include and address.
In a framing workshop, participants work together to define a specific vision for what an MRA for their region would include. Because each participant brings different knowledge and background to the process, having everyone together makes it easier to understand and communicate what is already known about the region, where there are information gaps, and what kinds of information will be most useful in the future. In addition to establishing a set of working relationships among the participants, it is likely that robust discussion and framing of the issues for the region will lead to identification of additional decision makers, stakeholders, and technical experts who would be valuable participants in the MRA. A modular team structure, such as that shown in the highlight on pages 22-23, makes it relatively easy to expand or contract teams as necessary throughout the process. 


\section{Multi-Resounce Analysis Process}

\section{Analysis and Modeling}

A significant amount of data collection, synthesis, modeling, and analysis is necessary to produce the MRA products shown in figure 1 and described in detail in the "Development of Multi-Resource Analysis Components" section. The analysis and modeling step involves several related tasks (fig. 2). First and most importantly, the analysis and modeling is conducted iteratively and with feedback between those with a management and decision focus and those whose focus is on science and modeling. All of the detailed work necessary to create the MRA Baseline and the MRA Change Analysis components happens in the analysis and modeling step.

As discussed further in the "Multi-Resource Analysis Baseline" section, the MRA Baseline provides a "snapshot in time" of the status of colocated resources in the study region. The first part of the Analysis and Modeling step is for the scientists and modelers to begin collecting information on the relevant resources in the study region and working with data scientists on constructing one or more ways to communicate and explain the baseline information. This information collection is bounded by the frame defined in the first step of the MRA process, especially the geographic and temporal boundaries and the resources to be considered. Both development of the Baseline and development of the overall information delivery platform(s) begin as soon as framing is far enough along to provide a starting point for data collection. Baseline information is a prerequisite for the later modeling, although some work in this area may continue throughout the Analysis and Modeling step. Methods for information delivery are considered from the very beginning, and development of delivery platforms continues throughout the entire MRA process. Ideally, information delivery serves as a tool to communicate intermediate modeling results to the decision-oriented participants, giving them an opportunity to suggest modifications and improvements in how information should ultimately be delivered to them and their peers.
The framing step described in the "Framing the MultiResource Analysis Study" section includes the initial definition of the study scope, which identifies some of the key stressors and disruptions of concern or interest in the area. As the Baseline is developed, the MRA teams acquire new information on the resource history and trends in the region and its economic, social, and regulatory contexts. This increased understanding may suggest refinements and revisions to the MRA's initial scope and framing, such as definitions of important scenarios of change to be considered in the MRA and conceptual models of resource interrelationships and resource values. This refinement precedes detailed modeling and may be repeated more than once as models are developed and tested.

Detailed and quantitative modeling of resource interrelationships and resource values is primarily a scientific and technical task and thus a major focus of the scientific participants in the MRA. Given the complexity of an MRA, modeling is a considerable challenge and requires close interaction between modelers and process scientists as they proceed through iterations of model development. Work from the proof-of-concept studies and other USGS scientists (Bristol and others, 2013) suggests that the complexity can be managed by using a modular approach (for example, energy resource modules, water modules, ecological modules) and by identifying variables that act as "links" from one module to another. Information delivery experts are also closely involved in this step, providing guidance on software tools and facilitating data manipulation and interactions between different tools. 


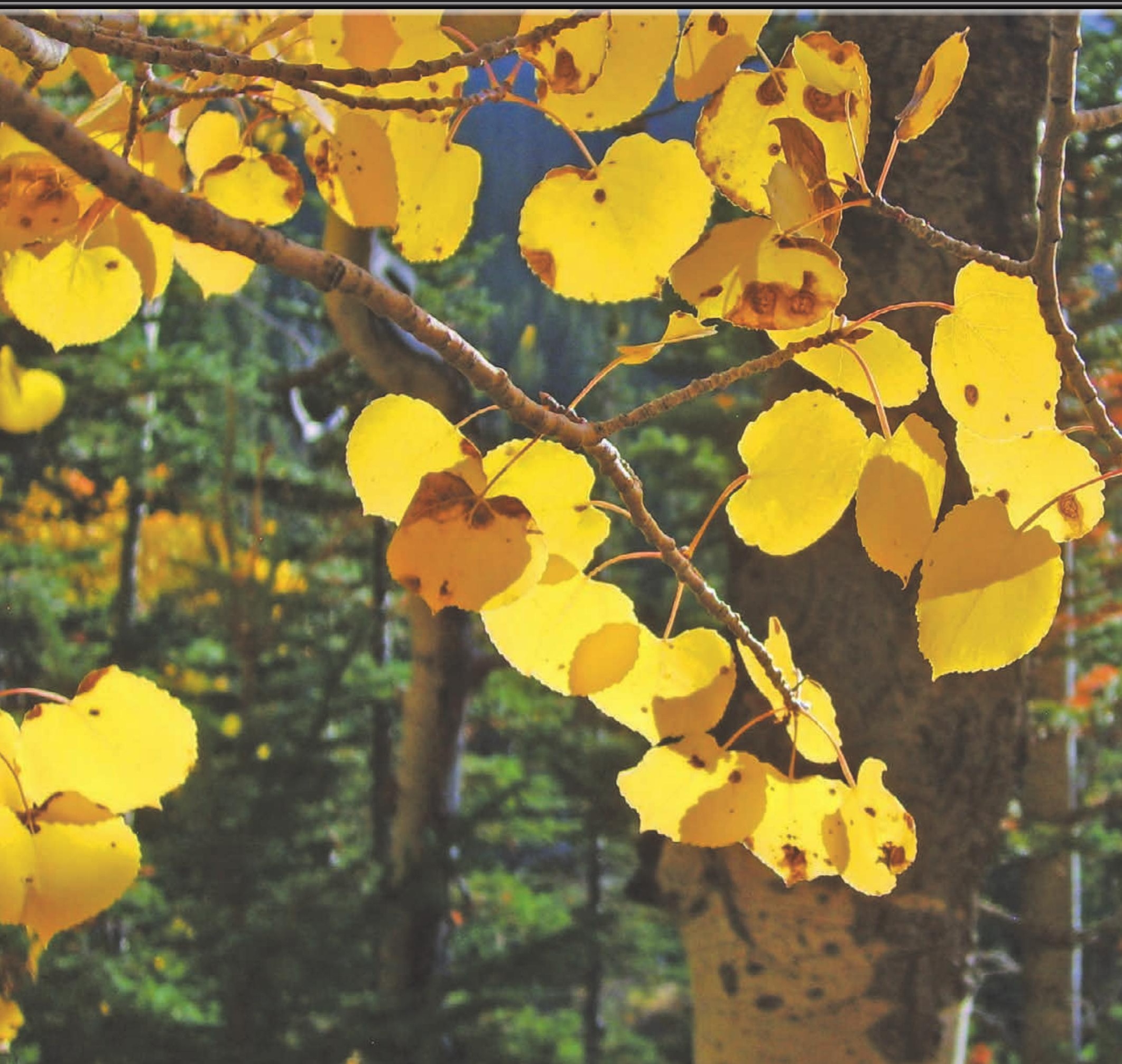




\section{Multi-Resource Analysis Process}

Although model development and quantification is primarily undertaken by the technical team members, stakeholder input is also relevant. Reviewing the models with potential end users of the information at intervals throughout the development process can provide several benefits.

- Stakeholders often have insights that were not captured or have changed since the initial framing. These insights should be reflected in the models.

- Stakeholders can assist in structuring the model by identifying sets of connections and information needs most directly tied to their objectives or outcomes of interest. Their perspectives are often different from those of the scientists, who may identify other connections and uncertainties.

- Stakeholders often have important data and information sources for the models. Increased interaction helps ensure the modelers know about these sources and incorporate them into the model.

- Stakeholders, in turn, may learn from the modelers about the types of analyses that can be conducted and what information products the MRA can provide. Early identification of how stakeholder expectations might conflict with what is scientifically feasible provides an opportunity for early communication and alignment of expectations. This will improve working relationships and lead to products that are more useful.

- Ongoing modeling team interaction maintains stakeholders' knowledge of the details of the MRA, which increases their comfort with the models' capabilities, strengths, and weaknesses and the likelihood that they will use the MRA upon completion.

\section{Running Models and Reporting Results}

The final steps in the MRA process are to actually run the models developed in the previous steps, to evaluate and understand the results, and to develop useful information delivery products to clearly communicate the MRA results. The Baseline is one important MRA result; the other is the projections of the future status of colocated resources under different scenarios. These projections are essentially the results of running the model of resource interrelationships and values under the scenarios identified by the decision makers and stakeholders, or other scenarios of interest, in the region.

A typical MRA can perform numerous types of analyses and generate a wide variety of outputs, each of which could be presented in numerous ways. Analyses performed at this stage benefit both internal and external MRA participants. Some analyses are used primarily by the analysis team to ensure the models are appropriate and validated and produce reasonable results and to determine if additional model changes are warranted or if additional information should be collected to reduce uncertainties. Other analyses, such as various model runs and sensitivity analyses, are directed more towards the end users. It is likely that additional model refinements could be made even during this run-and-report stage.

The full team is involved in generating the final analyses for delivery. Those who developed the integrated models conduct a variety of analyses and work with those more focused on information delivery to develop useful approaches to communicate the results. Those with a decision-making perspective review preliminary runs and results and provide input on what information they think is most useful and how they would like to view it. The teams then iterate the models. "Final" results could be in the form of formal reports or data layers packaged with the tools for displaying those data, though both types of products would likely be provided. The MRA teams could produce very focused analyses, specified by a stakeholder to explore particular management decisions or other investigations, or a more generalized information delivery platform designed to allow a stakeholder to perform model runs and generate outputs on their own with no direct guidance from the analysis team. 

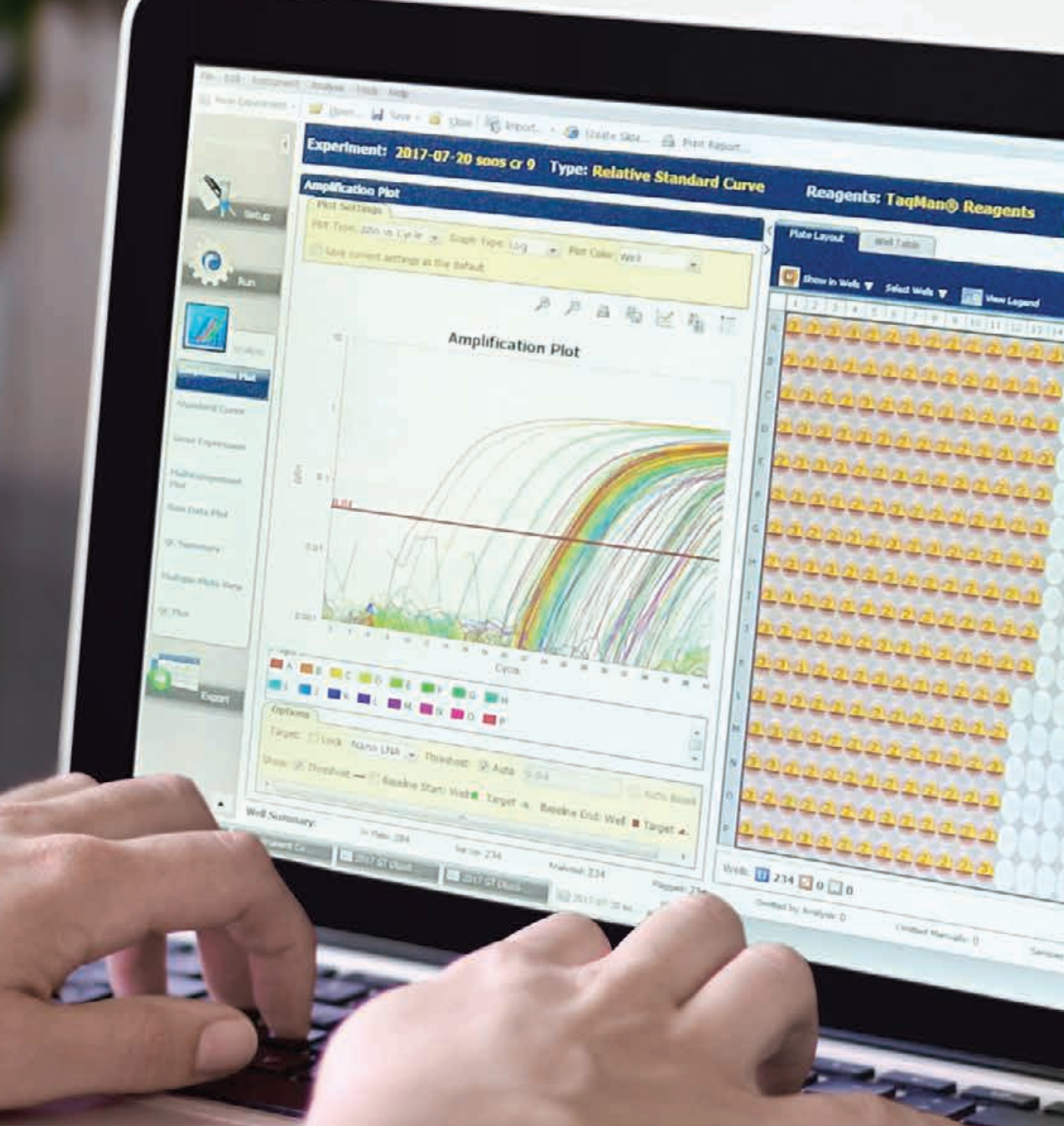


\section{Development of Multi-Resource Anallysis Components}

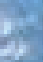

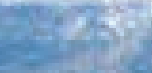

$-4$

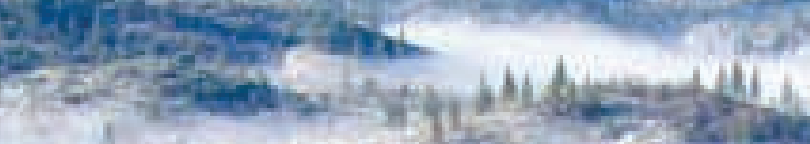

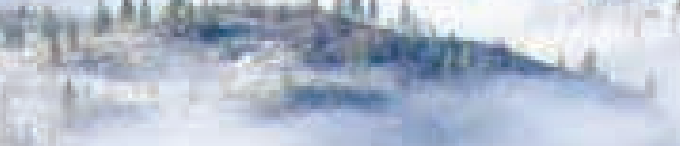
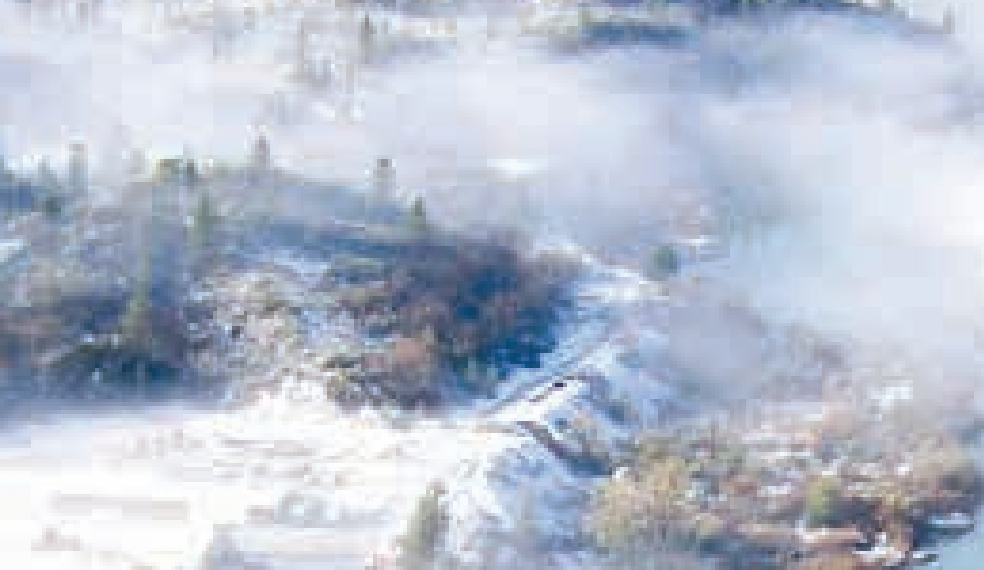

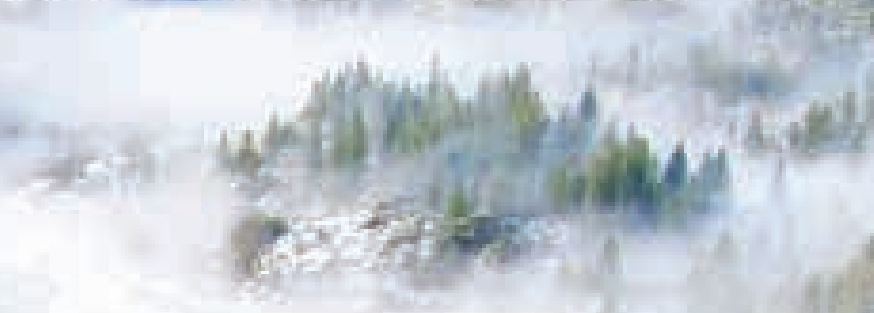

$x_{1+1}^{2}+y^{2}$

is

axpect

का $2+1,20^{2}$

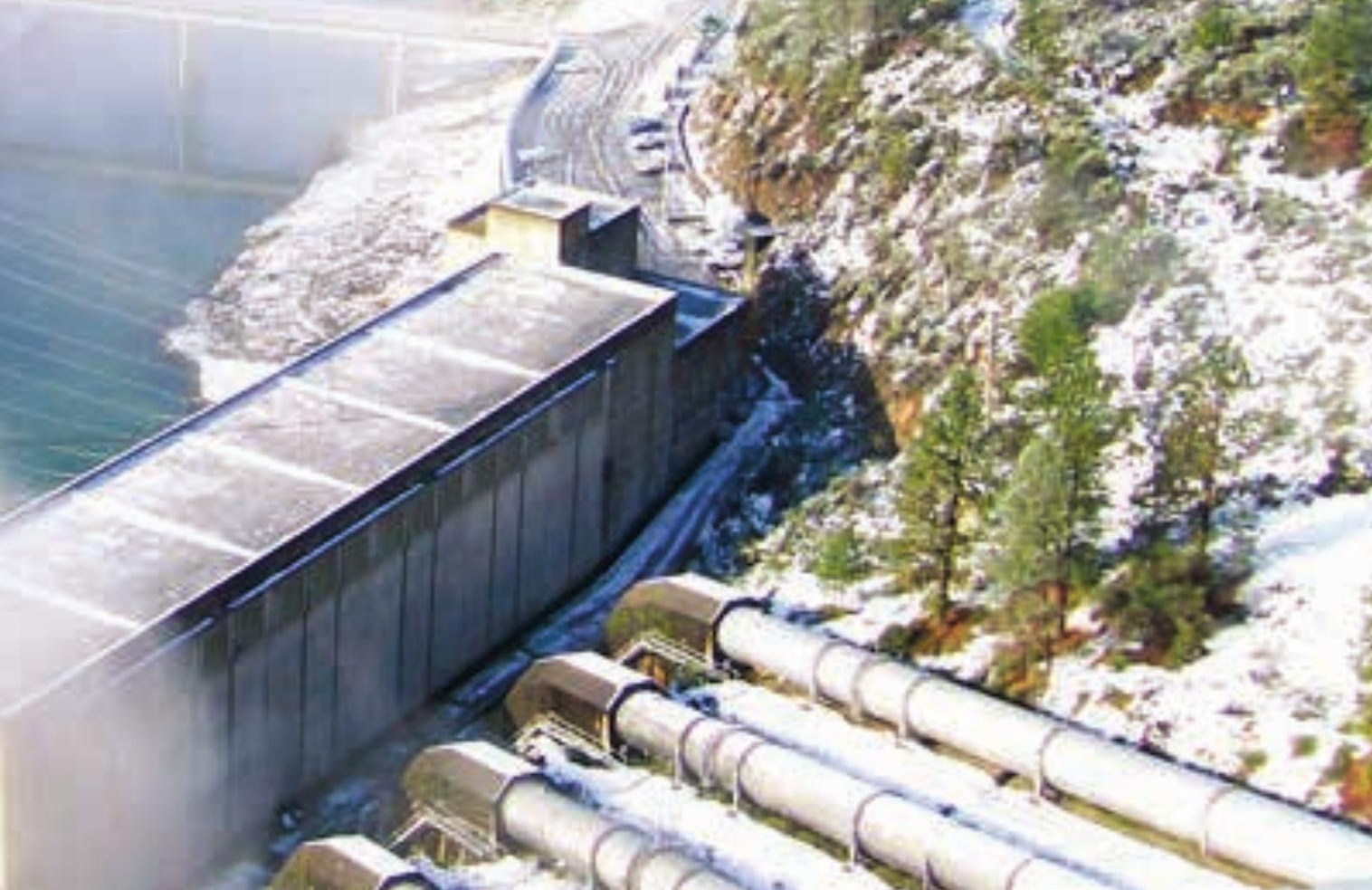




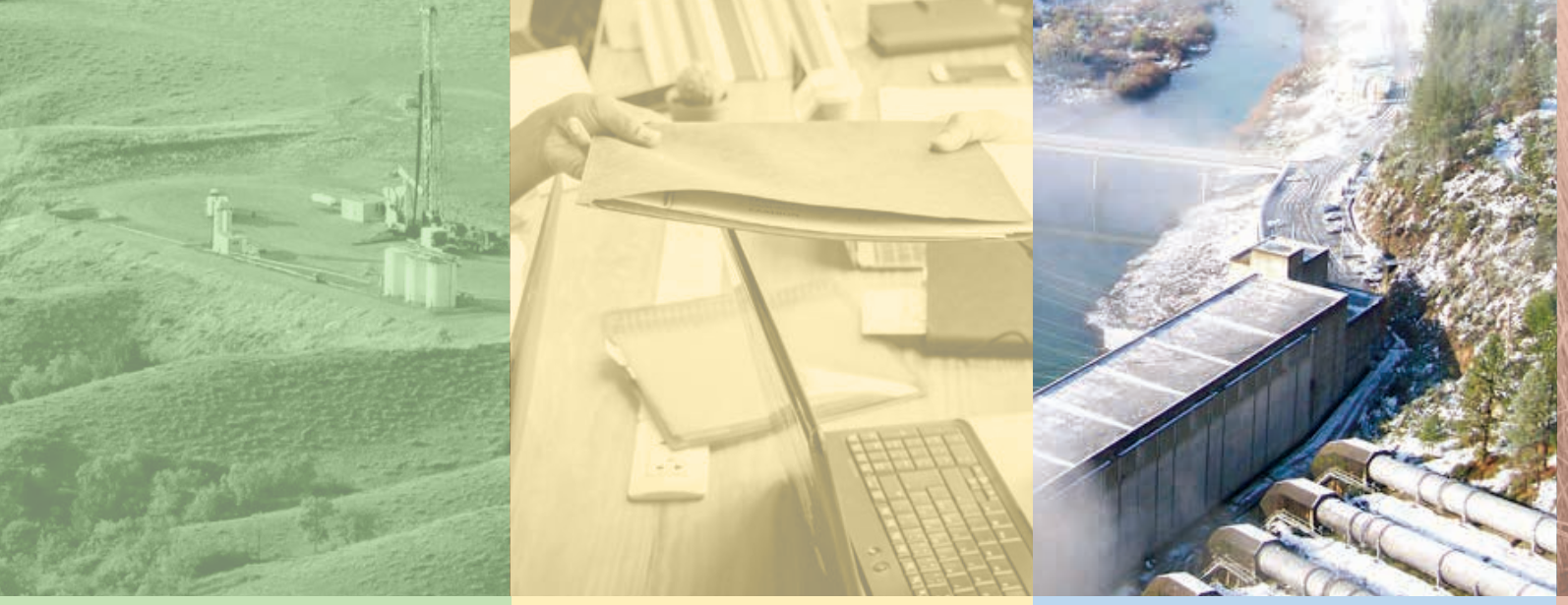

This section describes each of the three components of the MRA in more detail: describing what the component is, giving examples and synthesizing results from the two proof-of-concept studies with respect to the component, and then discussing some challenges associated with developing each component.

\section{Multi-Resource Analysis Baseline}

The MRA Baseline is a compilation and synthesis of data pertaining to colocated natural resources in a study region. As described in the "Multi-Resource Analysis Process," section, prior to assembling the baseline information, the MRA study team identifies the spatial boundaries of the MRA being conducted and develops an initial list of the important natural resources in the region that should be included in the MRA.

A key aspect of the Baseline is that it is built up by integrating the best available scientific and technical information on relevant resources in the region. Summaries of detailed scientific databases and reports will help bridge the gap that may exist between the interests and information needs of stakeholders and the way data are often presented. The summaries should identify key resource interrelationships, discuss resource use and values, and include historical and trend information and information on the economic, policy, regulatory, and societal context for the region. In the past, this is the kind of information that might have been assembled into a book of information on a region, similar to the large volume "Everglades-The Ecosystem and Its Restoration” (Davis and Ogden, 1997). That book summarized everything that was then known about the Florida Everglades ecosystem and provided a common baseline of knowledge available to everyone involved with or interested in work in that region. The MRA Baseline aims to provide a similar level of comprehensive, relevant information but in a more accessible and flexible online format.

The MRA Baseline provides a snapshot of the status of colocated natural resources at a specified point in time rather than a real-time portal with evolving information or data. The MRA Baseline may be updated periodically depending on external factors, such as new discoveries or decision needs, or as defined during the framing process for an individual MRA study.
The MRA Baseline is the primary building block for the MRA, but it is also a useful interim product on its own. As a central portal for accessing both summary and detailed information on the natural resources in a region, the MRA Baseline is a natural starting point for several different audiences and end users. Those interested in a big-picture view of the resources in a region, for example, would likely be interested in the summary information, which includes descriptions, graphics, and maps for the region's resources, their locations, and the values associated with those resources. As the MRA is implemented in different regions around the country, the Baselines can be considered together to better understand aggregate resource quantity and quality and the relevant tradeoffs in different regions. For land and resource managers charged with a more detailed evaluation of specific policy or decision options in the region, the MRA provides a natural starting point for data and information collection, even if more detailed or more localized information may also be required.

As a key building block for the overall MRA, the Baseline provides a consistent basis for comparing the effects of changes to the landscape over time. These comparisons allow stakeholders to explore the future changes in resources, services, and values within a given scenario and across scenarios.

\section{Baselines-Synthesis of Previous Efforts}

Team members participating in the Piceance Basin and PRB proof-of-concept studies used, analyzed, synthesized, and integrated available data and information for several of the key natural resources in their respective regions. The Piceance Basin study considered quantities of natural gas resources, stream locations, and information on the land surface relevant to mule deer habitat quality, such as elevation, slope, and vegetative cover. In this study, baseline data were used as input for later integrated-modeling steps and were not presented separately as a Baseline product. The PRB proof-of-concept study included similar data and information on multiple colocated resources. Specifically, the research team assembled information on coal, CBNG, surface water, groundwater, some wildlife species and associated habitats, grazing, land disturbance, and land ownership. The PRB Baseline was used as an input into integrated modeling and was also used directly to develop an interim product, as described in highlight on pages 32-33. 


\section{The Baseline as an Onterim Product}

The Baseline is a fundamental component of the Multi-Resource Analysis, and during development of the Powder River Basin proof-of-concept study, it emerged as a potentially useful interim product on its own. The Powder River Basin team did not attempt to develop a fully functional data management and delivery system, but instead developed and tested various examples of potential information delivery methods. They envisioned a web- and map-based interface that would connect a user to successively more detailed information through links, ending at the underlying technical data or reports. Between the "map" and the "data" is summary-level information at varying levels of detail. In the Powder River Basin example, summary documents were prepared that briefly describe the quantity and quality of specific resources and the potential interactions between resources. These summaries, in turn, connect to the detailed reports.

\section{Powder River Basin Resources}

\section{Energy Resources}

\section{Coal}

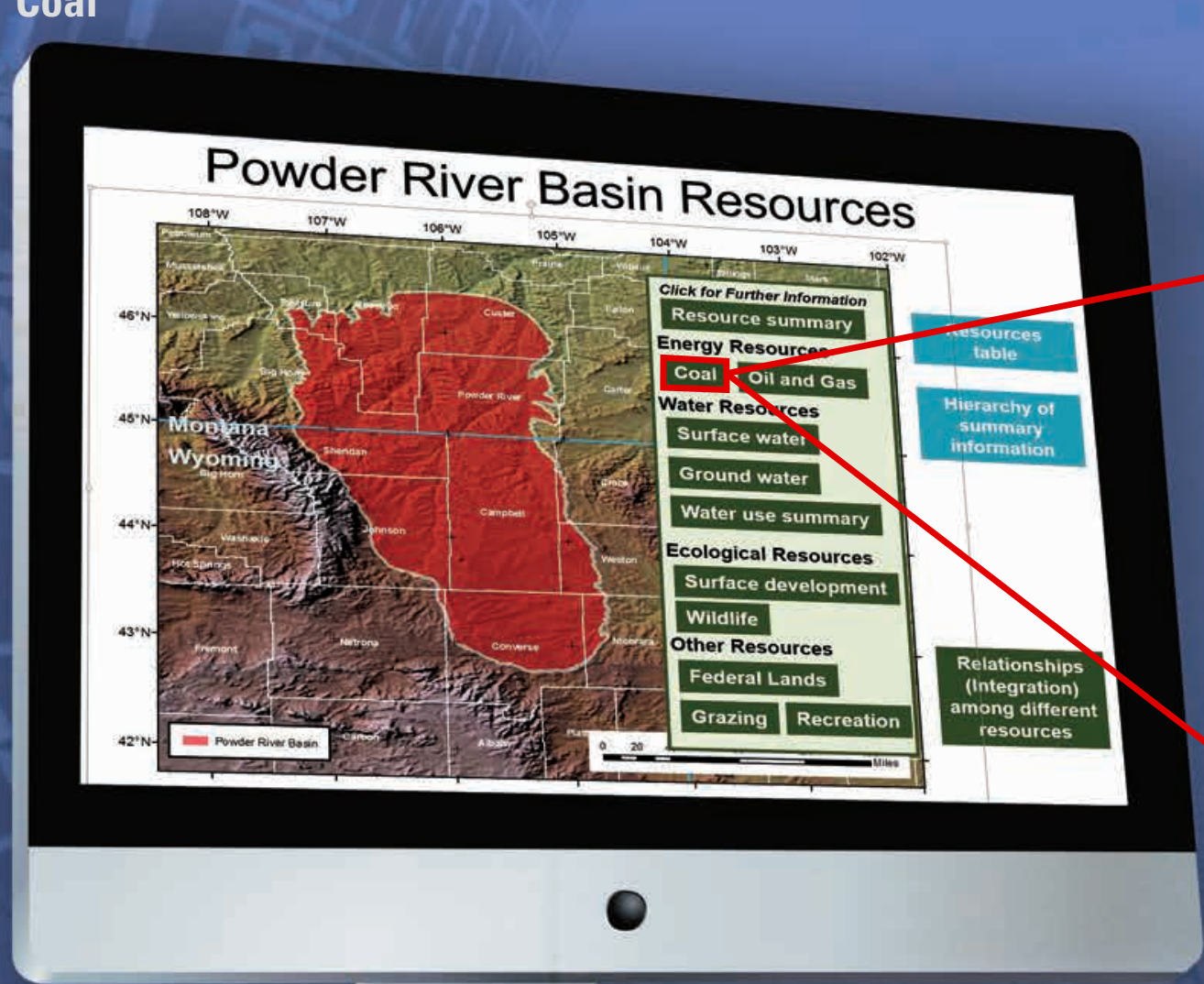

\section{Powder River Basin Coal Resources}

Coal resources summary information
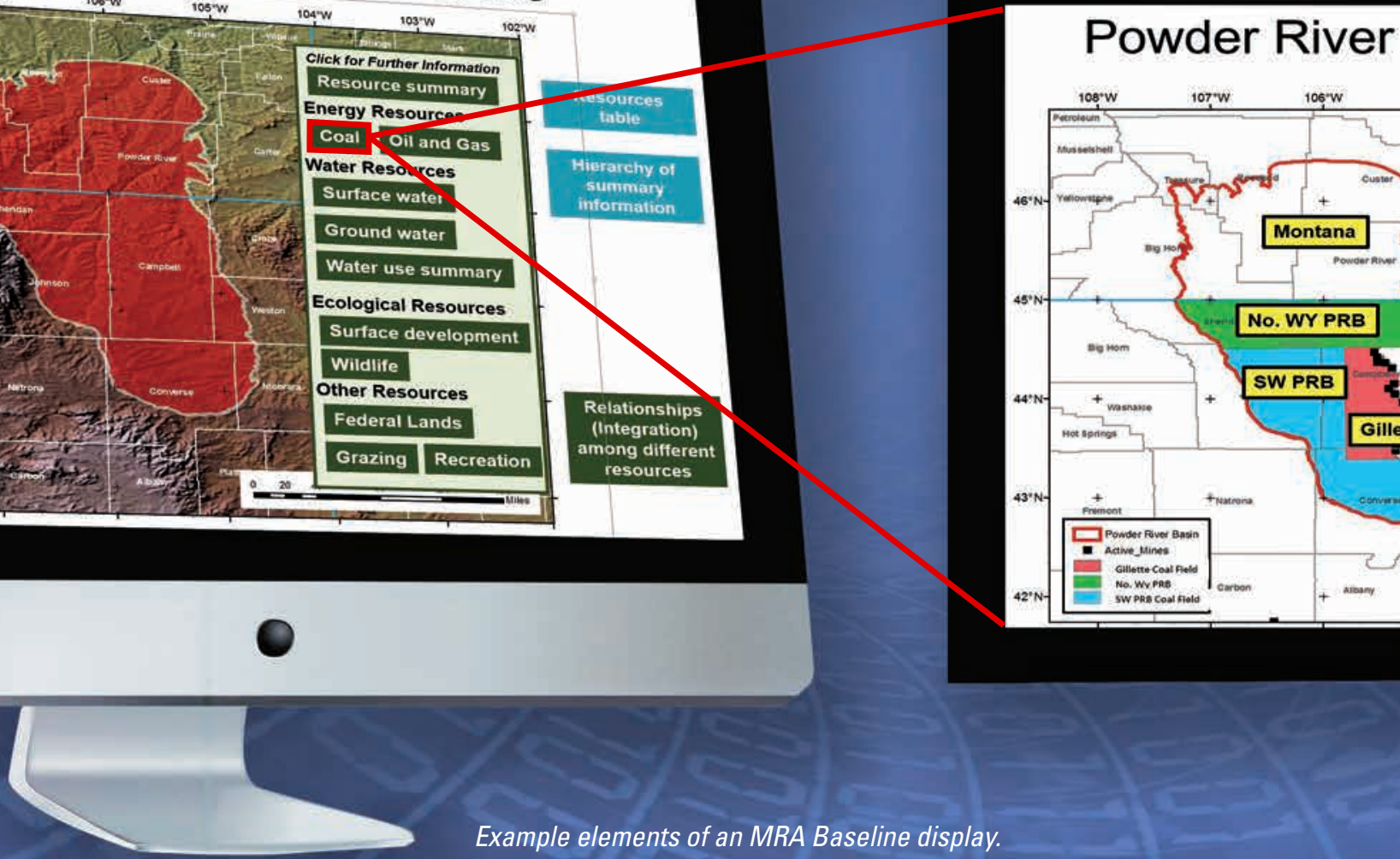

Example elements of an MRA Baseline display. 
Different audiences and stakeholders may have very different ways of thinking about and accessing information. To address different perspectives, the information in Baselines produced as Interim Products can be organized in different ways. For example, the screenshots shown here illustrate a flow from a regional map with a listing of different types of resources, to a more detailed resource-specific map with summary statistics related to a single resource, to a longer descriptive summary document. Other audiences for the Baseline may relate better to a different flow, for example, from the regional map and resource listing to a summary table of the quantity and quality of all the listed resources, then from that table to resource-specific maps and summaries.

\section{Basin Coal Resources}

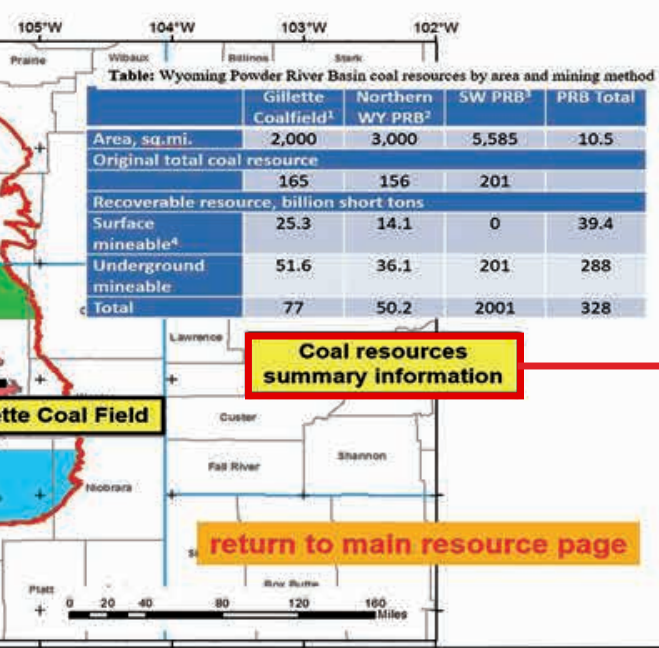

\section{Coal Resources and Coal Mining in the Powder River Basin}

\section{Summary description and data}

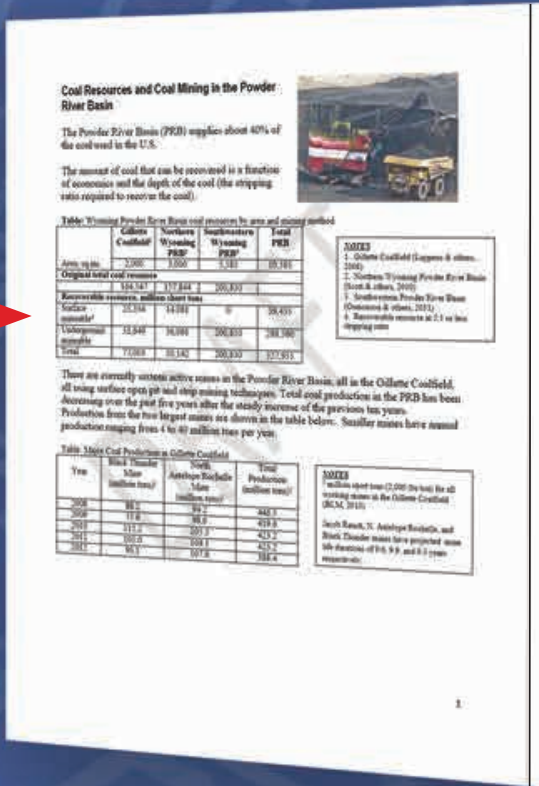

Direct impacts of cosil mining

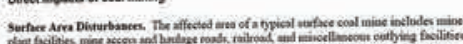

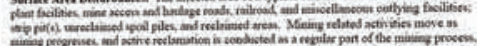

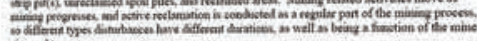

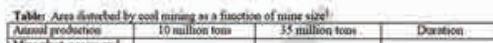

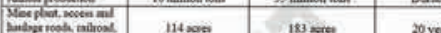

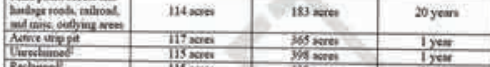

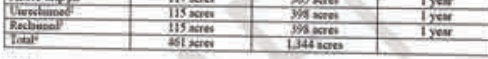

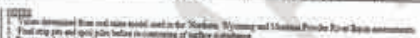

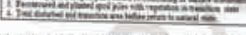

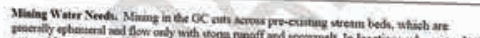

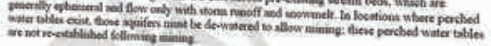

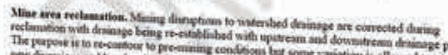

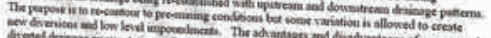

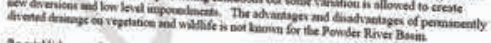

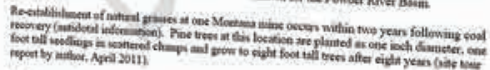

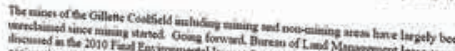

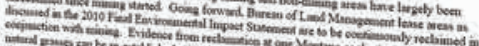

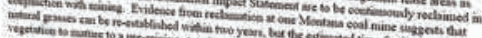

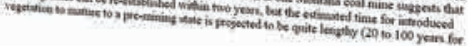




\section{Development of Multi-Resource Analysis Components}

Challenges for Future Multi-Resource Analysis Baselines

A fully functional prototype of data management and delivery for the MRA Baseline was not constructed in either proof-of-concept study. Therefore, the challenges described in this section are based on (1) efforts to synthesize information into illustrative Baseline products and from feedback gained from talking to stakeholders about those PRB MRA Baseline illustrations and (2) the data challenges experienced in collecting baseline information in most if not all studies similar to MRAs.

Challenge: Data availability, sources, quality, and sensitivity.-Selection of the data to be included in the Baseline is heavily dependent on the intended audience, identification of important stakeholders and their needs, and the specific goals of the individual MRA being developed. There are, however, several general issues regarding the source and quality of data to be included (or excluded) from a Baseline. A successful MRA requires consideration of the following questions regarding data to be included in the Baseline.

- Should baseline data be limited to peer-reviewed sources? If non-peer-reviewed data are included, how do we communicate the quality of the data so that users are aware of its potential limitations?

- Should baseline data be limited to that produced and reviewed by USGS and (or) other Federal agencies? Stakeholders were largely complimentary of USGS data, especially for energy and water assessments, but indicated that there are often better sources of data for ecological resources and wildlife, including State and local databases. If non-Federal data are used, should they be limited to that produced by State and local agencies, or should data from nongovernmental agencies be allowed?
A geographic information system interface, in particular, raises questions about whether the MRA should (or can, practically or legally) include geographic locations of resources on private land or certain sites of archaeologic, cultural, or historic importance. When those resources are shown with location information, they are typically not located precisely on maps that are easily accessible by the public; additionally, datasets containing the information may be password restricted, or locations may be "fuzzed" in some way. On the other hand, these data are often important to the purpose of the MRA. Questions of how to present those data, make them available, and use them in the MRA will have to be resolved.

Data availability presented a major challenge in the proof-of-concept studies. Although some geologic, hydrologic, and ecologic data were available for both studies, considering the data at similar scales was complex. Ecological data in particular proved difficult to obtain, interpret, and present in both studies. Accessing socioeconomic data was also challenging. Social and economic data are important to the MRA Baseline and even more so to the subsequent Economic Analysis component of the MRA. Because the proof-of-concept studies were limited to secondary data sources, it was necessary to find social and economic data that were already available and could be used within the overall framework. However, to the extent that an MRA developer can collect primary information and (or) partner with other researchers conducting primary research, this challenge can be overcome. As the MRA concept expands and MRAs become a more common product, it is also likely that the demand for data will encourage needed research.

Finally, several stakeholders raised the issue of data management and the interoperability of different data management systems and tools. Although a successful MRA includes a unique information delivery platform, it is important that data used in the MRA be available for use in other contexts. In practice, data used in an MRA would likely be derived from research conducted for other purposes, so the challenge would be to integrate data and information from different sources into the MRA Baseline. The MRA's information delivery team would address any issues of data interoperability. 


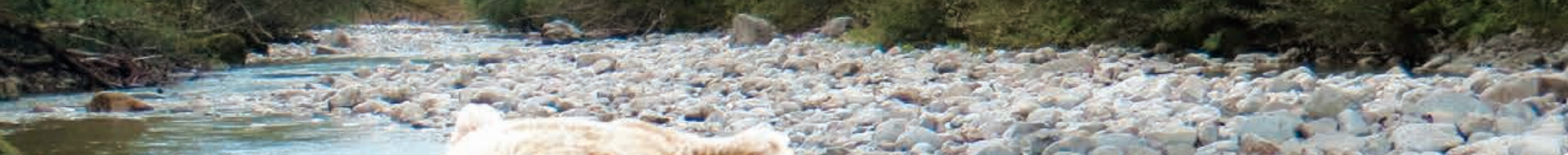

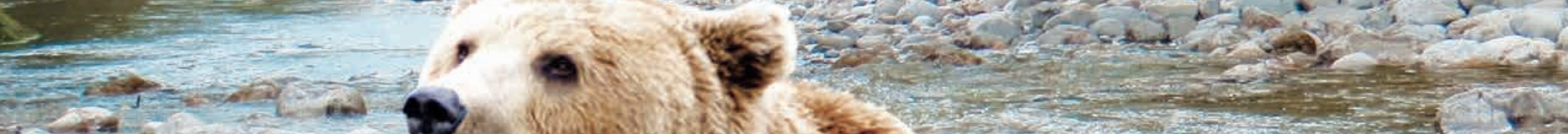

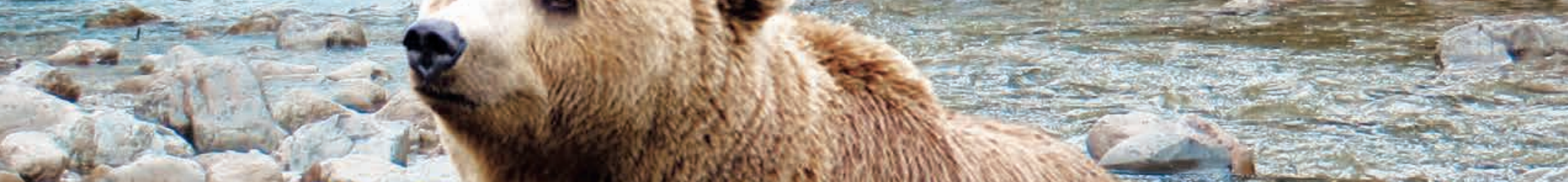
$x^{4}-2+2 x+2$

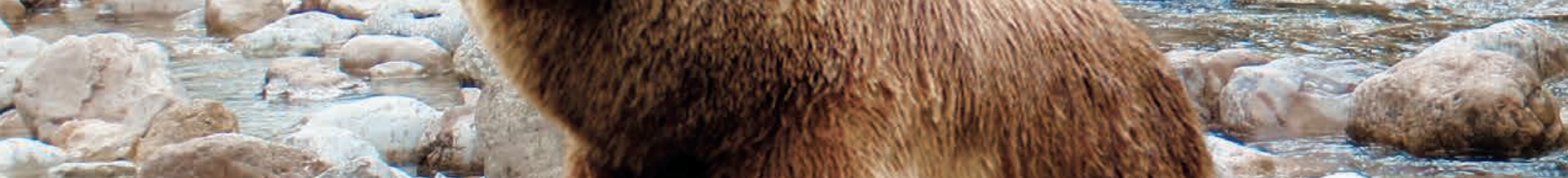
$2+x+x^{2}$

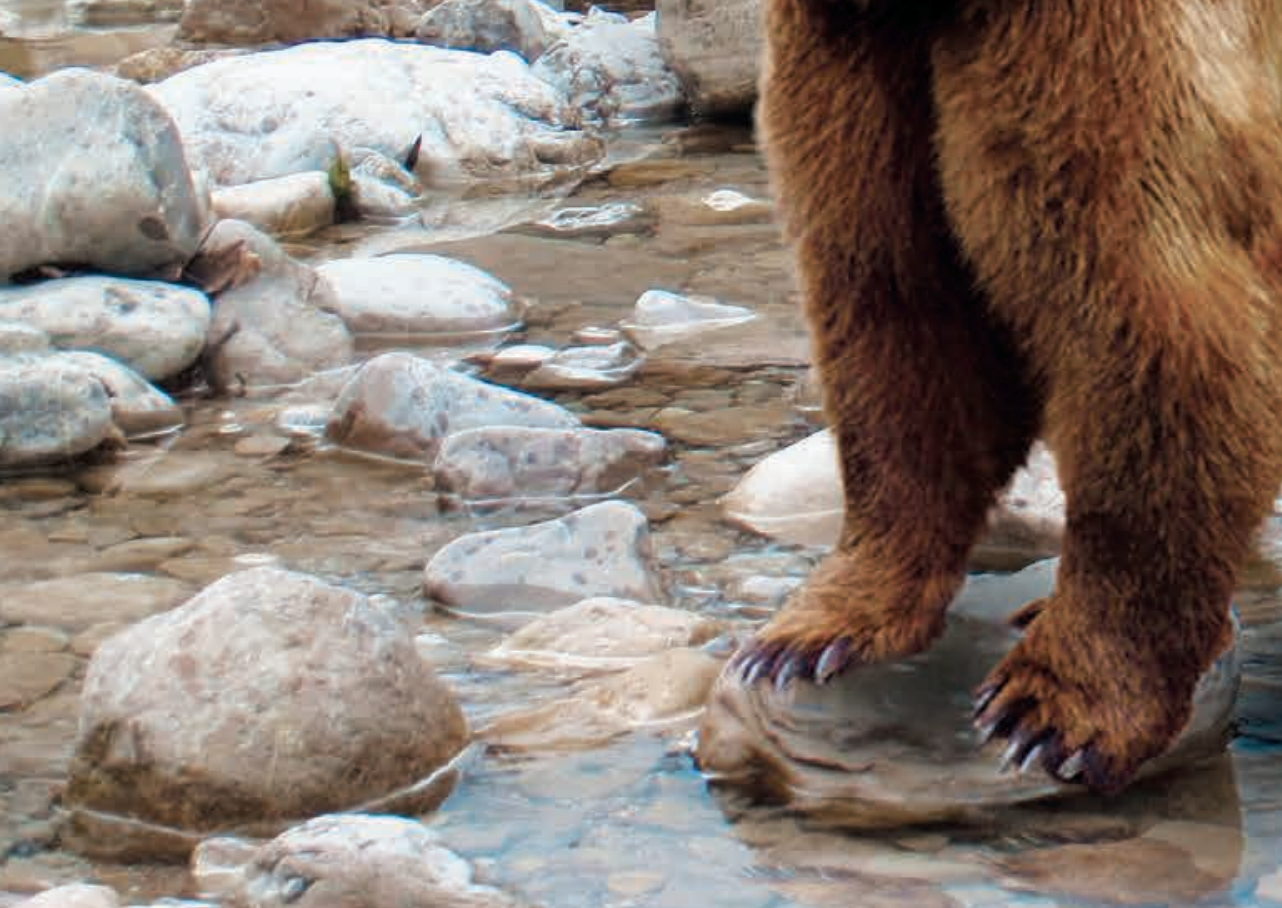

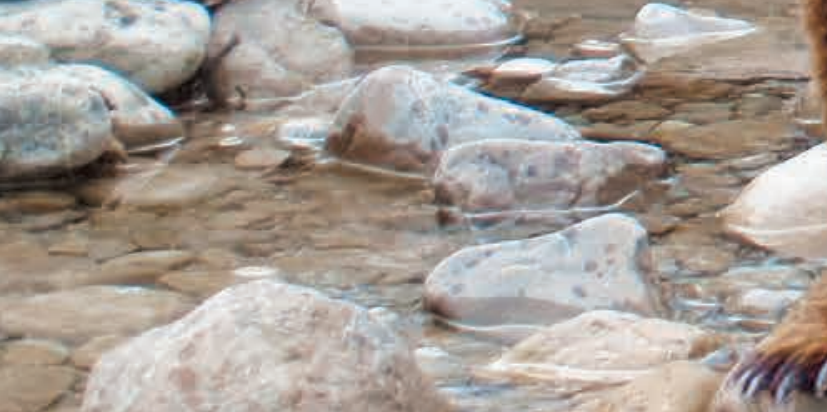

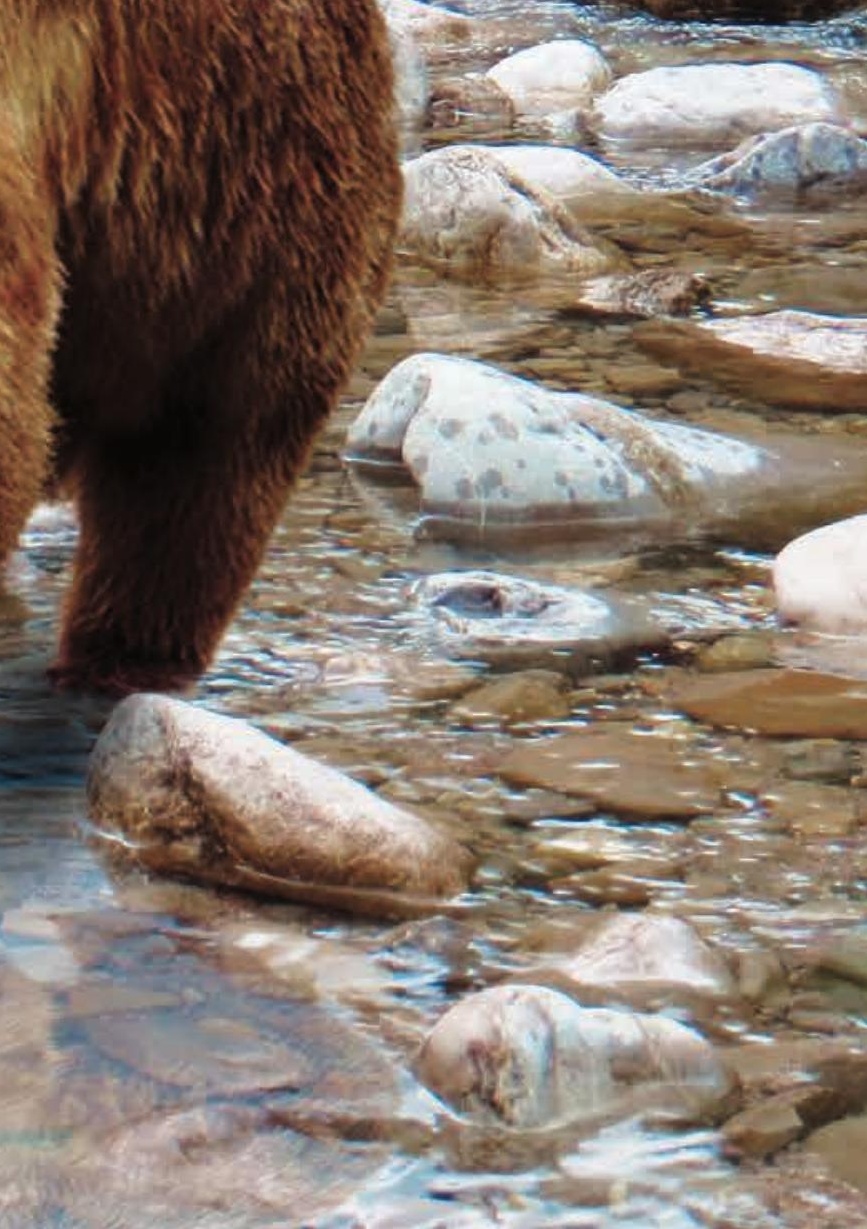




\section{Development of Multi-Resource Analysis Components}

Challenge: Resource summary information.-A key aspect of the vision for the MRA Baseline is that it should provide more than just links to resource data; it should include some historic and trend information, as well as summary information about the natural resources included in the MRA. Creating appropriate summaries is not trivial. The skills required to summarize large quantities of information into a format equivalent to an executive summary are often not the same as those required to perform the original scientific work, but the originators of that work need to be involved to ensure appropriate and correct presentation of the data. In a successful MRA, some effort might be required to find or cultivate the skills needed to prepare these summaries. In addition, a successful MRA would need to address questions related to which types and levels of baseline data will most benefit from being summarized, whether such summaries can be used as separate or standalone documents, and if so, what level of peer review might be required for those products.

Challenge: Timing and mechanism for keeping the Baseline relevant.-Numerous stakeholders stated that a one-time creation of an MRA Baseline has only limited use, and without periodic updates, the Baseline would rapidly lose relevance and value as a standalone product. This criticism is somewhat in tension with the vision for the MRA Baseline - that it represents the status of colocated resources in a region at a specific point in time. Ensuring that the Baseline is relevant would require clear communication about its purpose and how it fits within the full MRA; it would also require identifying a schedule or process for updating the baseline information periodically. The timing of updates to the baseline information may differ for different data types. For example, energy resource assessments are updated relatively infrequently, typically when new information or technologies are discovered that have the potential to significantly change previous assessments. In contrast, some stakeholders suggested that biology data go out of date quickly relative to the energy and mineral assessment time frame. The developers of an MRA would have to consider the planned timing of updates for different types of data in the context of funding and manpower constraints.
Challenge: Displaying multiple types of data to multiple users. - In talking to stakeholders and both USGS and non-USGS scientists, it became apparent that there exists a wide variety of preferences for how data should be organized and presented. Some individuals prefer map views, others like charts, and others prefer tables and text. Most agreed that there should be more than one way to access and display the information. Because there is no single best format for a given type of information, the challenge is to decide how to display the data, how to provide multiple ways to view the same information, how to display several types of information together, and how to ensure that the user can understand data displayed in different views. 

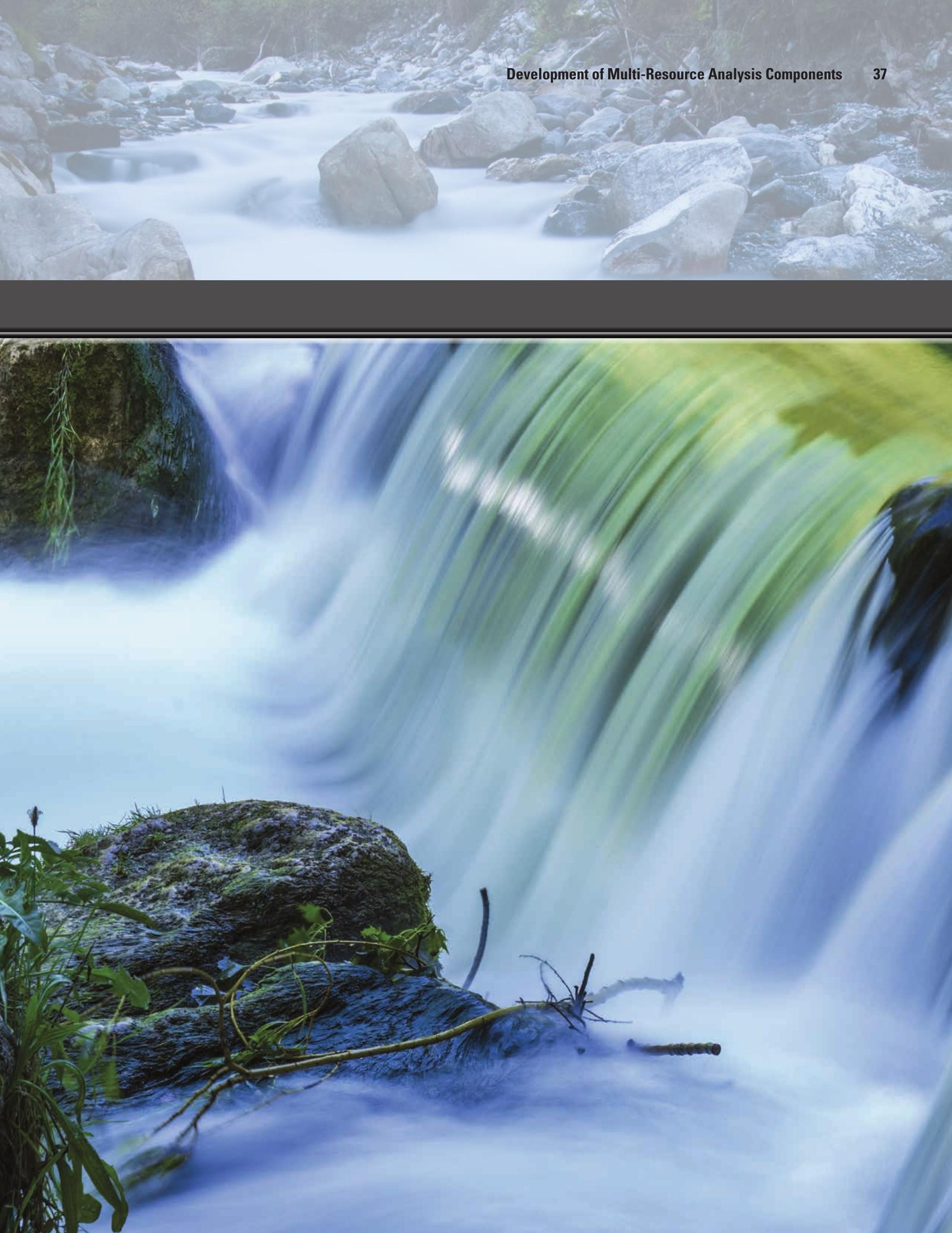


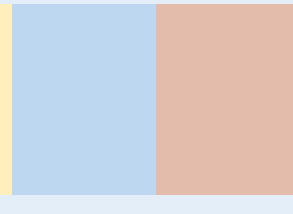

\section{Development of Multi-Resource Analysis Components}

\section{Multi-Resource Analysis Change Analysis}

Several types of analyses are required to help scientists, decision makers, and other stakeholders understand the range of potential future conditions of multiple colocated resources in a region. The MRA focuses on analysis of changes and includes elements related to identifying the broad-scale stressors, disruptions, and decisions that are relevant for the region; modeling the dynamic physical and biological interrelationships among resources so that the implications of those changes on future conditions can be projected; and analyzing the economics of those resources and resource changes.

\section{Scenarios and Scenario Analysis}

Natural processes and events and human decisions can change landscapes, their natural resources, and the benefits those resources provide. Decision makers often need to make decisions despite the significant uncertainty about how the future will evolve. One hurdle is simply the vast number of potential stressors, disruptions, and decisions that have the potential to affect a region. Another hurdle is that, for many of these stressors and disruptions, there is insufficient information or knowledge to make even probabilistic estimates of the likelihood of occurrence.

The MRA uses a scenario approach to address the multitude of possible stressors, disruptions, and decisions. Use of scenarios as a means to consider possible future conditions is a hallmark of scenario planning and scenario analysis, methods that are used in business and finance (Schwartz, 1996), geopolitical analyses (Hillebrand and Closson, 2015), projections of future climate conditions (Nakicenovic and Swart, 2000), and environmental decision making (Mahmoud and others, 2009). See the highlight on pages 40-41 for a description of a userspecified energy development scenario and the highlight on pages 42-43 for information on scenarios considering potential development restrictions. 
In an MRA, scenarios are created and defined as part of the framing process and may be refined several times as the analysis is conducted. Scenarios are specific to the region being analyzed and depend on the spatial and temporal scope of the study as defined by the multidisciplinary MRA team. Decision-maker engagement in the scenario identification process is essential for decision relevance. Engagement by scientists is also essential to ensure technical relevance. Having different groups bring their own unique perspectives on future changes during scenario development is the best way to be comprehensive. Scenario analysis is a common tool used to help decision makers think broadly about what the future might bring, consider and evaluate the risks of different options more thoroughly, and even consider the effects of potential "unknown unknowns” (Olabisi, 2017). In some cases, there may be existing regional coordination groups that are well suited to developing locally and regionally relevant scenarios. Examples of such groups include the Cooperative Ecosystem Studies Units National Network (http://www.cesu.psu.edu/) and the Landscape Conservation Cooperative Network (https://lccnetwork.org); both are multiagency collaboration and cooperation groups that address science and decision making at large geographic scales.
Identifying drivers of change and important future scenarios for a region is beneficial even apart from the role those scenarios play in the MRA. By bringing together the decision makers and stakeholders who have overlapping responsibilities and interests across a relatively broad geography, the scenario development process provides an opportunity for those decision makers to develop a joint vision of what different futures might look like and to identify things each of them might do to affect that future or respond to externally driven changes. In addition to identifying scenarios of change to be considered in the MRA, the process is likely to identify a large number of additional scenarios and potential changes that would be relevant at different scales and to different subsets of the participants. These scenarios and potential changes could become useful or important considerations for various planning exercises undertaken by an agency or organization.

Developing a relevant and manageable set of scenarios is a critical component of an MRA. These scenarios determine the scope of resources and interrelationships that are modeled in the subsequent analysis steps; a defined scope ensures that the MRA focuses on resources and issues that are relevant for the region. Scenarios also allow an MRA to consider "what if" analyses and determine the types of comparisons that can be made, such as comparisons between current and future conditions and between different possible future conditions. 


\section{Example: User-Specified Energy Development Scenario}

The Piceance Basin proof-of-concept study developed a flexible decision-support modeling tool that allows a user to define a future energy development scenario with considerable specificity. Users are given the option to specify the number of wells per pad, the density of well pads in the development area, and the future price of natural gas, all through the main model interface.

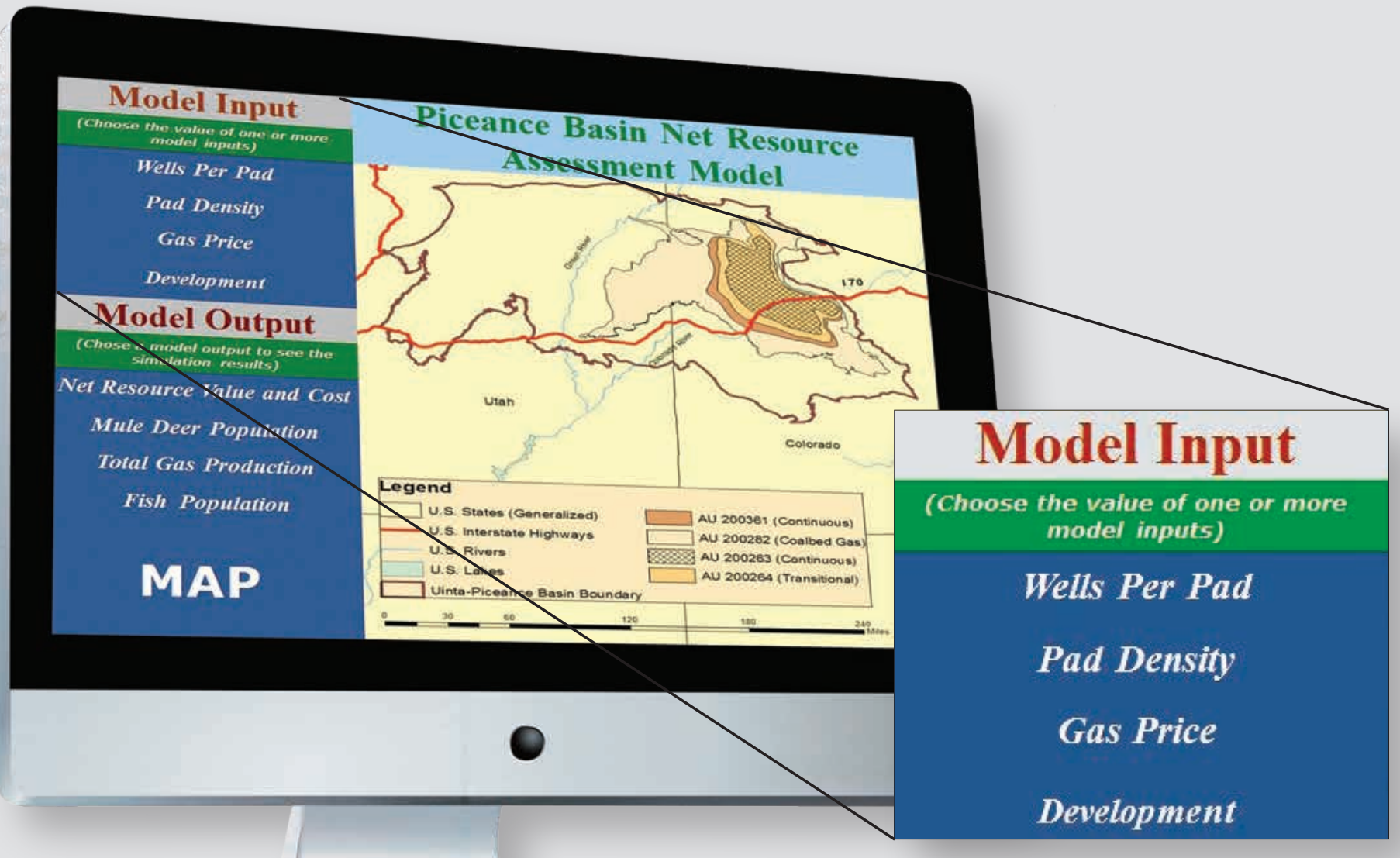

Example model interface with user input options shown under "Model Input." 


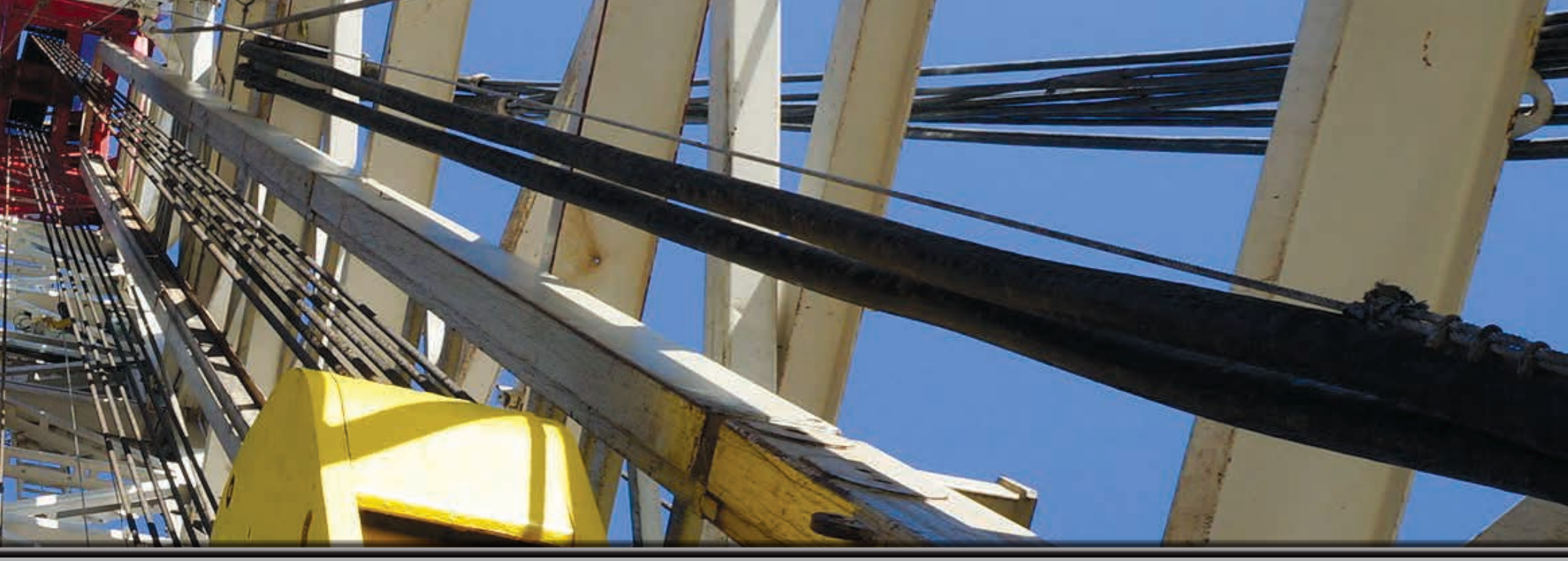

Users then specify where and when gas extraction will occur in the region by indicating on a simple map the "cells" that would be developed each year. In the figure below, 10 years of development activity are shown and the new regions developed in each year are shown in red. By using this simple interface and selecting different combinations of options (single or multiple wells per pad, high density or low density of well distribution, and different development locations), a user can define and compare any scenario they wish to consider, perhaps representing alternative development plans.

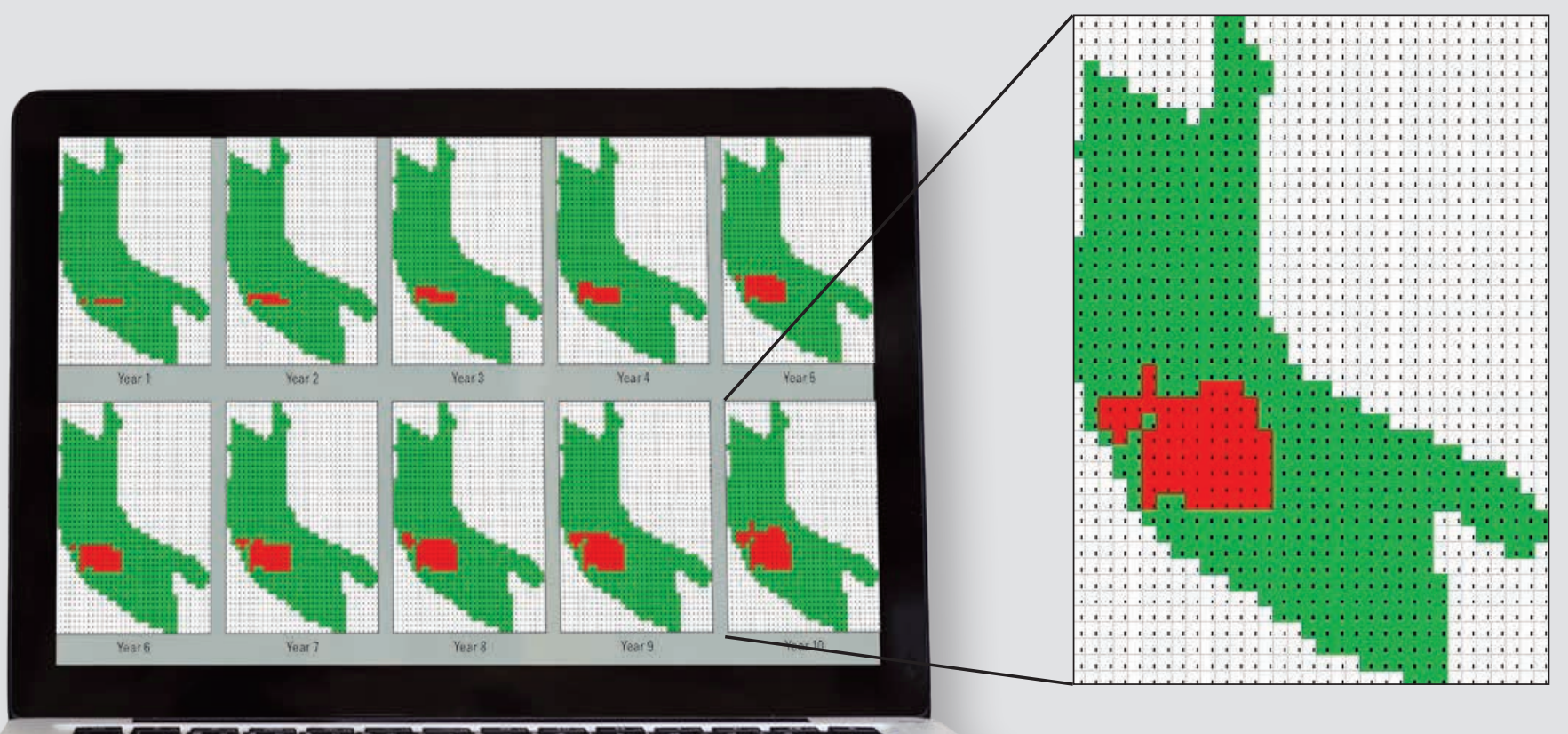

Example user-specification of locations of energy development (red cells) over time. 


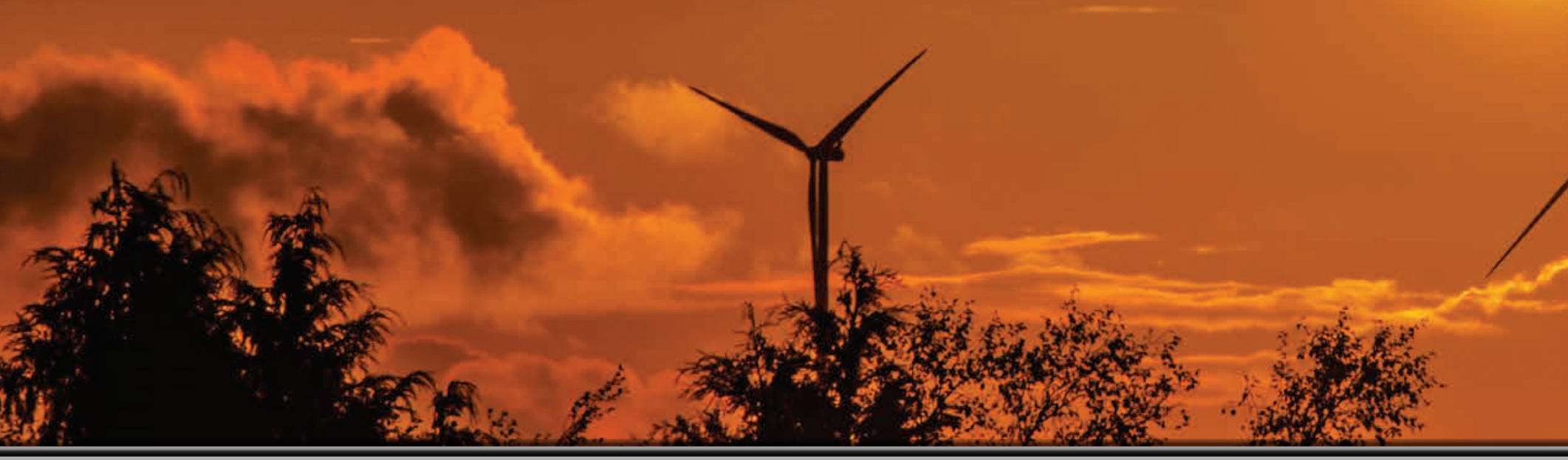

\section{Example: Potential Development Restrictions}

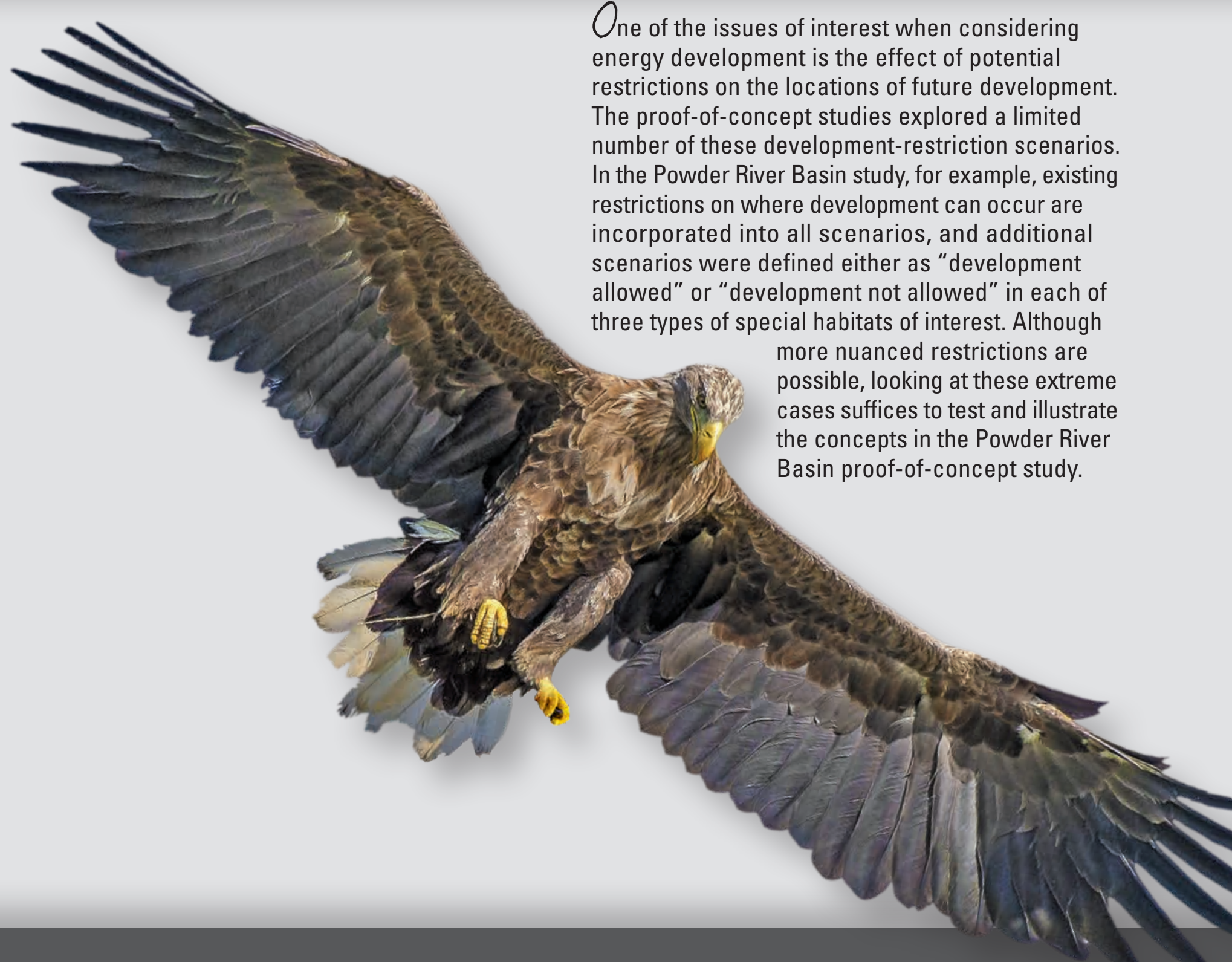



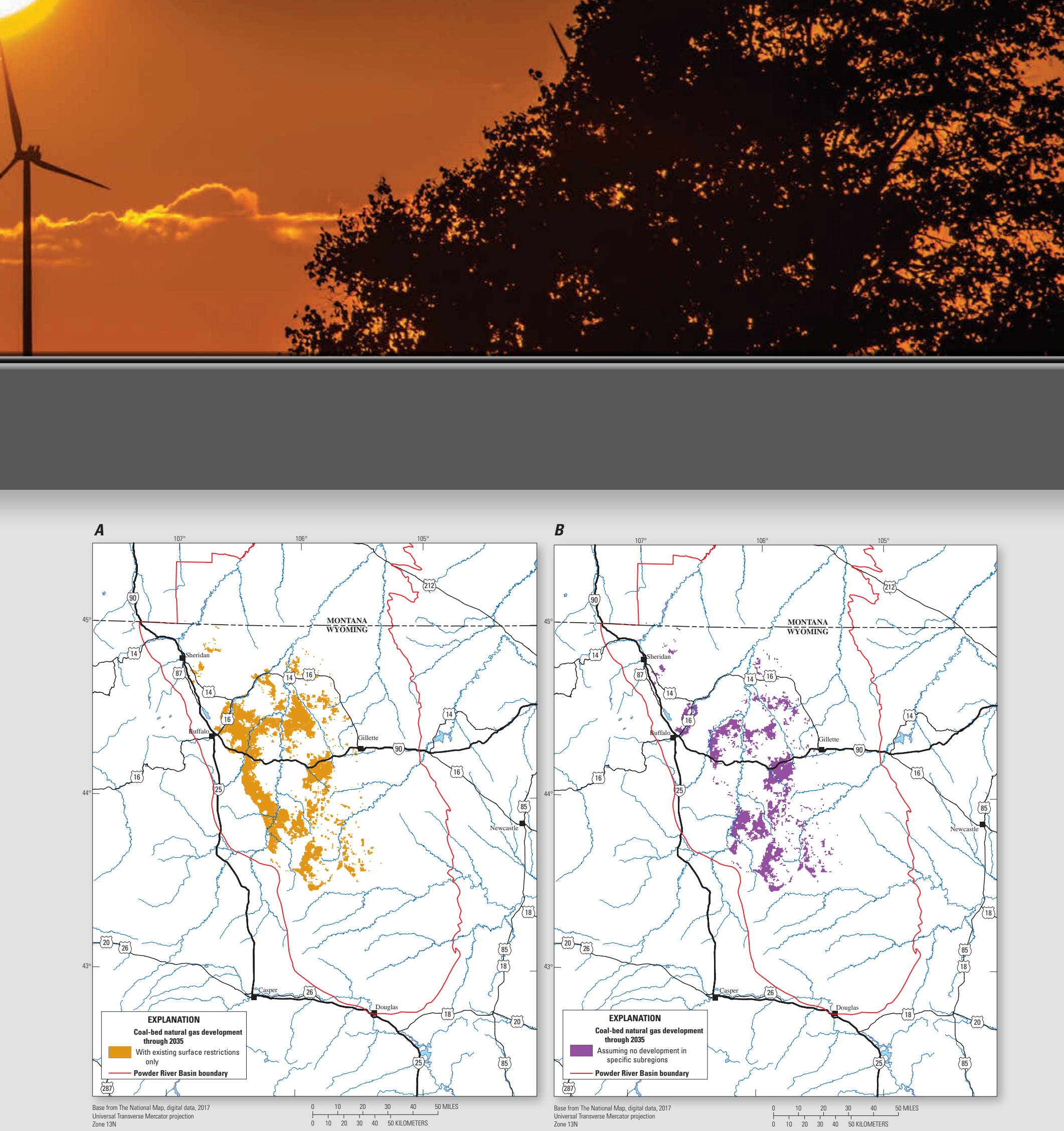

Maps comparing possible future development under $\boldsymbol{A}$, unrestricted and $\boldsymbol{B}$, restricted development scenarios. 


\section{Development of Multi-Rerource Analysis Components}

\section{Scenario Development-Synthesis of Previous Efforts}

The two proof-of-concept studies focused on energy development activities as primary drivers of change. The PRB study considered both coal mining and CBNG development. Additionally, environmentally driven surface restrictions on where such development activities would be permitted were considered as part of specific scenarios. The Piceance Basin proof-of-concept study used natural gas extraction by means of hydraulic fracturing as the driver of change.

Several different approaches to developing scenarios were explored. Both research teams considered the input of stakeholders critical to a useful MRA and to creating informative scenarios. The PRB proof-of-concept team had close contact with stakeholders at the local, regional, and Federal level during the development of the proof-of-concept study; they designed scenarios based on input from stakeholders and documented potential energy scenarios in the PRB. The Piceance Basin proof-of-concept team did not have that level of stakeholder contact; they instead designed a model that would allow any user to specify the development scenario explicitly during use.

Quantity, timing, location, and method of resource extraction and reclamation activities are the key elements that must be determined in a scenario that considers the effects energy development may have on other colocated resources and the ecosystem services and human values those resources provide. One approach to defining a development scenario is simply to specify all four elements explicitly. Both proof-ofconcept studies included these types of scenarios.
When dealing with large spatial and temporal scales, direct and detailed specification of the full development trajectory is not practical in many cases. Rather, it is common to specify some of these elements (for example, the amount and method of development) and model the remainder (such as timing and location) by using a combination of data and assumptions. The PRB proof-of-concept study explored these additional approaches to defining scenarios. For example, with CBNG, the issue of how much gas would be produced over time was separated from the question of where that production occurs. Production-specified scenarios and price-driven scenarios were used to estimate how much gas would be produced over time. For locations, combinations of randomly located wells (following Haines and others, 2013) and drilling driven by returns on investment were explored. The proof-of-concept studies also explored a limited number of development restriction scenarios.

There are benefits to having stakeholders define the relevant scenarios; there are also benefits to creating a highly flexible tool that allows any user to specify how development or other drivers of change will occur on the landscape or to revise input assumptions that will modify scenarios. A hybrid approach that utilizes stakeholder input while also maintaining flexibility is likely to be most useful. 

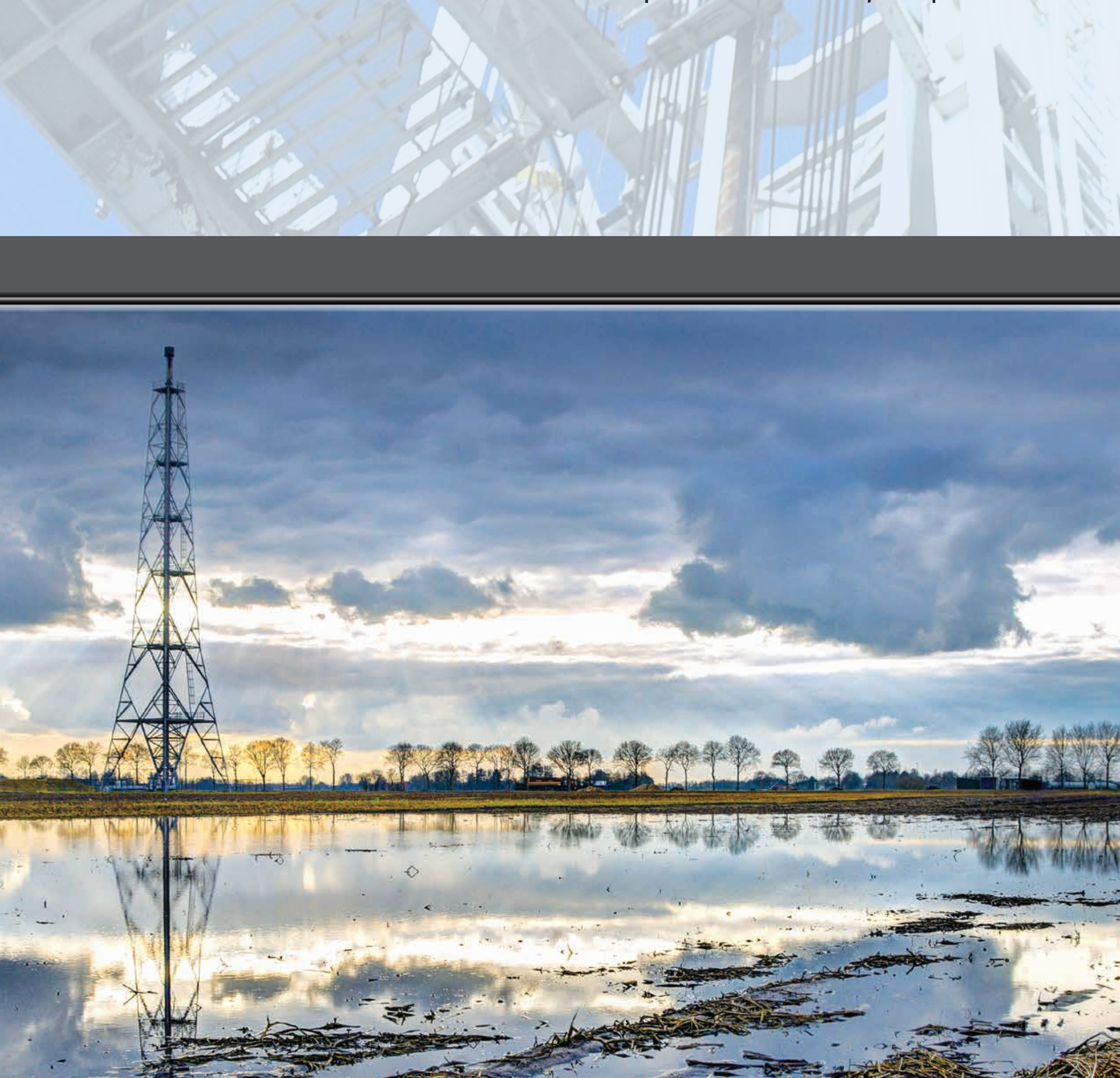


\section{Development of Multi-Resource Analysis Components}

\section{Challenges for Future Multi-Resource Analysis}

\section{Scenario Development}

Both of the proof-of-concept studies focused on energy development and its impacts. The synthesis workshop participants asked if (and how) an MRA should include a common or consistent set of scenarios or if it should focus on only the most locally relevant scenarios. The current vision is that an MRA would include both scenarios that are relevant across regions and scenarios that are locally significant. A successful MRA would have to address several key challenges.

Challenge: Identifying, defining, and choosing scenarios.The importance of understanding the effects of energy development on colocated natural resources was emphasized in the USGS Energy and Minerals Science Strategy (Ferrero and others, 2013) and was one of the motivations for development of the MRA concepts. However, there is an almost endless set of decisions, disruptions, and (or) stressors that affect a region and that could potentially be defined and explored in an MRA. In the MRA process, decision makers, scientists, and other stakeholders all have a role in identifying potential scenarios. Stakeholders are likely to focus on scenarios based on decisions of interest to them, and scientists are likely to identify scenarios based on important external drivers of change. In choosing a manageable set of scenarios to include in a specific implementation of an MRA, there are several issues to consider.
- There may be scenarios of interest that have already been defined by other agencies or stakeholders, as there were for some of the coal-development scenarios in the PRB MRA. If so, it may be desirable to include them and build on existing completed work.

- If there are scenarios being considered that might be relevant to other geographies, it may be desirable to include such scenarios in a future MRA study to increase the likelihood that this work could be leveraged in subsequent implementations.

- It may be challenging to prioritize scenarios, but it is important to focus initially on a somewhat constrained set of scenarios. Project participants with strong local knowledge and policy- and decision-making perspectives should have the strongest role in deciding what scenarios should be included.

- Scenarios can be described at different levels of detail. For example, in the Piceance Basin proof-of-concept study, development scenario definitions were detailed, based on user input on specific locations that would be developed in each year of the model time horizon. In contrast, some scenario options in the PRB proofof-concept study were much more loosely described, such as those that specified only a price trajectory for CBNG. In such scenarios, significant modeling may be required to have a well-defined scenario; the "boundary" between scenario definition and integrated modeling is not always clear. 


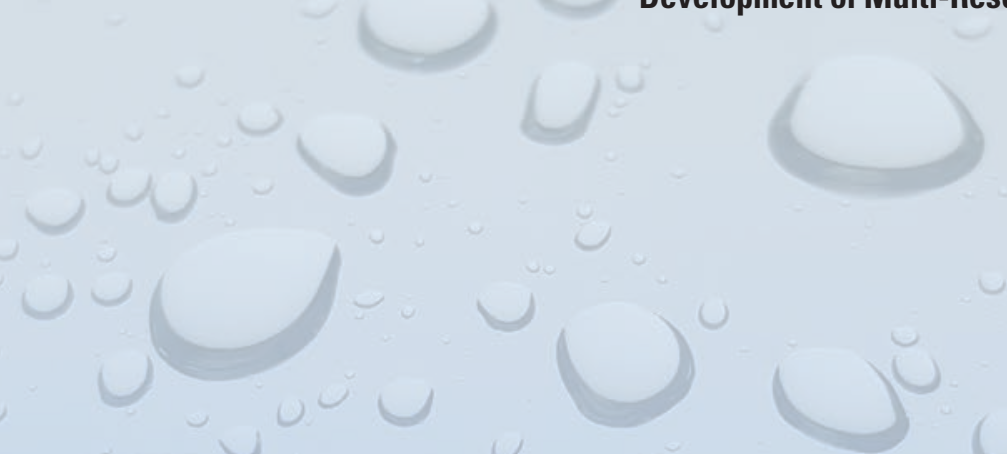

Challenge: Modeling scenarios.-Some scenarios likely will be identified and discussed at a high level; in those cases, detailed modeling would be necessary to translate the scenario concept to a level of detail sufficient for exploring the implications of that scenario on multiple natural resources. For example, a scenario on rapid energy development across a region would need detailed data on the number and locations of gas wells installed at various points in time. Some of the required modeling could become quite complex, and choices made in modeling scenarios could constrain or affect modeling choices elsewhere in the MRA development. Particular challenges that may arise in modeling scenarios are listed below.

- Balancing simplicity and complexity—Simple scenarios have the advantage of being easy for users to understand, but they may not capture important details. Complex scenarios may be more accurate and realistic, but it is a challenge to communicate those details to users effectively. Transparency and documentation are necessary for users to understand how scenario forecasts are constructed and what is and is not included.

- Selecting spatial- and time-scale increments-The selection of proper spatial- and time-scale increments for modeling is a challenge throughout the MRA process, from discussion during framing, to issues raised during modeling, to deciding how to deliver information and results across different scales. Although this challenge is not specific to scenario modeling, the discussion of scenarios may be the first point in the MRA development process where modeling challenges related to scales are encountered. The challenges are similar to those of balancing simplicity and complexity. Time and spatial units that are too coarse may not capture important details, but those that are too fine present challenges of excessive detail and potential problems with model size and runtimes.

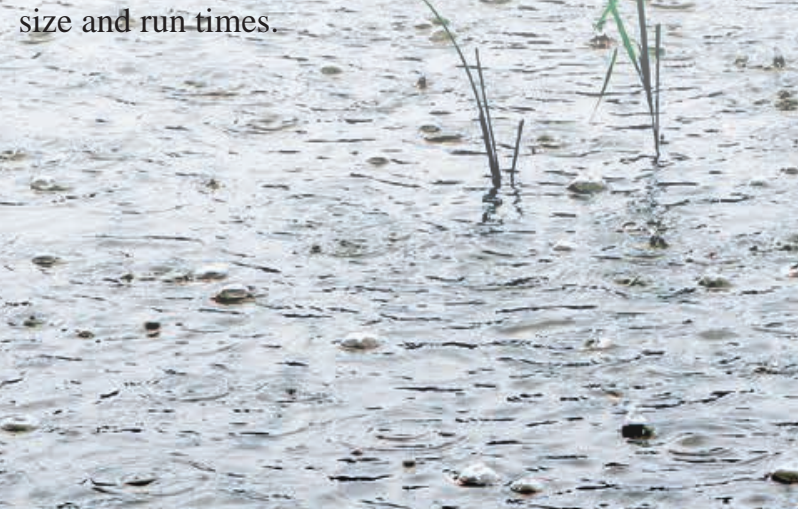

- Understanding and defining a scenario-The understanding and definition of a scenario may evolve during scenario modeling. At this step, the interactions among all perspectives represented in the multidisciplinary MRA team are critical to ensure that the scenarios remain relevant to the MRA audience.

- Forecasting change-Finally, models, methods, and expertise for forecasting change under some types of scenarios may not exist during an MRA, so approaches would need to be developed. This challenge is also faced when creating integrated and dynamic models of resources and their connections.

A final challenge relates to communicating what the scenarios represent. Many scientists in the USGS, and scientists generally, are reluctant to make "predictions" or "forecasts" of the future. Because MRA scenarios are by definition forward looking, some participants in the MRA proof-of-concept studies and synthesis workshop expressed concern that MRA scenarios could be interpreted as official USGS predictions of what will happen in the future rather than as projections of what might happen. Clearly communicating what scenarios are (and what they are not) is likely an ongoing challenge. 


\section{Development of Multi-Resource Analysis Components}

\section{Integrated, Dynamic Models of Physical and Biological Interrelationships}

Understanding how stressors, disruptions, and decisions can change future conditions of colocated natural resources requires an understanding of the interrelationships among those resources. Integrated, dynamic models of the physical and biological relationships among resources are fundamental to the MRA; it is through these models that the MRA connects the Baseline (current conditions) to the Outlook (projected future conditions under different scenarios). Making this connection requires models that

- are spatially explicit to identify colocated resources and resources for which location is relevant to their use and value;

- capture the physical and biological connections among resources so that the effect of changes in one resource on other resources can be considered;

- address the temporal dynamics of systems so that change over time can be considered and the effect of different scenarios on future outcomes is recognized; and

- recognize, incorporate (where possible), and communicate the uncertainties that exist in all of these interrelationships.
This type of integrated physical and biological modeling is an active area of research and focus, both within and outside the USGS. Laniak and others (2013) described the goal of integrated environmental modeling as "to develop and organize relevant knowledge and information and apply it to explain, explore, and predict the behavior of environmental systems in response to human and natural sources of stress" (page 3). Some examples of modeling relevant to the resource interrelationships that might be considered in an MRA include (1) models of how land-use change affects water quality (Booth and others, 2011), (2) spatially explicit population models that evaluate the links between landscape and habitat changes and the populations of specific animals of interest (Turner and others, 1995; Chandler and Clark, 2014; DeAngelis and Yurek, 2017), (3) models of the impacts of energy development on the landscape (Hernandez and others, 2015) and on habitats and species (Copeland and others, 2009), and (4) models that connect soil and water conditions to watershed -scale issues and to ecosystem services (Francesconi and others, 2016). Although much exciting work is being done in this area, robust integrated modeling has also been identified as one of the "grand challenges" for integrated science at the USGS (Jenni and others, 2017).

An important product from the Change Analysis component of an MRA will be one or more integrated models of resource interrelationships that allow scientists, decision makers, and other stakeholders to explore the implications of the various scenarios on multiple resources in the region. The dynamic physical and biological models focus on biophysical outcomes that are of interest to the decision makers and stakeholders, such as changes to the quantity and quality of the various resources identified in the Baseline. As these models are developed for an MRA, they also provide a starting point for more detailed analyses that might be desired. For example, an MRA-scaled set of models of water requirements for hydraulic fracturing of a shale-gas resource extraction might be scaled down both geographically and temporally to examine water needs for a proposed lease or play and then extended to consider site-specific water availability and alternative uses. 


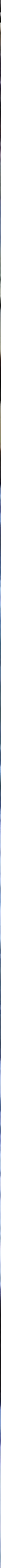




\section{Development of Multi-Resource Analysis Components}

\section{Integrated Dynamic Models-Synthesis of Previous Efforts}

Because of the relative complexity of modeling resource interrelationships, both proof-of-concept teams used a set of resource-specific models and identified a limited number of variables that act as "links" from one module to another. This modular approach allowed the teams to leverage existing data and models, where such models exist, and to focus efforts on connecting those models and carrying the implications through the entire set of resource connections and interactions. An advantage of the modular approach to building integrated dynamic models is that each module can also be used separately, if desired, and scaled up, scaled down, or modified in some other way to support a range of additional studies.

Both proof-of-concept studies used Esri ArcGIS to capture and summarize the spatially explicit nature of the resources. Both research teams also used a second model to create and run models of resource interrelationships and changes over time. One study used Analytica, a highly flexible Monte Carlo simulation engine that allows quantification of a wide range of complex relationships. The other study used PowerSim, a systems dynamics model. The interrelationships that are modeled in the PRB and Piceance Basin proof-of-concept studies are displayed in figure 3 and figure 4, respectively.

Both proof-of-concept studies estimate the physical effects of energy extraction activities (coal, CBNG, and unconventional natural gas) on hydrological and ecological resources in the study region. The PRB proof-of-concept models include (1) water consumption and water production associated with coal and CBNG development; (2) changes to the land surface from development activities summarized in a “Terrestrial Development Index,” a proxy for ecological disturbance modified from Carr and Means (2013); and (3) greenhouse gas emissions. The Piceance Basin proof-ofconcept models include (1) water consumption for hydraulic fracturing of natural gas wells, (2) changes to the land surface from new well pads and roads and how those changes might affect mule deer use of the local habitats, and (3) how additional erosion from construction activities might affect stream quality and how those changes in stream quality might affect an illustrative fish species potentially present in local streams.
The nature of resource relationships is not always well understood, and sometimes it is even uncertain if changes in one resource have any effect on another. Although it can be tempting to either ignore uncertainties or to delay modeling until uncertainties are resolved, neither approach is helpful to decision makers. Ignoring uncertainty often leads to incorrect conclusions and delaying modeling can leave decision makers without useful scientific and technical insights. Beginning the integrated modeling steps early in the overall MRA process, as well as being flexible in the tools and approaches used to address uncertainty, leads to more useful and more timely results. A variety of approaches for accommodating different types of uncertainties were explored in the proof-of-concept studies. They included the use of bounding analyses with different assumptions about the nature and level of resource interrelationships, sensitivity analyses to explore a large range of values, and in cases where there was some data to support quantified relationships, probability distributions to capture input uncertainties and simulation models to carry those initial uncertainties through to uncertainty in the outcomes of interest.

The models of land surface disturbance from energy development in both proof-of-concept studies are highly simplified and include only the amount of total disturbance for well pads and roads. Related modeling efforts have demonstrated that much more detailed modeling of surface disturbances from energy development is feasible. Garman $(2015,2018)$ describes an "energy footprint" model in which actual well pad and road networks from recent development in a region of interest are digitized and then sampled within a simulation framework to make more realistic predictions of what the surface disturbance for a given development buildout would look like on the ground. This computationally intensive approach provides fine-grained information that is likely to be more useful in detailed ecological modeling than simpler aggregated approaches. 

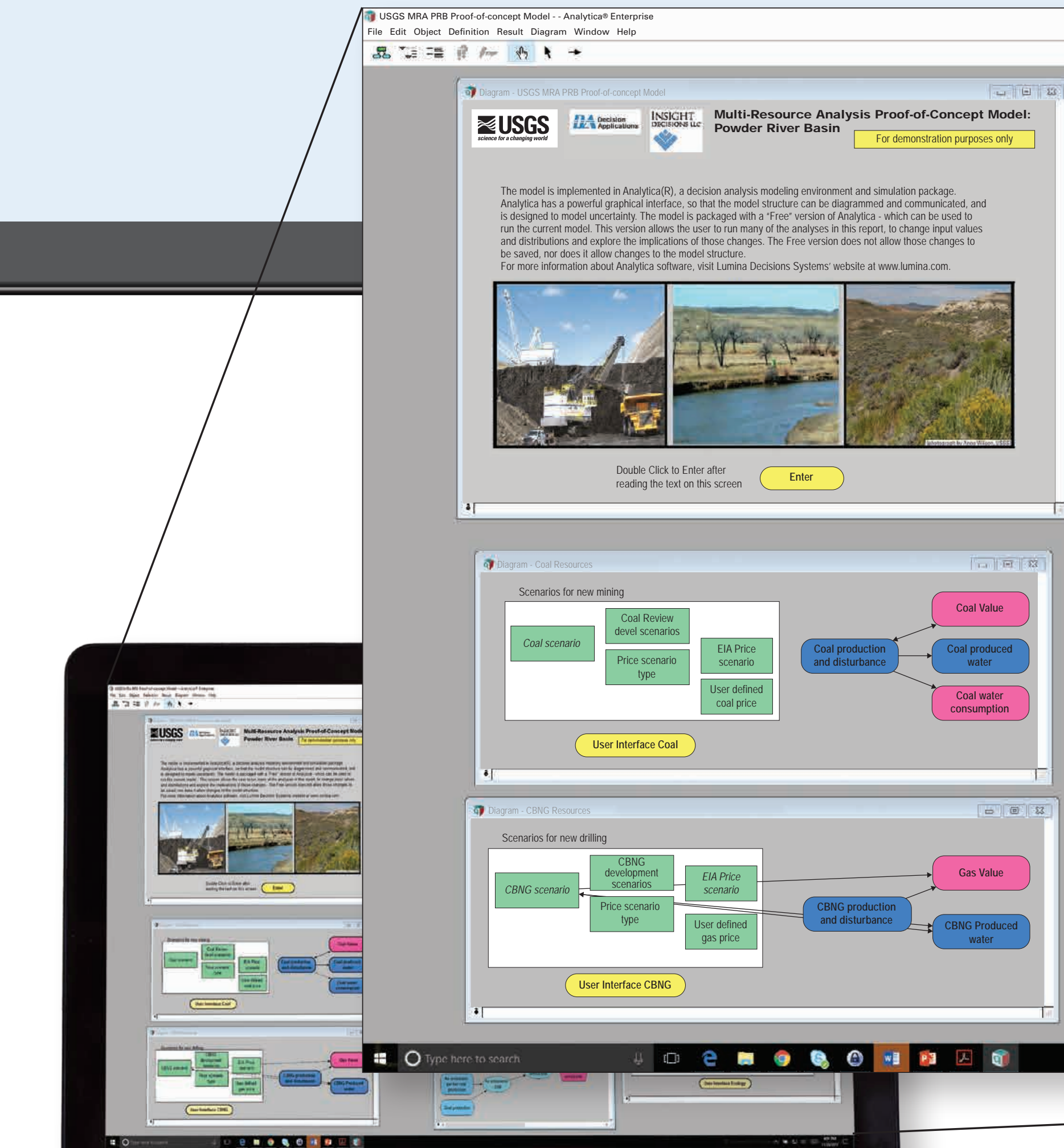

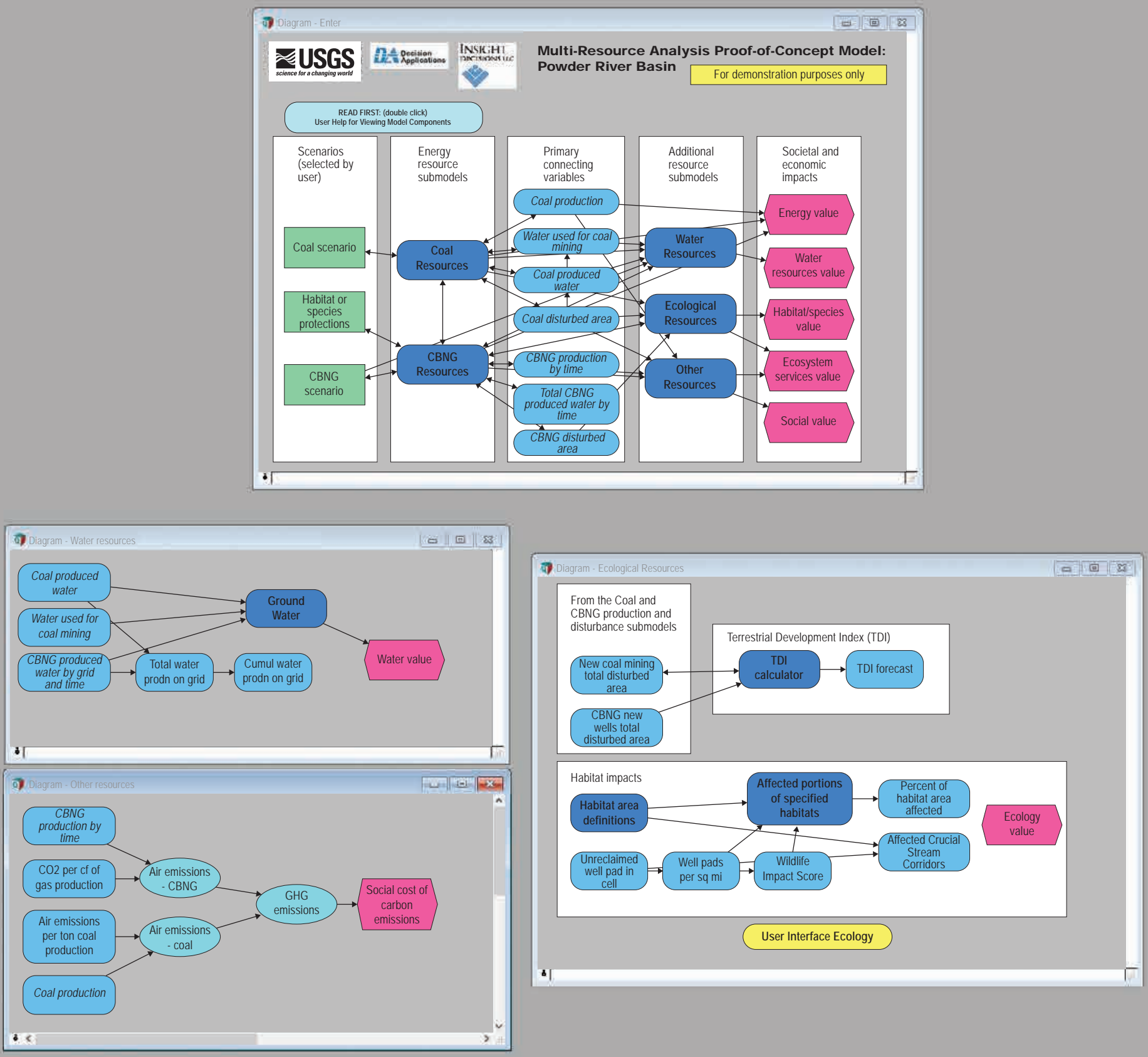

Figure 3. Overview of the Powder River Basin Multi-Resource Analysis models of interrelationships among resources.

(USGS, U.S. Geological Survey; CBNG, coal-bed natural gas; EIA, U.S. Energy Information Administration; prodn, production; $\mathrm{CO}_{2}$, carbon dioxide; cf, cubic foot; GHG, greenhouse gas; TDI, Terrestrial Development Index; sq mi, square mile) 


\section{Development of Multi-Resounce Analysis Components}

\section{EXPLANATION}

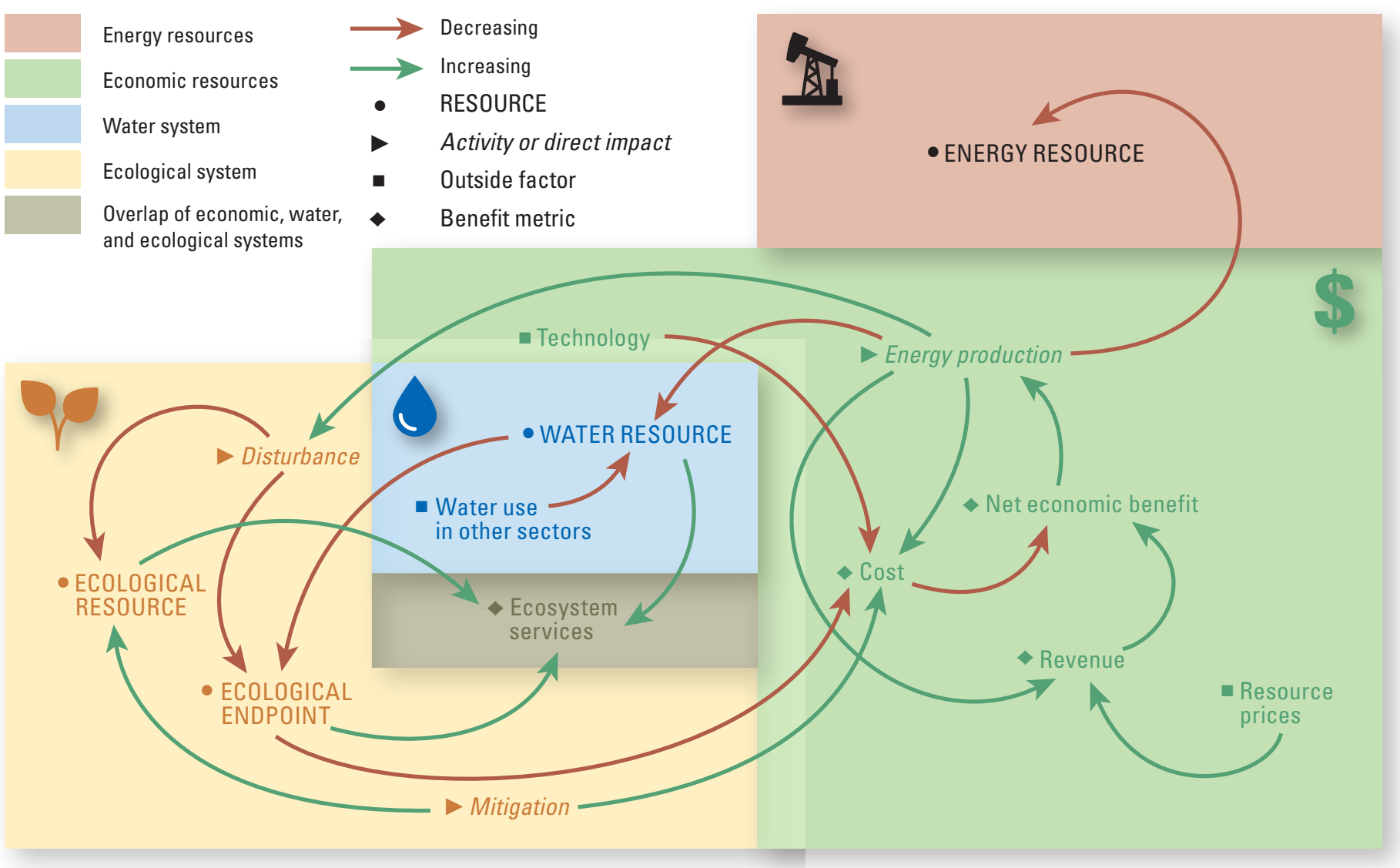

Figure 4. Overview of the Piceance Basin Multi-Resource Analysis models of interrelationships among resources and other factors. The arrows in this causal loop diagram indicate how changes in one factor affect another. For example, the decreasing arrow from "Technology" to "Cost" means that costs will decrease as technology improves, and the increasing arrow from "Resource prices" to "Revenue" means that revenue will increase as resource prices increase. 


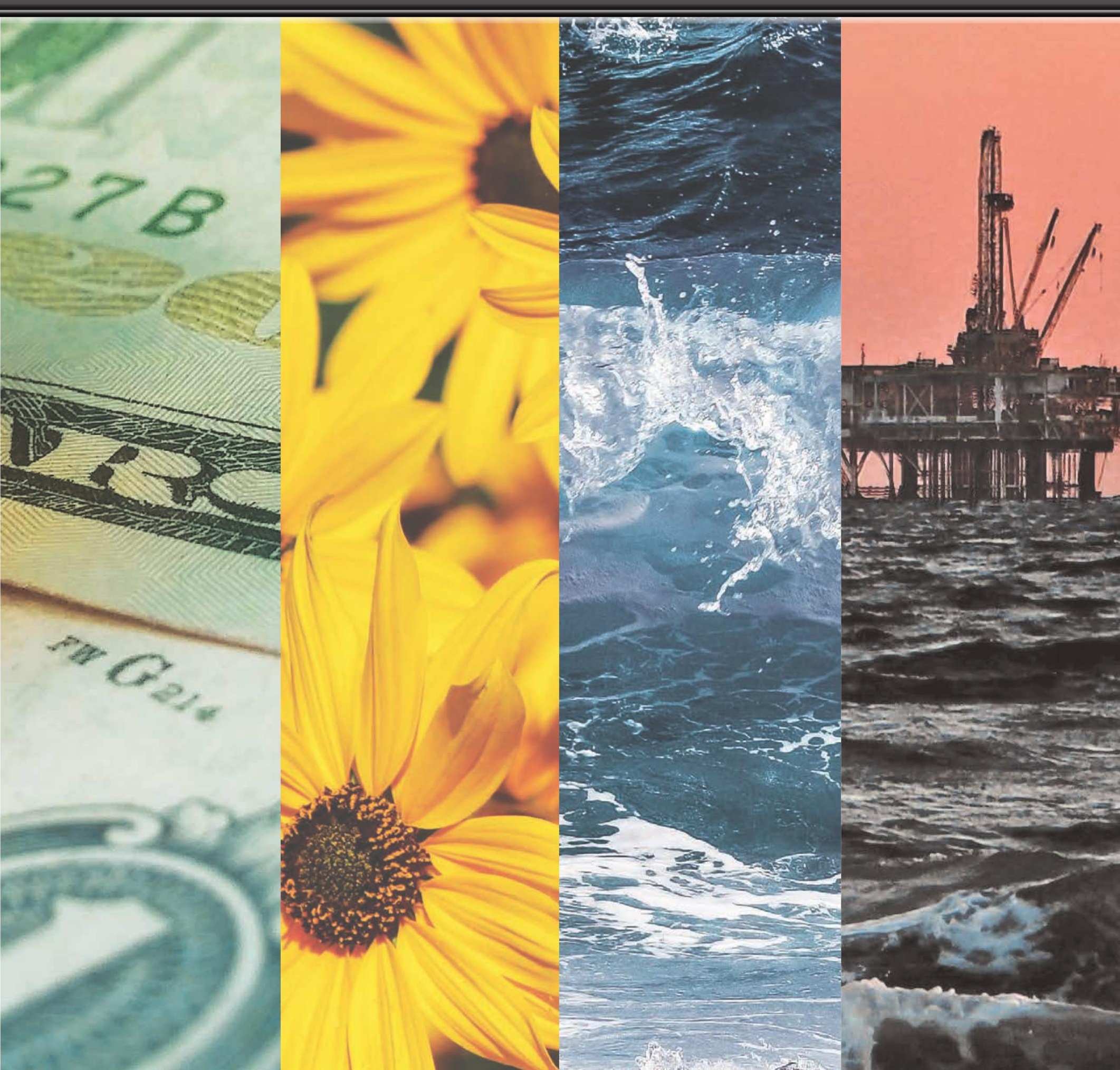




\section{Development of Multi-Resource Analysis Components}

\section{Challenges for Future Multi-Resource Analysis Modeling}

The creation of integrated, dynamic models of resource interrelationships across long time horizons and landscape scales is a significant challenge. Both proof-of-concept studies were able to identify and model a limited number of links from resources through scenarios to some biophysical and economic outcomes. In both studies, the ability to identify, modify, or create such models was limited by uncertainty about the nature and strength of the relations and limited availability of data and models to support regionally specific integrated models. Local and regional stakeholders who provided input on the PRB proof-of-concept study stressed the importance of providing transparency and traceability in the conceptual and numerical models. Some of the challenges in defining and modeling these interrelationships are listed below.

Challenge: Balance of complexity and simplicity/clarity.Multiresource models are inherently complex, and experience with the proof-of-concept studies revealed that there are a large number of choices that must be made to complete models of this complexity. Some if not most modelers have a tendency to continue to add detail as models develop, but it is important to strike a balance. Too much detail robs the end user of clarity; too little detail robs the end user of accuracy and insight. Transparency and documentation are critical in this step, as they are throughout the MRA process, because they allow users to readily understand how models are constructed and calculated.

\section{Challenge: Integration across disciplinary modeling norms.-} Integrated modeling requires interdisciplinary modelers, and building a cohesive analysis team across disciplines is not a trivial matter. Subject matter experts are often not accustomed to considering or working with resources outside of their expertise, and models that connect those resources are often lacking. Interdisciplinary modelers with expertise in making these connections may not, initially, have sufficient credibility with the subject matter experts to have their trust. However, scientific support for the models of resource relationships is essential both for the accuracy and the credibility of the MRA products. A successful MRA would identify approaches and methods for facilitating this kind of integrated modeling work.

In addition to the general challenge of integrated modeling, several challenges related to the use of varying scales for spatial and temporal data have been identified. The scale of the data commonly used in one domain may not conform to the scale used in the other domains being integrated. Methods for reconciling different scales may have to be developed. 
Challenge: Accounting for and communicating uncertainty.Model uncertainty includes both scientific uncertainty about resource relationships and values and uncertainty that stems from natural variability in resource location, quality, and the strength and nature of the resource relationships. These uncertainties are often both numerous and very large, so modeling all of them completely poses implementation and communication challenges. However, ignoring them threatens the credibility of the MRA Baseline and Outlook results. The following issues could be addressed in a future MRA.

- Uncertainty in relationships-An MRA explores the interrelationships among different resources over temporal and spatial scales that are not traditionally modeled. These functional relationships are often not well understood, and more than one conceptual model may exist. This conceptual model uncertainty can be very large; accounting for and communicating that uncertainty is important.

- Uncertainty in models and data—Even within a single conceptual model of resource connections and interactions, there may be significant uncertainty about the nature and strength of that relation because data may be lacking, incomplete, or conflicting. The proof-of-concept work showed that experts are often uncomfortable trying to quantify these relationships. To accurately convey this uncertainty, experts were encouraged to use probability to capture and express their state of knowledge, but the experts had varying levels of comfort with probabilistic approaches.

Identification and propagation of uncertainty through the modeling chain also provides an opportunity: it can clarify which "input" uncertainties lead to the greatest uncertainty in understanding the effects of change on the resources and values that are important to decision makers and stakeholders. This understanding may be useful in establishing research priorities and may provide opportunities to reduce costs and increase the value of science research by directing funding to the most relevant research.
Challenge: Selection and integration of modeling software and tools. - Selection or development of appropriate modeling software is a challenge common to several MRA components, especially to developing scenario models; modeling physical, biological, and economic interrelationships; and information delivery. The challenges may be most acute for modeling the physical and biological systems and connections, but are also challenging for the information delivery component of the MRA.

There are many choices for modeling tools: off-the-shelf modeling packages such as Analytica and PowerSim as used in the proof-of-concept studies; mathematical modeling languages that are suited to these types of models such as $\mathrm{R}$ and Python; or custom software code written in Fortran, $\mathrm{C}++$, or other programming languages. In the proof-of-concept studies, modeling software was chosen based primarily on the immediate goals of the studies and on familiarity of the investigators with particular tools. It is likely that in any MRA study, the subject matter experts and the modelers will all have personal preferences and individual areas of tool and software expertise. The philosophy of the MRA is to build on, not replace, existing tools, just as it builds on existing data. The challenge is to use the best available software and tools to create a cohesive integrated model and information delivery system (see the section "Multi-Resource Analysis Outlook and Information Delivery”).

Finally, computational limits played a role in limiting the spatial and temporal scale of the analyses in both proof-ofconcept studies. Especially in light of the need to account for uncertainty, and because of the very large geographic and temporal scale of an MRA, these computational limits are likely to be an important consideration in software development and selection. 


\section{Development of Multi-Resource Analysis Components}

\section{Economic Analysis}

The integrated dynamic models of resource relationships focus on the physical and biological connections among resources and on how changes in the quantity and quality of one resource affect the quantity and quality of other resources. Understanding these connections and changes is only part of the information that decision makers and stakeholders need when considering their management options. They also need information on how those changes affect and are valued by the people who live in the region or rely on the resources provided by the region. Accordingly, the connections between resources, the environment, and people will be a principal consideration in the MRA.

The MRA Economic Analysis is necessary to make the connection between changes in the quantity and quality of multiple resources and changes in the economic, ecosystem, and societal values that those resources provide. It has two elements. The first is to connect the physical outcomes from the physical and biological models to the fundamental features and services that regional decision makers and stakeholders value. For example, the integrated dynamic models of the physical and biological systems may lead to estimates or projections of the amount of groundwater extracted from an aquifer for a particular use, but stakeholders might be concerned with the near- and long-term availability of water from that aquifer for agricultural irrigation. Expressing future conditions in the context of the stakeholders' values makes the outcomes more meaningful to those affected by the changes and allows them to consider the potential tradeoffs and how they value different outcomes. The second element is to connect the valued aspects of the resources to an economic value, where possible. In the previous example, water markets or the price of agricultural water from other sources may be used to translate changes in the availability of water for irrigation to an economic value (benefit or cost). Economic valuation includes assessing conventional, market-derived costs and benefits and using nonmarket valuation techniques to estimate economic values associated with natural resources and the ecosystem services they provide.
Identifying the fundamental aspects of the ecosystem and natural resources that produce economic and social value for various stakeholders gives land and resource managers a powerful tool they can use to communicate with those stakeholders about the full range of issues they face and decisions they make. The identification of those valued aspects of resources in a given region is part of the initial framing process and may continue through the modeling steps. Existing studies and literature that describe the more general ecosystem services that humans derive from different resources (Millennium Ecosystem Assessment, 2005) can enhance the identification of stakeholder and region-specific economic and social resource values; site-specific studies can also provide a useful starting point. Although there may be additional factors that are relevant to management decisions at a smaller scale, starting with an understanding of what stakeholders want to hear about allows managers to provide information that is more consistent and more targeted to those participating in and affected by decisions. Economic valuation models provide a starting point for tradeoff analyses and other economic analyses and give decision makers an opportunity to scale up or down the MRA models to support specific decisions. The MRA valuation process also identifies areas where site-specific studies may be necessary to fully support economic valuation; those studies may then become relevant for more detailed analyses.

In the context of an MRA, economic analysis provides a powerful extension of the more common USGS research products of technical information and data. It also provides the primary integrated picture of how people may be affected by changes in multiple colocated natural resources in a region under the various scenarios being considered. 

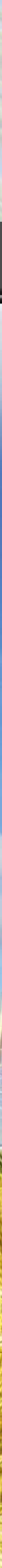


\section{Development of Multi-Resource Analysis Components}

\section{Economic Analysis-Synthesis of Previous Efforts}

The two proof-of-concept studies focused on economic valuation to different extents. The Piceance Basin research team emphasized the economic valuation of resource extraction and changes to the impacted resources. The research team defined the concept of a "net resource value," intended to combine the economic benefits of extracting energy resources with the economic costs of the associated adverse impacts on colocated resources. The PRB proof-of-concept study translated the physical effects of changes in resource conditions to economic effects for a limited set of physical outputs; it did not focus on producing a net value.

The PRB proof-of-concept study estimated the economic costs and revenues from coal mining and CBNG development, the value of alternative uses for produced groundwater, and the social costs of greenhouse gas emissions. Neither of the main ecological endpoints used in the modeling, the Terrestrial Development Index and the wildlife impact score, was amenable to valuation (economic or other) that would inform tradeoffs between those impacts and other effects. The Terrestrial Development Index has a physical interpretation; that is, it shows how much of an area is in a disturbed versus a natural condition, but it has not yet been connected to outcomes that can be valued economically. The wildlife impact score is used by the State of Wyoming in conservation planning, but it is not very well defined in terms of actual effects on species and thus would be difficult to value through economic metrics or by considering tradeoffs with other more concrete metrics.
For the Piceance Basin proof-of-concept study, the monetary value of natural gas in the market provided a simple proxy for the economic value of natural gas production to society. Groundwater, mule deer, and aquatic species were used as examples of ecosystem elements affected by energy extraction where nonmarket valuation approaches could be used. Values for mule deer and aquatic species were derived from a metaanalysis of previous studies. The research team combined values from these metaanalyses with estimates of the physical effects on those species to yield an economic cost of changes in species populations. All of the economic values were considered temporally, with discounting, and aggregated to provide a net resource value.

Feedback from stakeholders gathered prior to building the proof-of-concept models in the PRB study suggested that the aim should not be for a "single integrated value" of resources or effects on resources. Rather, the stakeholders indicated that they would prefer that evaluation and valuing each type of resource be based as clearly as possible on the state of the art for a specific resource, which may be a clear quantitative description of the biophysical state of the resource, an economic valuation of that resource state, or some other metric. Although a net resource value in isolation may not be enough information for a land manager to make a decision, the value fully integrates resource information and is useful in evaluating tradeoffs and providing one component of a suite of outputs to support land-use decisions. 

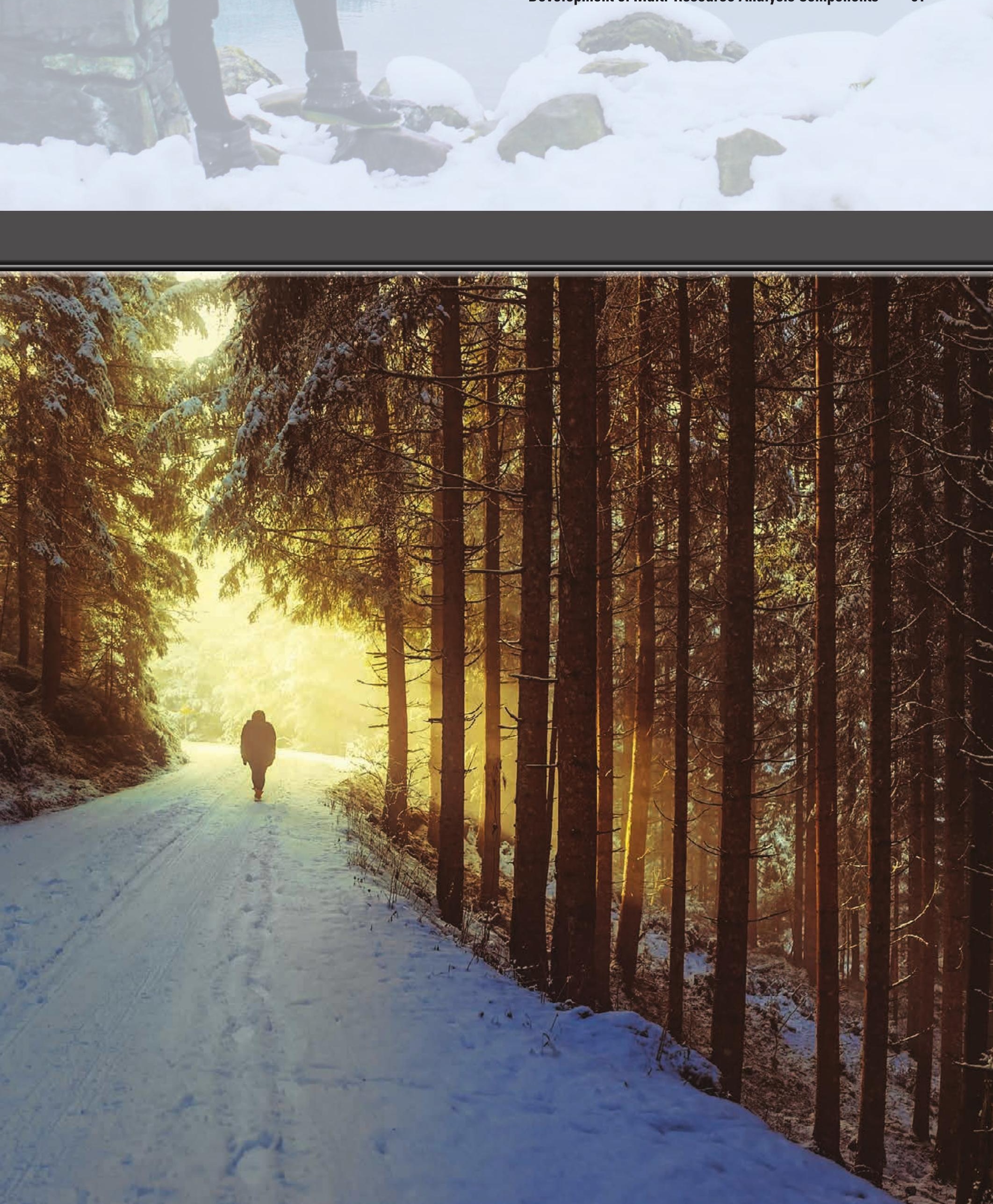


\section{Development of Multi-Resource Analysis Components}

\section{Challenges for Future Economic Analysis}

Resource management decisions are complicated in part because they almost always involve tradeoffs among competing values. The key challenge for the Economic Analysis component of the MRA is how to provide clear and meaningful metrics that resource managers can use to make decisions. The goal is to find both clear and common metrics for comparing disparate impacts.

Challenge: Facilitating understanding of tradeoffs.The Economic Analysis component of the MRA starts with identification of the fundamental value(s) that stakeholders derive from the natural resources on the landscape. Clearly connecting the biophysical changes to these fundamental stakeholder values poses some modeling challenges. If valuation stops at this point, the results provide resource managers with important value-relevant information to support decision making. In some cases, they may be able to identify dominant options without having to address tradeoffs, but many if not most challenging decisions require tradeoffs between several things that decision makers and stakeholders care about. The Economic Analysis component includes explicit consideration and analysis of tradeoffs among multiple objectives. These concepts might be explored in more depth in a future MRA study.

Challenge: Lack of data to support monetary valuation of changes in resources.-A key challenge in both proof-ofconcept studies was estimating an economic value for changes in resource quantity and quality, particularly for resources that have not historically been valued in economic terms. Although the economics of energy development are well understood and readily modeled, estimating the economic value of changes in other natural resources is a newer science. It is generally believed that the economic value of a nonmarket good or service is locally or regionally specific; that is, the economic value depends on the value placed on the good or service by those people who benefit from the good or service. Primary social and economic valuation analyses are time consuming and expensive to conduct. Secondary analyses, especially benefit-transfer approaches, are considered a second-best approach but it may be difficult to find studies that are similar enough to the MRA study region to be appropriate for benefit transfer. Future MRA studies could address this issue in more depth than was done in the proof-of-concept studies.
Challenge: Integrated net metrics can be useful but require context.-The Piceance Basin proof-of-concept study demonstrated that it is possible to produce a net monetary value for different scenarios by summing the monetary value of impacts on several biophysical endpoints. The idea of a single metric that summarizes all the changes may be very attractive, and in some sense it simplifies communication of the MRA Outlook. However, combining the monetary values from several economic studies that have very different foundations may be problematic from both theoretical and practical perspectives, and work remains to be done to ensure that such combinations are meaningful and clearly understood. Decision makers and stakeholders who participated in the PRB MRA proof-ofconcept study uniformly agreed that limiting reporting to a single integrated value of the effects of changes on colocated resources would be viewed with suspicion. They expressed a strong preference for results that clearly communicate the outcomes in natural terms (relevant to the resource value) and in economic terms, where feasible, and with any basis for combining values clearly communicated. A future MRA could explore further when and how net values should be presented and how they can enhance presentations of multimetric results. 

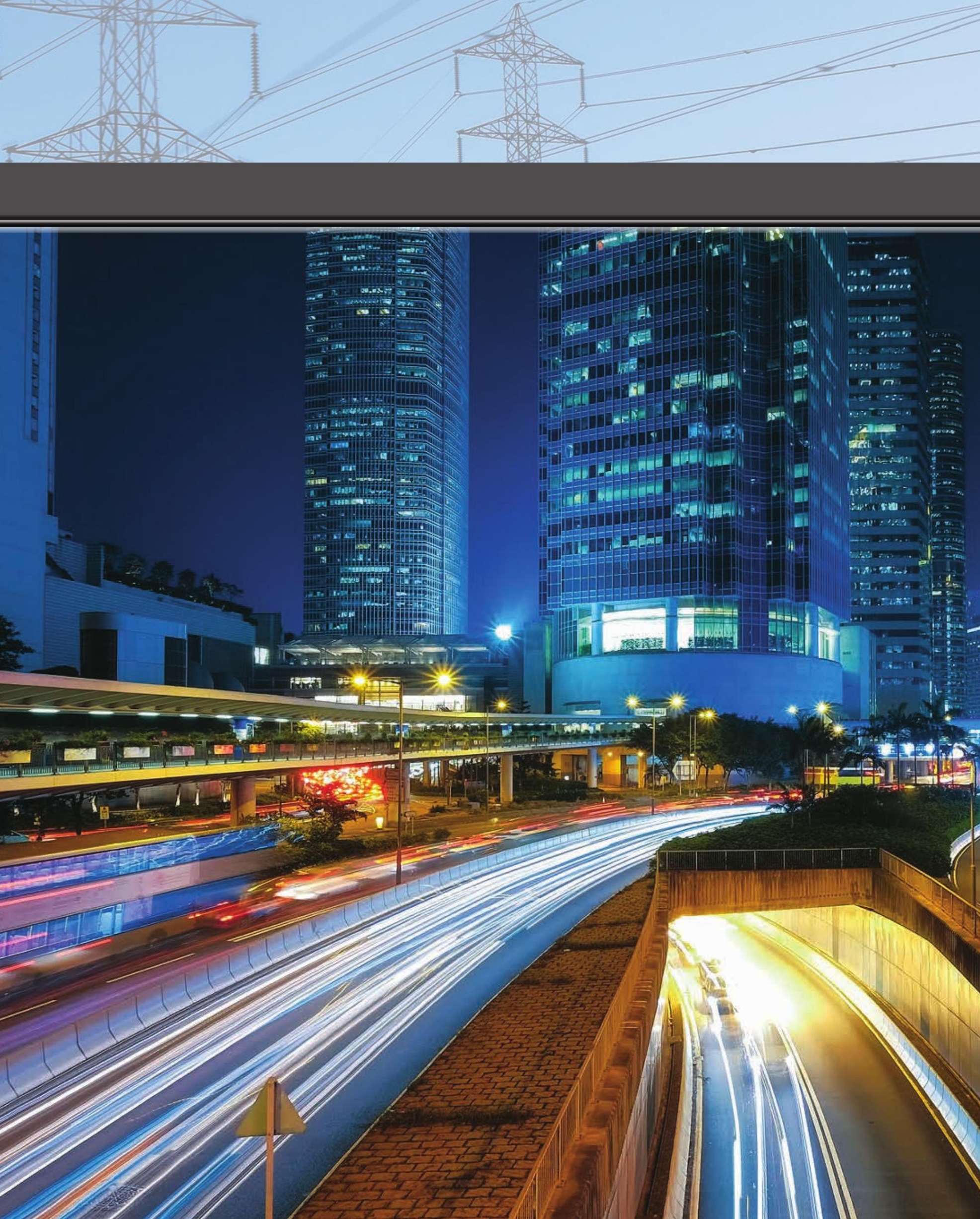


\section{Development of Multi-Resource Analysis Components}

\section{Multi-Resource Analysis Outlook and Information Delivery}

The results of the analysis components constitute the MRA Outlook, the culmination of the MRA. Comparing the Outlook to the Baseline allows land and resource managers to better understand the potential changes in colocated resources over time under a set of future scenarios that they have chosen as relevant for their region.

The Outlook provides information about the projected state of the natural resources included in the Baseline under each of the scenarios being evaluated, as well as information on the economic and social implications of changes in those resources from their Baseline status to the projected future status. The Outlook gives decision makers information on the potential outcomes of decisions, actions, and other factors that affect resources over time. It uses the results of the integrated, dynamic models of the biophysical interrelationships to describe the quality and quantity of each resource under changed conditions. It also uses the results of the economic analysis and the scenarios of change to provide information on the effect and value of changes in those resources under the scenarios considered in the MRA.

A key part of the vision for the Outlook and information delivery components of the MRA is that the results of the analysis are presented in several ways. At a minimum, the Outlook provides (1) maps to communicate spatial relations, (2) tables to summarize the outcomes in physical and value terms and facilitate comparison of those outcomes over time and (or) across scenarios, and (3) graphs to provide easier visual comparison of some of those outcomes. Ultimately, the information delivery may include all of these, as well as software tools that would allow an interested user to access the underlying data (from both the Baseline and the Outlook) and create their own customized displays or outputs.

\section{Outlook and Information Delivery- Synthesis of Previous Efforts}

The PRB and the Piceance basin proof-of-concept studies explored various ways to illustrate the results of modeling and analyses. A brief summary and some examples are provided in the highlight on pages 66-67. A compact way to communicate the MRA Outlook is to summarize resource conditions in a single table. Conditions can also be illustrated in graphical displays, which draw attention to relatively small changes in the total resource over time, especially for energy and groundwater resources, and terrestrial disturbance. Within-region differences, however, some of which might be important to decision makers and stakeholders, can be masked if the summary results are focused at the scale of the outer boundary of the MRA region (the PRB or the Piceance Basin in the two proof-of-concept studies). For example, the key issues and questions for water resources are typically considered at a watershed (or smaller) scale-a much smaller region than the entire PRB. A similar issue arises when considering the change in terrestrial disturbance. In this case, the overall effect is better communicated through maps.

Another way of communicating the Outlook is to focus on differences across scenarios at specific points in time. This approach may be particularly helpful to decision makers and stakeholders who want to consider and compare future outcomes of different decisions or policy choices. 


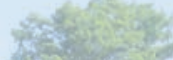

$-\operatorname{lin}^{2}$

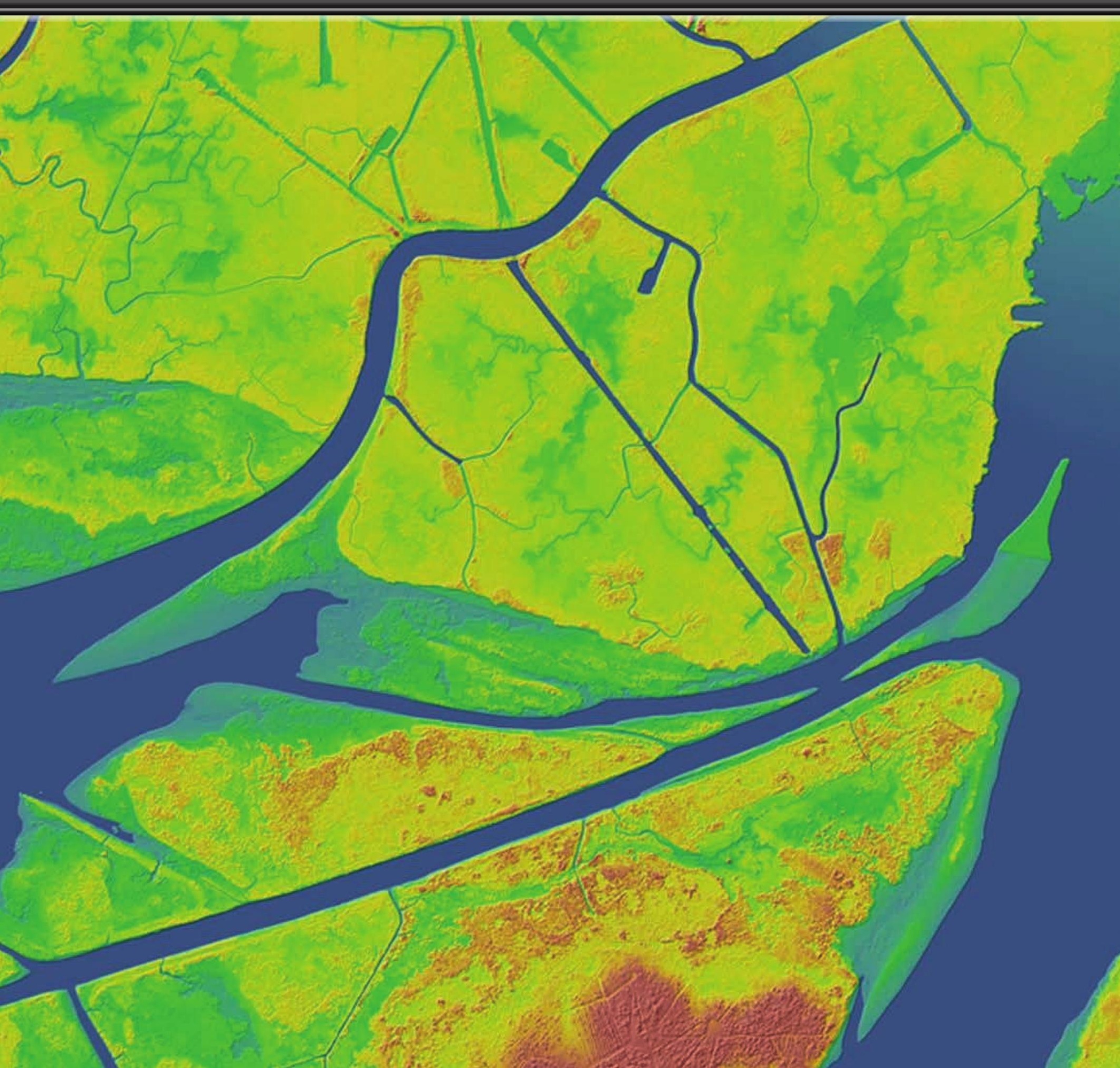




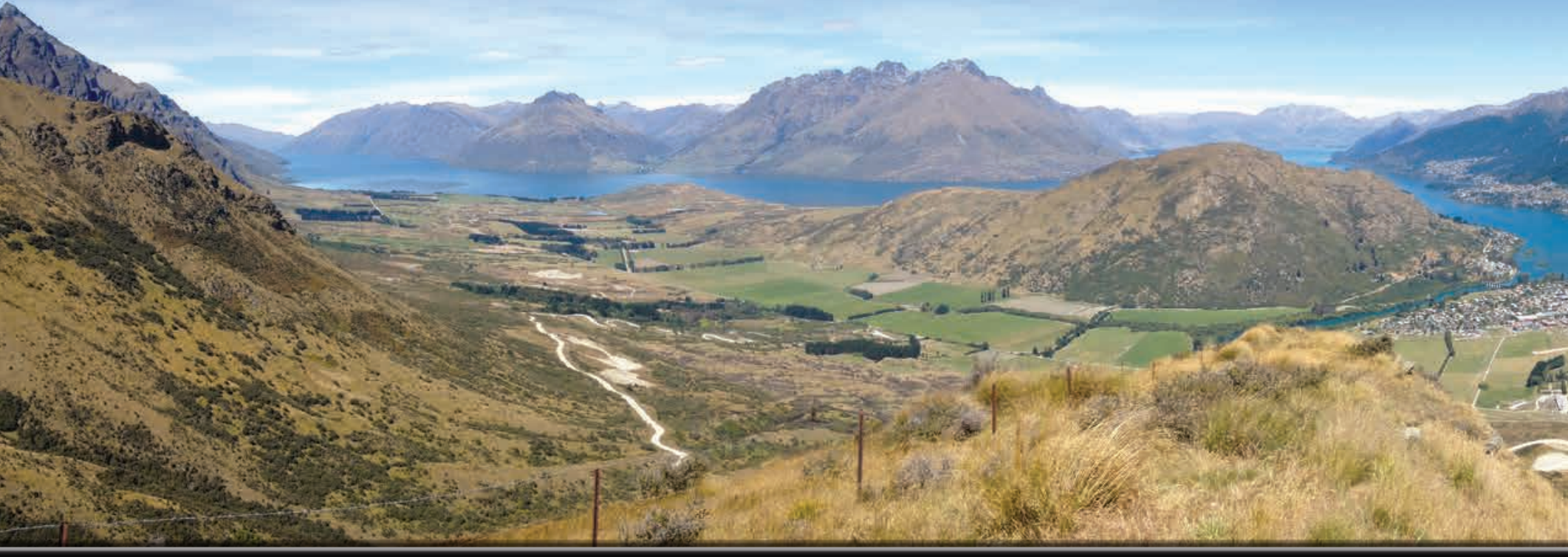

\section{Examples of Outlook Presentations}

By design, the Multi-Resource Analysis considers multiple colocated natural resources, both in present day and under several possible future scenarios. The analysis may span a large landscape and consider a time frame that spans years or decades. Presenting this information to end users in a way that is useful and understandable is a significant challenge. The two proof-of-concept studies highlighted in this circular each explored several ways of presenting the Outlook.

Annual energy production for four development plans.

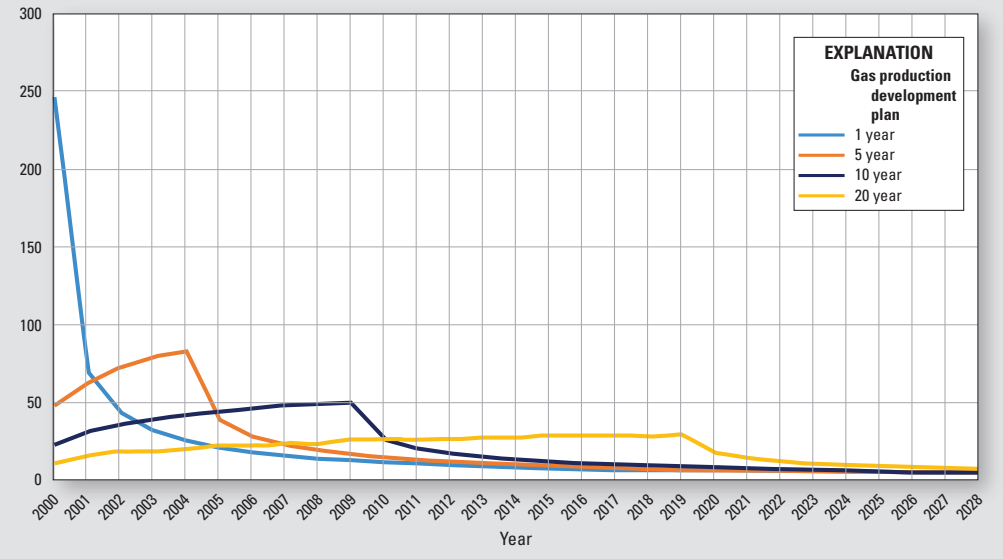

Summary table comparing the Baseline and Outlook in terms of the quantity and quality of natural resources in the region. [\%, percent; $\mathrm{CBNG}$, coal-bed natural gas; $\mathrm{CO}_{2}$, carbon dioxide]

\begin{tabular}{|c|c|c|c|c|}
\hline & Resources & Baseline value & Future value & Change \\
\hline \multicolumn{5}{|c|}{ Energy Resources } \\
\hline \multirow{2}{*}{ Coal } & Recoverable resources (billion short tons) & 125.1 & 116 & $-7 \%$ \\
\hline & Reserves at 10:1 stripping ratio or less (billion short tons) & 8.2 & 0 & $-100 \%$ \\
\hline CBNG & Technically recoverable resources (trillion cubic feet) & 9.106 & 4.94 & $-46 \%$ \\
\hline \multicolumn{5}{|c|}{ Water Resources } \\
\hline Groundweter & Quantity potentially recoverable (millions of acre-feet) & 826.4 & 825.7 & $-0.09 \%$ \\
\hline \multicolumn{5}{|c|}{ Ecology and Biology Resources } \\
\hline Air quality & Cumulative greenhouse gas emissions from development activities (million tons of $\mathrm{CO}_{2}$ ) & 50 & 268 & +217 \\
\hline \multirow{2}{*}{ Terrestrial disturbance } & $<1 \%$ terrestrial disturbance (million acres) & 3.32 & 3.11 & $-6 \%$ \\
\hline & $>20 \%$ terrestrial disturbance (million acres) & 0.39 & 0.44 & $14 \%$ \\
\hline
\end{tabular}



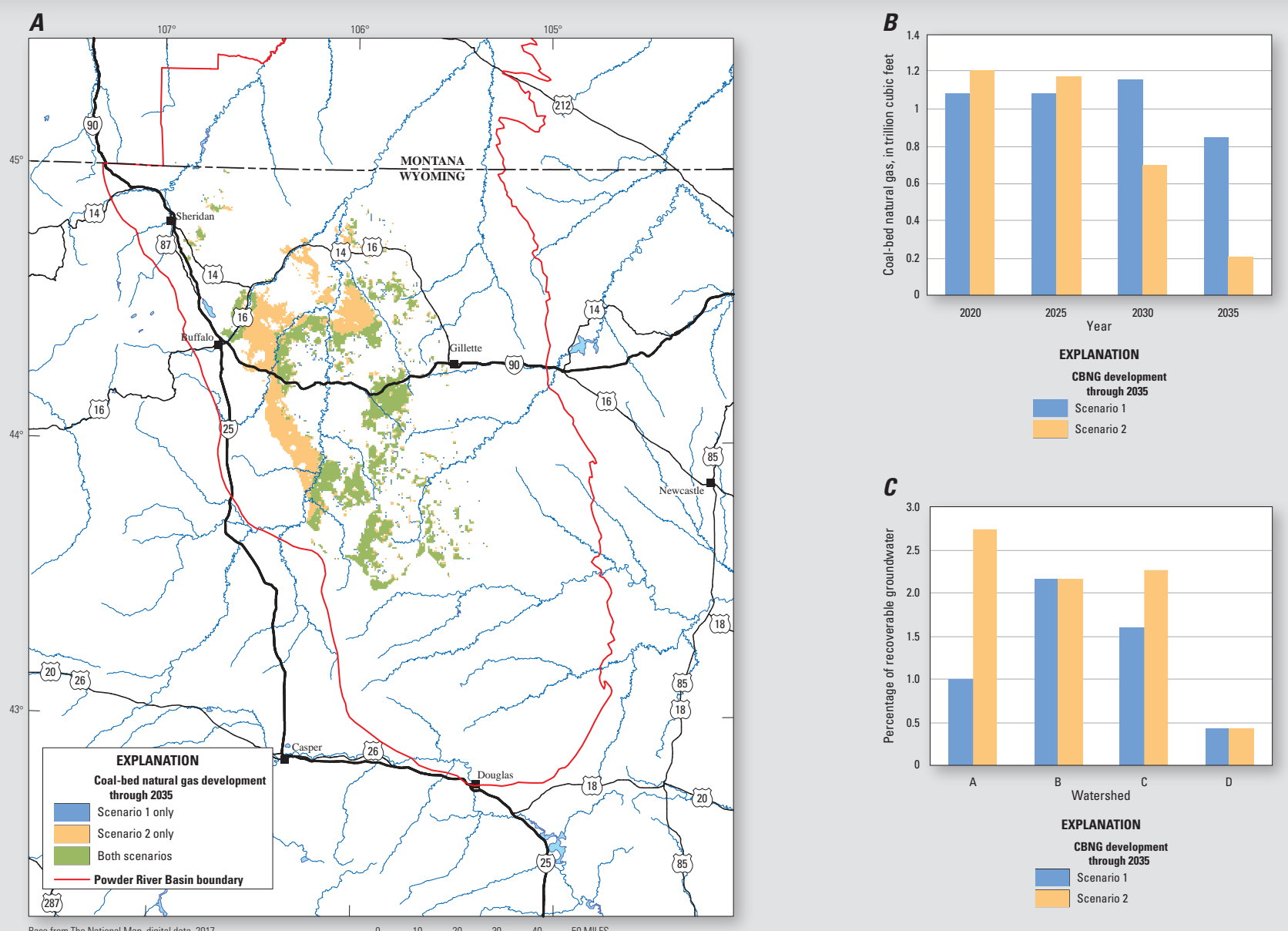

Universal Transverse Mercator projection
Zone $13 \mathrm{~N}$

Comparison of development scenarios. A, Map of development locations. $\boldsymbol{B}$, The quantity of energy produced.

c. Water use for each scenario. 


\section{Development of Multi-Resource Analysis Components}

\section{Challenges for Future Multi-Resource Analysis Information Delivery}

The MRA addresses multiple resources and scenarios, spans large landscape scales and long time frames, and includes uncertainty in models where appropriate. The sizeable amount of information in an MRA yields Outlook results that are complicated and diverse. Presenting this information to end users in a way that is useful and understandable is a significant challenge. In developing an MRA, it is vitally important to work with decision makers and stakeholders to decide on appropriate and useful information-delivery vehicles. Some of the challenges in information delivery, especially with respect to delivering the Outlook, are described below.

Challenge: Communicating multidimensional results.The Outlook results for an MRA encompass many dimensions; that is, they are spatially explicit and characterize the effects of change on multiple resources over time. All of those dimensions cannot easily be displayed at once, requiring ways to "slice" through the multidimensional results in different forms so the end user can gain a more complete understanding. At a minimum, we expect that end users will want to be able to see and compare changes in the quantity, quality, and value of multiple resources over time and across scenarios. Each of the proof-of-concept studies explored a variety of tools for displaying this information, including maps, tables, and charts. Participants in the synthesis workshop suggested providing access to "raw" data as part of the Outlook as well as a set of tools that would allow an end user to create their own views of that data. In a successful MRA, it would be critical to work with decision makers and stakeholders to explore the utility of different information displays and delivery methods.

Challenge: Data interoperability.-Both proof-of-concept studies faced significant challenges related to modeling software and data interoperability. A decision-ready MRA needs to address these issues for both modeling and information delivery. Ideally, a user would be able to slice, rotate, and otherwise format both the Baseline data and the Outlook results and view them in various forms with reasonable ease. Model-generated data would be translated efficiently into forms that are viewable, often by other software products (for example, generating model outputs into a geographic information system map).
Challenge: Delivery of Baseline summaries.-In the PRB study, one of the concepts used for effective delivery of the Baseline is to include summary information at each level as the user drills down into the hierarchy of information. This approach presents at least two challenges. The first is to identify the types of summary information end users will find most useful. The second is to actually summarize, in some cases, a large amount of very detailed information and data, which may have originally been developed for a different purpose, in a way that addresses the needs and interests of the end users. The skills required to provide this kind of decision-relevant summary information are not necessarily the same skills required to develop the detailed analyses that provide the foundation for the MRA Baseline and the Change Analysis components. Tension between the need for simple, straightforward summaries and the need to respect the strengths and limitations of the supporting data and information is likely.

Challenge: Information delivery and sustainability of the models.-The models themselves represent an additional information delivery challenge. End users are unlikely to trust and use the other MRA products, such as the Outlook projections, without understanding and trusting the basis of the often complex models used to create those results. In the PRB proof-of-concept study, conceptual model diagrams were used to illustrate model structure, with a hierarchical approach illustrating different levels of model detail. Other tools and approaches may be useful as well. Understanding these models and the Outlook itself requires an investment of time; the process of developing an MRA builds in stakeholder and decision-maker learning, but extending that learning and understanding to new users poses an additional challenge. 


\section{Potential Next Steps}

Nownely How How A.

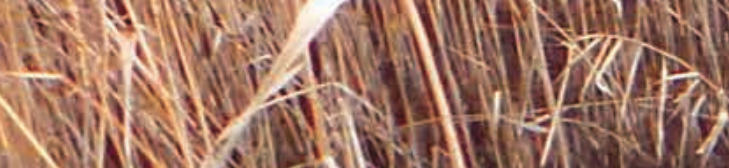
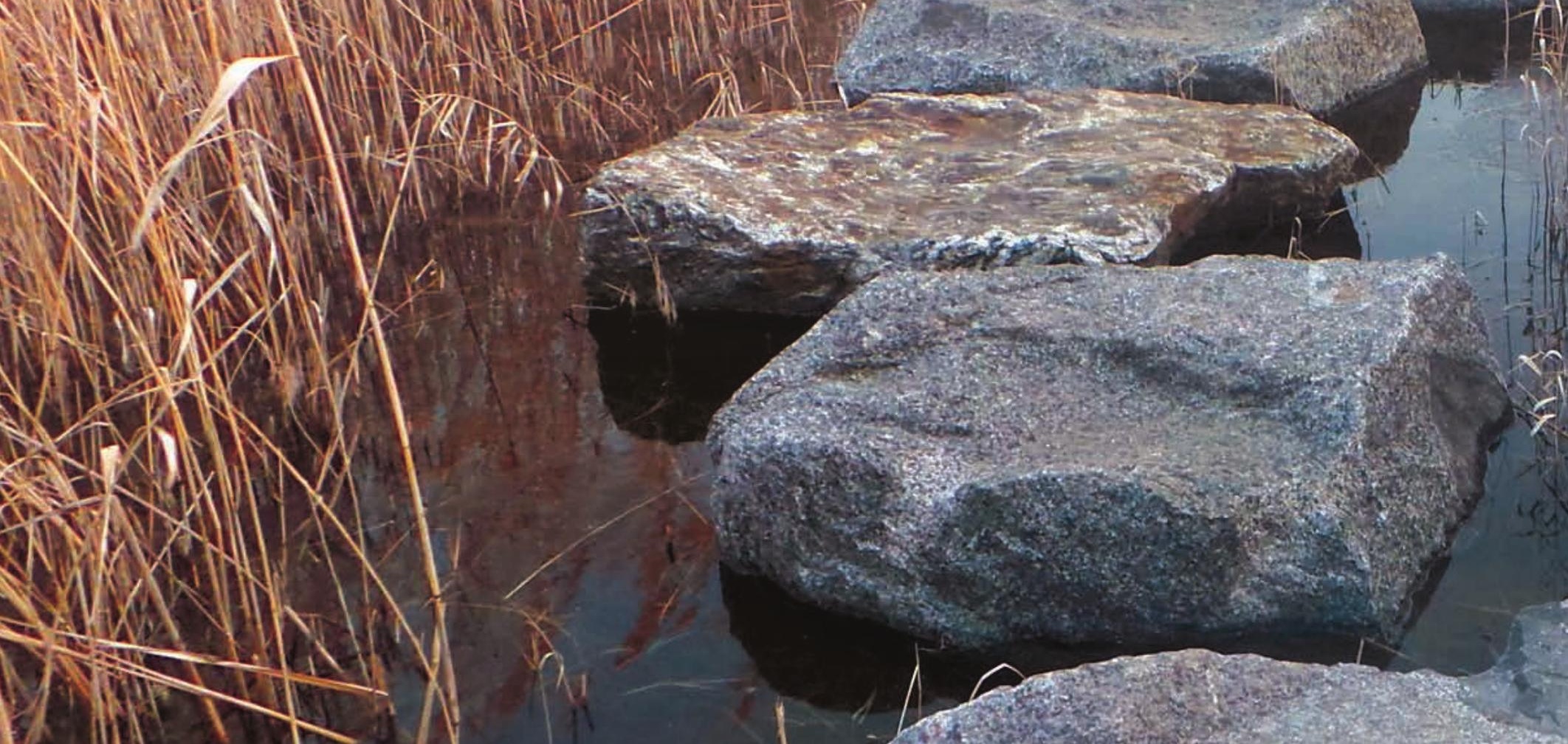


\section{References}


Barabba, V.P., 1995, Meeting of the minds-Creating the market-based enterprise: Boston, Harvard Business School Press, 247 p.

Barber, N.L., 2014, Summary of estimated water use in the United States in 2010: U.S. Geological Survey Fact Sheet 2014-3109, 2 p., accessed March 15, 2018, at https://doi. org/10.3133/fs20143109.

Booth, N.L., Everman, E.J., Kuo, I-Lin, Sprague, L., and Murphy, L., 2011, A web-based decision support system for assessing regional water quality conditions and management actions: Journal of the American Water Resources Association, v. 47 , no. 5 , p. $1136-1150$.

Bristol, R.S., Euliss, N.H., Jr., Booth, N.L., Burkardt, N., Diffendorfer, J.E., Gesch, D.B., McCallum, B.E., Miller, D.M., Morman, S.A., Poore, B.S., Signell, R.P., and Viger, R.J., 2013, U.S. Geological Survey core science systems strategy-Characterizing, synthesizing, and understanding the critical zone through a modular science framework: U.S. Geological Survey Circular 1383-B, 33 p., accessed March 14, 2018, at https://pubs.usgs.gov/circ/1383b/circ1383-B.pdf.

Byrd, K.B., Flint, L.E., Alvarez, P., Casey, C.F., Sleeter, B.M., Soulard, C.E., Flint, A.L., and Sohl, T.L., 2015, Integrated climate and land use change scenarios for California rangeland ecosystem services-Wildlife habitat, soil carbon, and water supply: Landscape Ecology, v. 30, no. 4, p. 729-750, accessed March 14, 2018, at https://doi.org/10.1007/ s10980-015-0159-7.

Carr, N.B., and Means, R.E., 2013, Wyoming Basin Rapid Ecoregional Assessment: U.S. Geological Survey Fact Sheet 2013-3062, 2 p., accessed September 12, 2016, at https://pubs.usgs.gov/fs/2013/3062/.

Chandler, R.B., and Clark, J.D., 2014, Spatially explicit integrated population models: Models in Ecology and Evolution, v. 5, no. 12, p. 1351-1360, accessed March 16, 2018, at https://doi.org/10.1111/2041-210X.12153.

Charpentier, R.R., and Cook, T.A., 2012, Improved USGS methodology for assessing continuous petroleum resources (ver. 2.0, November 2012): U.S. Geological Survey Data Series 547, 22 p. and program.
Coleman, J.L., Jr., Taylor, I.L., Nieman, T., and Jenni, K., 2006, A workshop investigating the potential for the application of decision analysis principles and processes to geoenvironmental situations-Selenium in West Virginia: U.S. Geological Survey Open-File Report 2006-1283, accessed December 1, 2016, at https://pubs.usgs.gov/ of/2006/1283/USGS\%20Open-file\%20Report\%2020061283.pdf.

Colorado Parks and Wildlife, 2014, Mule deer in northwest Colorado: Denver, Colo., Colorado Parks and Wildlife, 2 p., accessed January 13, 2017, at https://cpw.state.co.us/ Documents/Research/Mammals/Deer/MuleDeerResearchFactSheet.pdf.

Copeland, H.E., Doherty, K.E., Naugle, D.E., Pocewicz, A., and Kiesecker, J.M., 2009, Mapping oil and gas development potential in the US Intermountain West and estimating impacts to species: PLoS ONE, v. 4, no. 10, article number e7400, 7 p., accessed December 5, 2017, at https://doi. org/10.1371/journal.pone.0007400.

Coppersmith, K.J., Jenni, K.E., Perman, R.C., and Youngs, R.R., 2009, Formal expert assessment in probabilistic seismic and volcanic hazard analysis, in Connor, C.B., Chapman, N.A., and Connor, L.J., eds., Volcanic and tectonic hazard assessment for nuclear facilities: New York, Cambridge University Press, p. 593-611.

Davis, S., and Ogden, J.C., eds., 1997, Everglades—The ecosystem and its restoration: Boca Raton, Fla., CRC Press, $860 \mathrm{p}$.

DeAngelis, D.L., and Yurek, S., 2017, Spatially explicit modeling in ecology-A review: Ecosystems, v. 20, no. 2, p. 284-300, accessed March 16, 2018, at https://doi. org/10.1007/s10021-016-0066-z.

Deines, A.M., Bunnell, D.B., Rogers, M.W., Bennion, D., Woelmer, W., Sayers, M.J., Grimm, A.G., Shuchman, R.A., Raymer, Z.B., Brooks, C.N., Mychek-Londer, J.G., Taylor, W., and Beard, D.T., Jr., 2017, The contribution of lakes to global inland fisheries harvest: Frontiers in Ecology and the Environment, v. 15, no. 6, p. 293-298, accessed March 16, 2018, at https://doi.org/10.1002/fee.1503. 


\section{Reterences}

Ferrero, R.C., Kolak, J.J., Bills, D.J., Bowen, Z.H., Cordier, D.J., Gallegos, T.J., Hein, J.R., Kelley, K.D., Nelson, P.H., Nuccio, V.F., Schmidt, J.M., and Seal, R.R., 2013, U.S. Geological Survey energy and minerals science strategyA resource lifecycle approach: U.S. Geological Survey Circular 1383-D, 37 p., accessed December 4, 2017, at https://pubs.usgs.gov/circ/1383d/.

Francesconi, W., Srinivasan, R., Perez-Miñana, E., Willcock, S.P., and Quintero, M., 2016, Using the Soil and Water Assessment Tool (SWAT) to model ecosystem servicesA systematic review: Journal of Hydrology, v. 535, p. 625-636.

Garman, S.L., 2015, Forecasting and evaluating patterns of energy development in southwestern Wyoming: Rock Springs, Wyo., Wyoming Landscape Conservation Initiative Fact Sheet 7, accessed March 10, 2017, at https://pubs.usgs. gov/wlci/fs/7/pdf/wlci7.pdf.

Garman, S.L., 2018, A simulation framework for assessing physical and wildlife impacts of oil and gas development scenarios in southwestern Wyoming: Environmental Modeling and Assessment, v. 23, no. 1, p. 39-56 , 18 p., accessed March 15, 2018, at https://doi.org/10.1007/s10666-0179559-1.

Haines, S.S., Diffendorfer, J.E., Balistrieri, L., Berger, B., Cook, T., DeAngelis, D., Doremus, H., Gautier, D.L., Gallegos, T., Gerritsen, M., Graffy, E., Hawkins, S., Johnson, K.M., Macknick, J., McMahon, P., Modde, T., Pierce, B., Schuenemeyer, J.H., Semmens, D., Simon, B., Taylor, J., and Walton-Day, K., 2013, A framework for quantitative assessment of impacts related to energy and mineral resource development: Natural Resources Research, v. 23, no. 1, p. 3-17.

Hanks, T.C., Abrahamson, N.A., Boore, D.M., Coppersmith, K.J, and Knepprath, N.E., 2009, Implementation of the SSHAC Guidelines for Level 3 and 4 PSHAs-Experience gained from actual applications: U.S. Geological Survey Open-File Report 2009-1093, 66 p., accessed December 2, 2016, at http://pubs.usgs.gov/of/2009/1093/.
Hernandez, R.R., Hoffacker, M.K., Murphy-Mariscal, M.L., Wu, G.C., and Allen, M.F, 2015, Solar energy development impacts on land cover change and protected areas: Proceedings of the National Academy of Sciences of the United States of America, v. 112, no. 44, p. 13579-13584, accessed March 15, 2018, at https://doi.org/10.1073/pnas.1517656112.

Hillebrand, E., and Closson, S., 2015, Energy, economic growth, and geopolitical futures-Eight long-range scenarios: Cambridge, Mass., MIT Press, 248 p.

Jenni, K., Graves, D., Hardiman, J., Hatten, J., Mastin, M., Mesa, M., Montag, J., Nieman, T., Voss, F., and Maule, A., 2014, Identifying stakeholder-relevant climate change impacts - A case study in the Yakima River Basin, Washington, USA: Climatic Change, v. 124, p. 371-384.

Jenni, K.E., Goldhaber, M.B., Betancourt, J.L., Baron, J.S., Bristol, R.S., Cantrill, M., Exter, P.E., Focazio, M.J., Haines, J.W., Hay, L.E., Hsu, L., Labson, V.F., Lafferty, K.D., Ludwig, K.A., Milly, P.C., Morelli, T.L., Morman, S.A., Nassar, N.T., Newman, T.R., Ostroff, A.C., Read, J.S., Reed, S.C., Shapiro, C.D., Smith, R.A., Sanford, W.E., Sohl, T.L., Stets, E.G., Terando, A.J., Tillitt, D.E., Tischler, M.A., Toccalino, P.L., Wald, D.J., Waldrop, M.P., Wein, A., Weltzin, J.F., and Zimmerman, C.E., 2017, Grand challenges for integrated U.S. Geological Survey science-A workshop report: U.S. Geological Survey Open-File Report 2017-1076, 94 p., accessed March 15, 2018, at https://doi.org/10.3133/ ofr20171076.

Laniak, G.F., Olchin, G., Goodall, J., Voinov, A., Hill, M., Glynn, P., Whelan, G., Geller, G., Quinn, N., Blind, M., Peckham, S., Reaney, S., Gaber, N., Kennedy, R., and Hughes, A., 2013, Integrated environmental modeling-A vision and roadmap for the future: Environmental Modeling \& Software, v. 39, p. 3-23, accessed March 15, 2018, at https://doi.org/10.1016/j.envsoft.2012.09.006.

Lobos, V., and Partidário, M., 2014, Theory versus practice in Strategic Environmental Assessment (SEA): Environmental Impact Assessment Review, v. 48, p. 34-46. 
Mac, M.J., Opler, P.A., Puckett Haecker, C.E., and Doran, P.D., 1998, Status and trends of the Nation's biological resources: Reston, Va., U.S. Geological Survey, 2 v., 964 p.

Mahmoud, M., Liu, Y., Hartmann, H., Stewart, S., Thorsten, W., Semmens, D., Stewart, R., Gupta, H., Dominguez, D., Dominguez, F., Hulse, D., Letcher, R., Rashleigh, B., Smith, C., Street, R., Ticehurst, J., Twery, M., van Delden, H., Waldick, R., White, D., and Winter, L., 2009, A formal framework for scenario development in support of environmental decisionmaking: Journal of Environmental Modelling \& Software, v. 24, p. $798-808$.

McNamee, P., and Celona, J., 2008, Decision analysis for the professional (4th ed.): [Palo Alto, Calif.], SmartOrg, Inc., 341 p., accessed March 15, 2018, at https://smartorg.com/ wp-content/uploads/2011/08/Decision-Analysis-for-theProfessional.pdf.

Millennium Ecosystem Assessment, 2005, Ecosystems and human well-being-Synthesis: Washington, D.C., Island Press, 137 p., accessed November 16, 2017, at https://www. millenniumassessment.org/documents/document.356.aspx.pdf.

Nakicenovic, N., and Swart, R., eds., 2000, Special report on emissions scenarios-A special report of Working Group III of the Intergovernmental Panel on Climate Change: Cambridge, U.K., Cambridge University Press, 570 p., accessed November 21, 2016, at http://www.grida.no/climate/ipcc/ emission/index.htm.

National Park Service, 2013, Using scenarios to explore climate change-A handbook for practitioners: U.S. Department of the Interior, National Park Service, 57 p., accessed December 1, 2016, at http://climate.calcommons.org/sites/default/files/ CCScenarios-Handbook\%20FINAL\%20080113.pdf.

Olabisi, L.K., 2017, Dealing with deep uncertainty—Scenarios, integration and implementation insights: Blog at WordPress. com, accessed March 13, 2018, at https://i2insights. org/2017/01/05/deep-uncertainty-and-scenarios/.
Parthum, B., Pindilli, E., and Hogan, D., 2017, Benefits of the fire mitigation ecosystem service in the Great Dismal Swamp National Wildlife Refuge, Virginia, USA: Journal of Environmental Management, v. 203, part 1, p. 375-382, accessed March 16, 2018, at https://doi.org/10.1016/j. jenvman.2017.08.018.

Pierce, B.S., Aguilera, R.F., Bardin, D.J., Brown, P.J., Caggiano, J.A., Charpentier, R.R., Green, A.R., Harrell, D.R., Juckett, D.A., King, K.C., Riese, W.C., Rose, P.R., Schollnberger, W.E., Wiesepape, F.C., Wood, J.H., and Zyrianova, M.V., 2007, Topic Paper \#10-Geologic endowment. Working document of the NPC Global Oil \& Gas Study: Washington, D.C., National Petroleum Council, 41p.

Post van der Burg, M., Jenni, K.E., Nieman, T.L., Eash, J.D., and Knutsen, G.A., 2014, Decision analysis of mitigation and remediation of sedimentation within large wetland systems-A case study using Agassiz National Wildlife Refuge: U.S. Geological Survey Open-File Report 20141180, 24 p., accessed December 1, 2016, at https://doi. org/10.3133/ofr20141180.

Runge, M.C., LaGory, K.E., Russell, K., Balsom, J.R., Butler, R.A., Coggins, L.G., Jr., Grantz, K.A., Hayse, J., Hlohowskyj, I., Korman, J., May, J.E., O’Rourke, D.J., Poch, L.A., Prairie, J.R., VanKuiken, J.C., Van Lonkhuyzen, R.A., Varyu, D.R., Verhaaren, B.T., Vesekla, T.D., Williams, N.T., Wuthrich, K.K., Yackulic, C.B., Billerbeck, R.P., and Knowles, G.W., 2015, Decision analysis to support development of the Glen Canyon Dam Long-Term Experimental and Management Plan: U.S. Geological Survey Scientific Investigations Report 2015-5176, 64 p., accessed December 1, 2016, at https:// doi.org/10.3133/sir20155176.

Schoemaker, P.J.H., 1995, Scenario planning-A tool for strategic thinking: Sloan Management Review, v. 36, no. 2, p. 25-40.

Schwartz, P., 1996, The art of the long view-Planning for the future in an uncertain world: New York, Currency Doubleday, $288 \mathrm{p}$. 
Singer, D.A., and Menzie, W.D., 2010, Quantitative mineral resource assessments—An integrated approach: New York, Oxford University Press, 232 p.

Turner, M.G., Arthaud, G.J., Engstrom, R.T., Hejl, S.J., Liu, J., Loeb, S., and McKelvey, K., 1995, Usefulness of spatially explicit population models in land management: Ecological Applications, v. 5, no. 1, p. 12-16.

U.S. Environmental Protection Agency, 2017, What is the National Environmental Policy Act?: U.S. Environmental Protection Agency web page, accessed March 16, 2018, at https://www.epa.gov/nepa/what-national-environmentalpolicy-act.

U.S. Fish and Wildlife Service, 2016, Our conservation approach: U.S. Fish and Wildlife Service website, accessed March 16, 2018, at https://www.fws.gov/landscape-conservation/shc.html.

U.S. Geological Survey [USGS], 2016, National Biogeographic Map: U.S. Geological Survey, accessed December 14, 2016, at https://www.sciencebase.gov/catalog/item/5667130ee 4b06a3ea36c8be8.
U.S. Geological Survey [USGS] Assessment Team, 2015, Assessment of undiscovered sandstone-hosted uranium resources in the Texas Coastal Plain, 2015: U.S. Geological Survey Fact Sheet 2015-3069, 4 p., accessed December 2, 2016, at https://doi.org/10.3133/fs20153069.

von Winterfeldt, D., 2013, Bridging the gap between science and decision making: Proceedings of the National Academy of Sciences of the United States of America, v. 110, suppl. 3, p. $14055-14061$.

Woodward, A., and Jenni, K., 2014, Resource manager information needs regarding hydrologic regime shifts for the North Pacific Landscape Conservation Cooperative: U.S. Geological Survey Open-File Report 2014-1178, 28 p., accessed December 1, 2016, at https://doi.org/10.3133/ ofr20141178.

Wyoming Landscape Conservation Initiative, 2015, 2015 annual report: Rock Springs, Wyo., Wyoming Landscape Conservation Initiative, 45 p., accessed December 2, 2016, at https://www.wlci.gov/sites/default/files/misc-files/ 2015\%20ANNUAL\%20REPORT\%20\%28Upload\%29.pdf. 


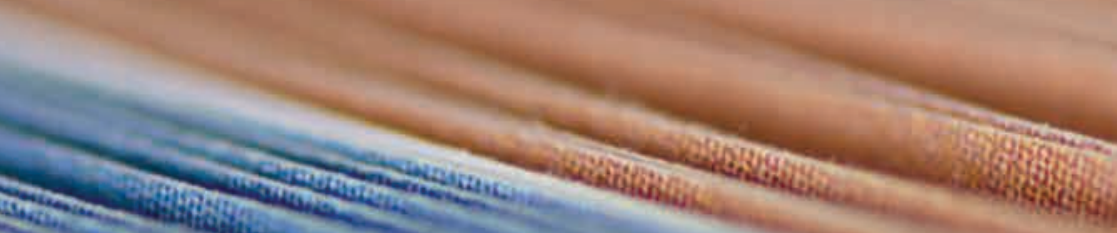




\section{Cover}

Eagle - Pixabay, morfar, Creative Commons CCO

Pump jack-Photograph by Leonid Ikan, Fotolia, purchased license

Sky behind pump jack-Photograph by Dewang Gupta on Unsplash

Water-Pixabay, Free-Photos, Creative Commons CCO

Wheat-Pixabay, malsawm, Creative Commons CCO

Forest-Pixabay, Bergadder, Creative Commons CCO

Raft on river-Pixabay, skeeze, Creative Commons CCO

Red mountains-Pixabay, esudroff, Creative Commons CCO

\section{Page}

Title page

vi

2

3

3

5

5

7

7

9

9

11

11

12-13

14-15

17

17

17

17

17

18

21

22-23
Colored mountains - Photograph by Simon Matzinger on Unsplash

Well pads along the Missouri River-flicker, Chris Boyer, Kestrel Aerial Services, Inc., Creative Commons CCO

\section{Figure 1}

Drought-Pixabay, PellissierJP, Creative Commons CCO

Pump jacks-Wikimedia, Tim Evanson, Creative Commons CCO

Canoe-Wikimedia, Keri Boothe, 2012 Photo Contest, 1st Place Recreation Category, Creative Commons CCO

New York City-Wikimedia, Igor Iric, public domain

Mangroves-Pixabay, Ravini, Creative Commons CCO

Everglades, contrasting photographs showing hurricane damage-

National Aeronautics and Space Administration, public domain

Petroglyph Point-U.S. National Park Service

Pictographs on rock-Photograph by Cori Dolan, U.S. Geological Survey

Anthracite coal-Photograph by Donna Pizzarelli, U.S. Geological Survey

Coal mine-Photograph by Nobilior, Fotolia, purchased license

Spring Index Leaf Map (November 20, 2017)—National Phenology Network

Spring leaves-Pixabay, GLady, Creative Commons CCO

Trout-Pixabay, LoveToTakePhotos, Creative Commons CCO

Fish biologists working in stream - Photograph by Chris Kennedy, U.S. Fish and Wildlife Service

Coal mine-flicker, James St. John, Creative Commons CCO

Deer-Pixabay, skeeze, Creative Commons CCO

Cornfield-Pixabay, Cassi, Creative Commons CCO

Crystal ball-Pixabay, Хихихи97, Creative Commons CCO

Green corn-Pixabay, adege, Creative Commons CCO

Corn in snow-Pixabay, Lichtmagnet, Creative Commons CCO

Fall corn-Pixabay, summa, Creative Commons CCO

Meeting-Pexels, rawpixel, Creative Commons CCO

Men reviewing map - flicker, U.S. Bureau of Land Management

Puzzle pieces-Pixabay, rawpixel, Creative Commons CCO 


\section{Page}

Group of people \#1-Pixabay, geralt, Creative Commons CCO

Gears-Pixabay, qimono, Creative Commons CCO

Group of people \#2-Pixabay, geralt, Creative Commons CCO

Meeting-Pixabay, rawpixel, Creative Commons CCO

Group of people-Pixabay, geralt, Creative Commons CCO

Aspen grove-Pixabay, calharkins, Creative Commons CCO

Aspen leaves-Pixabay, BetsyD, Creative Commons CCO

Graph-Pixabay, Mediamodifier, Creative Commons CCO

Woman at computer-Pixabay, Free-Photos, Creative Commons CCO

Mountain pipelines-Photograph by Sheri Harral, Bureau of Reclamation

Computer screens-Pixabay, geralt, Creative Commons CCO

Digital background-Photograph by alphaspirit, Fotolia, purchased license

Bear on mountain-Pixabay, Free-Photos, Creative Commons CCO

Bear in stream-Pixabay, Gellinger, Creative Commons CCO

Rocks in stream-Pixabay, Free-Photos, Creative Commons CCO

Waterfall-Pixabay, giorgiacocco27, Creative Commons CC0

Pipeline - Photograph by Dave Houseknecht, U.S. Geological Survey

Pipeline closeup-Pixabay, LoggaWiggler, Creative Commons CCO

Oil rig_Pixabay, anita_starzycka, Creative Commons CCO

Computer screen-Pixabay, geralt, Creative Commons CCO

Computer screen-Pixabay, rawpixel, Creative Commons CCO

Wind turbines at sunset-Pixabay, Myriams-Fotos, Creative Commons CC0

Eagle-Pixabay, morfar, Creative Commons CCO

Oil rig-Pixabay, anita_starzycka, Creative Commons CCO

Oil and gas field-Pixabay, Skitterphoto, Creative Commons CCO

Plant in drought-Photograph by Leigh Prather, Fotolia, purchased license

Water drops-Pixabay, Brett_Hondow, Creative Commons CCO

Plants in rain-Photograph by PhotoAlex, Fotolia, purchased license 


\section{Page}

Pelican-Wikimedia, Rui Ornelas, Creative Commons CCO

Pelicans on Marble Bluff Dam, Nevada-Bureau of Reclamation

Salmon migration-Pixabay, brigachtal, Creative Commons CCO

Salmon jumping - Pixabay, alexsutcliffe, Creative Commons CCO

Computer screen-Pixabay, rawpixel, Creative Commons CCO

Icons-Designed by Freepik from www.flaticon.com

Money_Pixabay, Brett_Hondow, Creative Commons CCO

Sunflowers-Pixabay, JamesDeMers, Creative Commons CCO

Water-Pixabay, dimitrisvetsikas 1969, Creative Commons CCO

Oil rig-Pixabay, catmoz, Creative Commons CCO

Keyboard-Pixabay, geralt, Creative Commons CCO

Digital background_-Photograph by Sarunyu_foto, Fotolia, purchased license

Digital background-Pixabay, geralt, Creative Commons CCO

Wheat grains - Pixabay, RObin, Creative Commons CCO

Balloons over wheat field-Pixabay, Gellinger, Creative Commons CCO

Feet in snow-Pixabay, Olichel, Creative Commons CCO

Person walking in snow - Pixabay, 12019, Creative Commons CCO

Power lines-Pixabay, sebaonflames, Creative Commons CCO

City lights-Pixabay, 12019, Creative Commons CCO

Atchafalaya Basin, Louisiana-Wikimedia, Chrismiceli, Creative Commons CCO

Atchafalaya Basin digital elevation map_Image by Jason Stoker, U.S. Geological Survey

Panoramic landscape-Pixabay, Successful4, Creative Commons CCO

Climate banner-Pixabay, Tumisu, Creative Commons CCO

USGS VisWall-Photograph by Tracy Holcombe, U.S. Geological Survey

Steps of stone-Pixabay, soej24, Creative Commons CCO

Books and glasses-Pixabay, DariuszSankowski, Creative Commons CCO

File folders-Pixabay, Coffee, Creative Commons CCO

Fall trees-Pixabay, Skeeze, Creative Commons CCO 


\section{For more information concerning this publication, contact}

Director, Science and Decisions Center

U.S. Geological Survey

913 National Center

12201 Sunrise Valley Drive

Reston, VA 20192

Or visit the Science and Decisions Center website at

https://www.usgs.gov/sdc/

Prepared by the USGS Science Publishing Network

Denver Publishing Service Center

Editing by Sally Almeria

Design and layout by Carol Quesenberry

Web support by Mari Kauffmann and Jim Hoffman

Printing support by Sally Almeria 


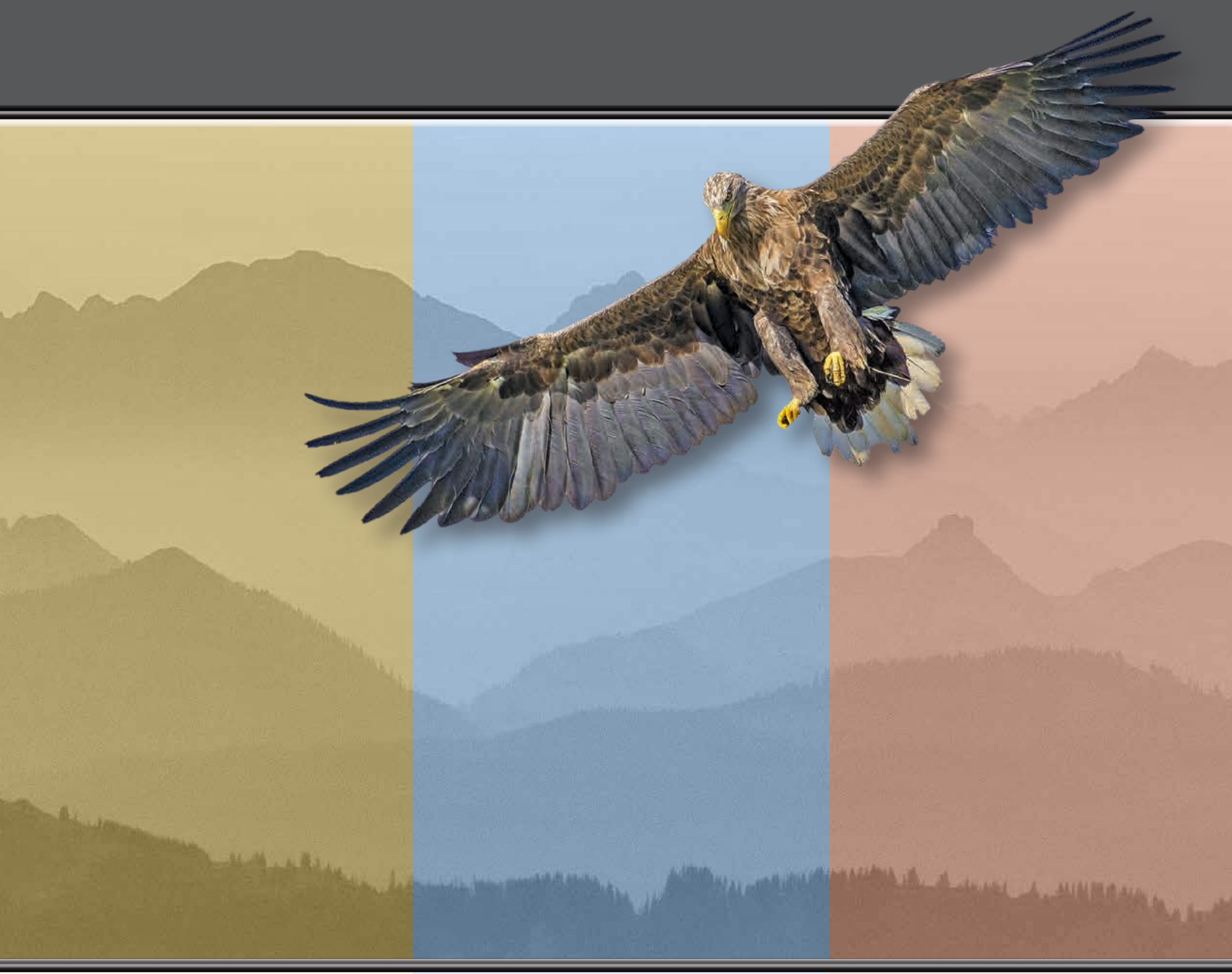




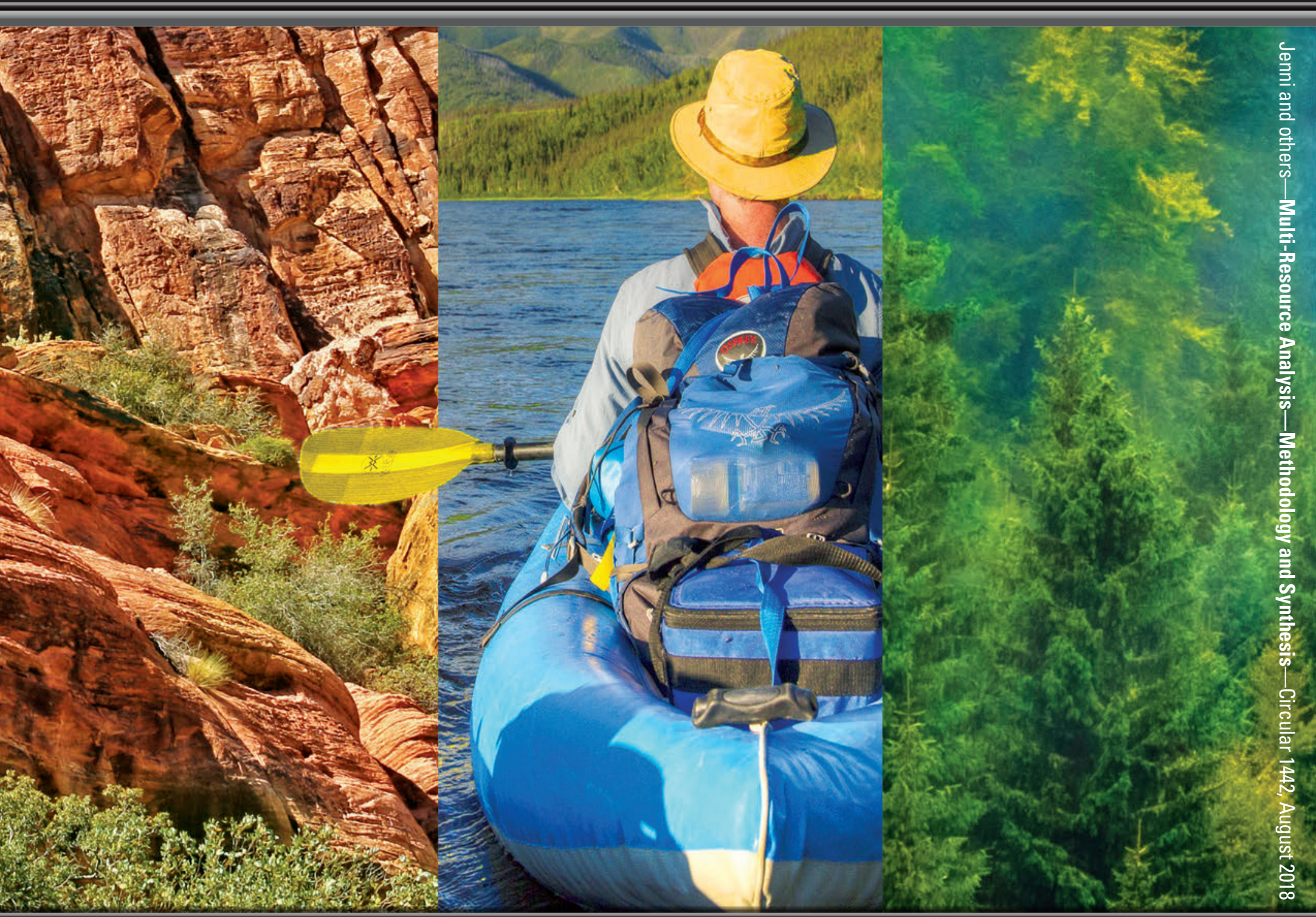

